\title{
WestVirginiaUniversity
}

THE RESEARCH REPOSITORY @ WVU

Graduate Theses, Dissertations, and Problem Reports

2019

\section{New Method of Manufacturing Carbon Foam}

Matthew D. Artimez

martime1@mix.wvu.edu

Follow this and additional works at: https://researchrepository.wvu.edu/etd

Part of the Other Chemical Engineering Commons

\section{Recommended Citation}

Artimez, Matthew D., "New Method of Manufacturing Carbon Foam" (2019). Graduate Theses,

Dissertations, and Problem Reports. 4039.

https://researchrepository.wvu.edu/etd/4039

This Thesis is protected by copyright and/or related rights. It has been brought to you by the The Research Repository @ WVU with permission from the rights-holder(s). You are free to use this Thesis in any way that is permitted by the copyright and related rights legislation that applies to your use. For other uses you must obtain permission from the rights-holder(s) directly, unless additional rights are indicated by a Creative Commons license in the record and/ or on the work itself. This Thesis has been accepted for inclusion in WVU Graduate Theses, Dissertations, and Problem Reports collection by an authorized administrator of The Research Repository @ WVU. For more information, please contact researchrepository@mail.wvu.edu. 


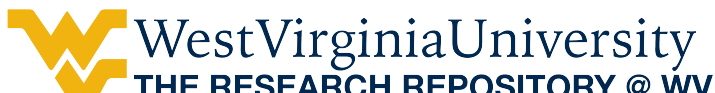

THE RESEARCH REPOSITORY @ WVU

Graduate Theses, Dissertations, and Problem Reports

2019

New Method of Manufacturing Carbon Foam

Matthew D. Artimez

Follow this and additional works at: https://researchrepository.wvu.edu/etd

Part of the Other Chemical Engineering Commons 


\title{
New Method of Manufacturing Carbon Foam
}

\author{
Matthew Artimez
}

Thesis submitted

to the Statler College of Engineering and Mineral Resources

In partial fulfillment of the requirements for the degree of

Master of Science in

Chemical Engineering

\author{
Alfred Stiller, PhD. Chair. \\ Robin Hissam, PhD. \\ Charter Stinespring, PhD. \\ Department of Chemical Engineering \\ Morgantown, West Virginia \\ 2019 \\ Keywords: carbon, carbon foam \\ Copyright 2019 Matthew Artimez
}




\section{Abstract \\ New Method of Manufacturing Carbon Foam}

\section{Matthew Artimez}

Carbon foam is a product that has some unique features. Carbon foam is a light weight material that has a high crush strength. It is electrically conductive, but because it is composed of air space between the tendrils, it is not a thermal conductor. Since it contains no volatile content, it is noncombustible. All these features allow carbon foam to have many modern applications. Currently, there are only three methods of producing carbon foam, and all three are not costefficient enough to meet the demand of potential new markets.

In this thesis, a new procedure of producing carbon foam using a patented process, assigned to $\mathrm{WVU}$, is investigated. The patented process produces carbon foam by using blends of a flux agent and a caking coal. The resulting product is a green coke foam. A detailed analysis of the addition of graphite into the production procedure of carbon foam to increase heat transfer within the microwave heating system is investigated. It was found that the process could be further improved by using graphite as an additive.

Large $1 \mathrm{ft}^{2}$ samples were manufactured using the newly modified process to be sent off for testing by third party companies, the possibility of using an alternative flux agent was explored, and the use of an inductive heater in place of a microwave was also investigated. 


\section{Contents}

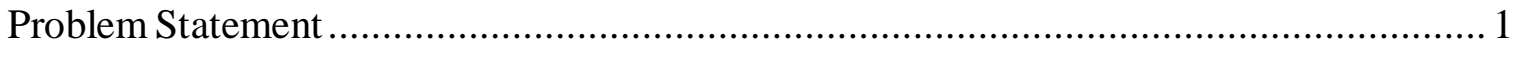

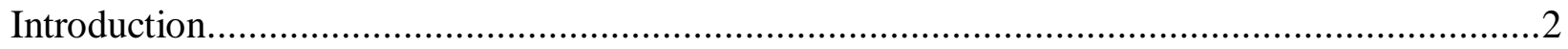

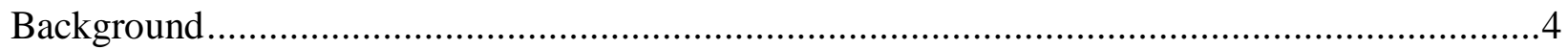

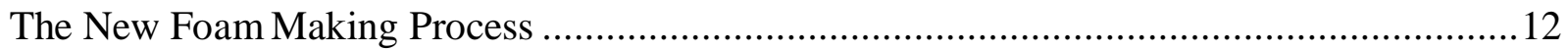

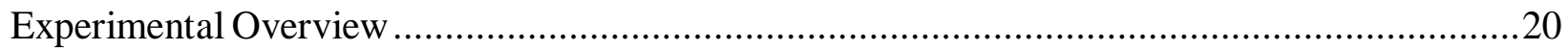

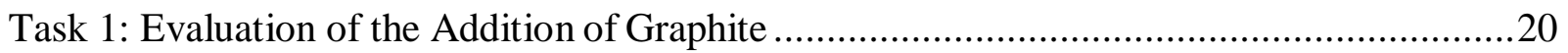

Task 2: Testing the Potential for Graphite Assisted Calcination .............................................24

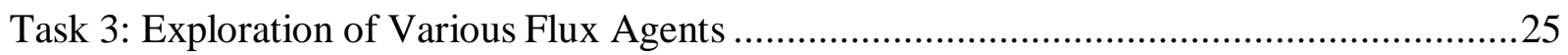

Task 4: The Use of an Inductive Heater for Calcination of Carbon Foam..............................26

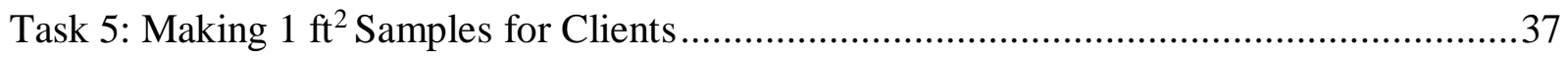

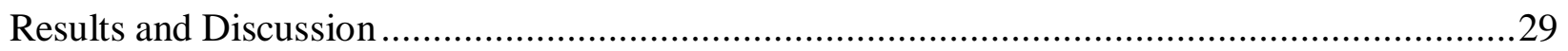

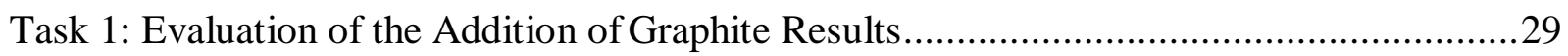

Task 2: Testing the Potential for Graphite Assisted Calcination Results ...................................34

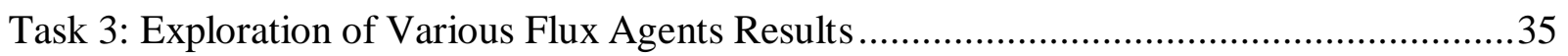

Task 4: The Use of an Inductive Heater for Calcination of Carbon Foam Results....................36

Task 5: Making $1 \mathrm{ft}^{2}$ Samples for Clients Results................................................................ 37

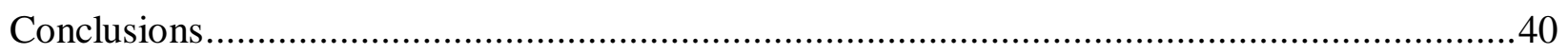

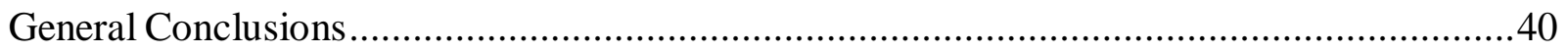

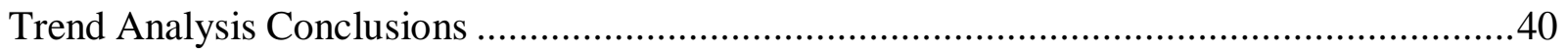

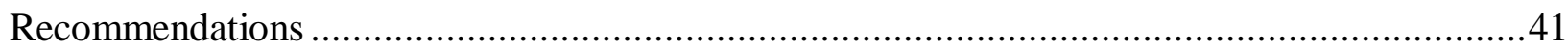

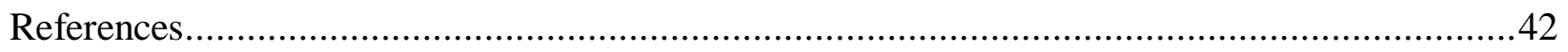

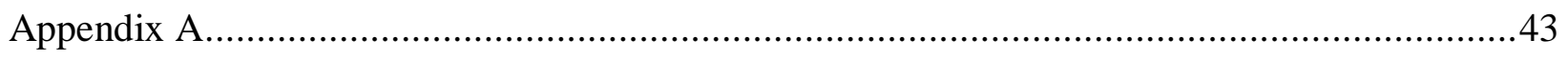




\section{Problem Statement}

Carbon foam is a product that has many modern applications, but currently cannot be made by a cost-efficient method to meet the demand of potential new markets. Currently, there are three methods for making carbon foam. The first of these involves making a polyurethane foam that is subsequently pyrolyzed. By driving off all the volatiles a pure carbon skeleton remains behind and a foam is produced. The second method for making foam involves soft coking a coal extract at $500^{\circ} \mathrm{C}$ and at high pressure $\sim 500$ psig. The third involves blending coal binder pitch with a caking coal and coking it again under high pressure. None of these processes are amenable to the manufacture of large pieces of foam at reasonable costs.

At West Virginia University (WVU), Dr. Alfred Stiller recently invented an entirely new method of producing carbon foam using microwave energy at atmospheric pressures. In this patented process assigned to WVU, blends of a flux agent, high fructose corn syrup, and a caking coal are exposed to microwave energy. Blends are mixed and poured into ceramic coffee cups and exposed to microwave energy for less than 10 minutes. The resulting product is a green coke foam. The initial reactions were done using a simple kitchen sized microwave. If this method is refined and perfected, carbon foam should be able to be mass produced at relatively low costs. The purpose of this research was to advance the technology described in the patent by evaluating the effects of graphite additions, other fluxing agents, the potential use of inductive fields, and the preparation of samples for industrial evaluation 


\section{Introduction}

Carbon foams have been produced for over a decade using primarily the three processes mentioned above. The first method produces carbon foam from coal pitches that are mixed with ground coal. The pitch and ground coal mixture is heated to about $500{ }^{\circ} \mathrm{C}$ while being held under 500 psig. Aluminum mold forms were used in this technique because coke does not stick to aluminum. However, this limits the temperature at which the green foam can be made since aluminum melts at $\sim 700{ }^{\circ} \mathrm{C}$. To make a strong non-friable foam, the foam must be further heat treated to temperatures of near $900{ }^{\circ} \mathrm{C}$. This is done in a typical furnace. At the green coking conditions, the pitch devolatilizes and cokes thus bonding the coal particles together.

Subsequently, the coal at the calcining temperature becomes molten, releases some volatiles, and becomes coke. Since coke produced this way is a porous solid, the final product is a foam. This method is used commercially by Touchstone Research Lab Ltd located in Triadelphia, WV.

The original method of producing carbon foam from coal material was invented at WVU by Dr. Alfred Stiller. That method uses N-Methylpyrrolidone (NMP) to dissolve a major portion of coal at less than $210^{\circ} \mathrm{C}$, the solution is filtered to remove ash material and non-soluble coal material; the NMP is evaporated and the resulting soluble extract is collected as a residue. This residue is referred as reconstituted coal or Solvent Extracted Coal Ore (SECO) since the dissolution process occurs at temperatures less than $210^{\circ} \mathrm{C}$ and only van Der Waals forces are broken. No strong chemical bonds which would alter the molecularity of coal are broken. It is important to note that the reconstituted coal does not have a softening point where it becomes a fluid before decomposing. The reconstituted coal is heated to $500{ }^{\circ} \mathrm{C}$ under 500 psig for 5 hours, this high pressure/thermal procedure was incorporated into the first method discussed. This produces a green foam that must be calcined to make the desired strong foam material. 
The third method for foam production is by pyrolysis of foamed organic material, polyurethane. This process was introduced by Ultramet Corp and refined by UCAR. The foams produced are thermal and electrical insulators; they are quite friable and do not have appreciable crush strength.

Carbon foams produced by the first two methods are considered green foams. They still possess a high percentage of volatile material. In order to enhance their strength and other desired properties, the foam must be heated to over $900{ }^{\circ} \mathrm{C}$ in a non-oxidizing environment. This process requires a slow heating rate and usually takes roughly 12 hours. This process is called calcining or baking. This process drives of any remaining volatiles and further bonds the coal materials which results in substantial shrinkage of the foam forms. This decrease in volume results in a strain which can cause failure to the structure. It also adds significant costs to the production of the foam pieces.

All three of these earlier processes suffer from the same issues. They are not mass producible due to cost efficiency and/or scalability issues. Two of the current methods must use relatively high pressures which cause all the equipment and operating costs to increase exponentially with increasing scale. The last stated process requires a costly raw material that drives the final product price to an unmarketable level. The polymer produced foams also lack strength for most applications. 


\section{Background}

The real importance of this research cannot be appreciated without an understanding of the history of carbon foam made from coal materials. The following history was related to me by Dr. Alfred Stiller, the principal inventor of the technology. The roots of the technology were initiated with the discovery of the dissolution of coal in dipolar aprotic solvents. This family of solvents and the coal solubility was discovered in 1978 when Dr. Stiller was a postdoc in the Chemistry department. He showed that some bituminous coals were over $85 \%$ soluble in this family of solvents. This discovery was described in patent US4272356A. One of the solvents defined in that patent was NMP. The general procedure to dissolve coal and recover the coal materials is described in that patent. Finely ground coal is boiled in NMP. The NMP solution was filtered to remove any of the insoluble materials that were principally ash and some carbonaceous material. Water was added to the in that patent filtrate solution. The NMP went into the water rejecting the solubilized coal, which precipitated. The precipitate was filtered and washed with water. The aqueous filtrate solution was distilled to recover the NMP for recycle. The recovered extract was termed reconstituted coal, and it contained no appreciable ash materials. This reconstituted coal was being tested on direct fired turbine engines when a representative of Oak Ridge National Laboratories (ORNL) visited WVU with a proposition to find a suitable material to make nuclear graphite. Investigators at ORNL knew that coal could be converted to isotropic coke suitable for conversion to nuclear graphite; however, the coal material had to have absolutely no ash material. Originally, ORNL thought that there must be a coal seam suitable for that conversion, but every coal seam has ash material. Since the reconstituted coal has no ash, it was felt that this could be a suitable feed stock for the isotropic 
coke. WVU was given a contract to make the precursor for nuclear graphite. This is what started the Nuclear Graphite Program at WVU.

Researchers at WVU made about $1 \mathrm{~kg}$ of reconstituted coal the first summer after the formation of the program. This was coked in a simple sealed steel pipe. This is called a selfcondenser coker system by representatives from UCAR. The green coked material was sent to UCAR, and they manufactured a graphite test piece. That test piece fit the descriptions for nuclear graphite and the Nuclear Graphite program was continued for the next three years.

It was during that next year a unique experiment was done. Some of the reconstituted coal extract was put in a sealed stainless-steel tube bomb. This was put in a muffle furnace for a day. When the tube was removed and opened, the coke produced was a foam. Since the program was trying to find a method to make coke, Dr. Alfred Stiller told me that he instructed the researcher, Francis Melonski Rommel, not to produce the carbon foam anymore. The material seemed intriguing, so after some amount of time, it was decided to see if the research team could duplicate the foam experiment. The initial foam making experiments were done in ceramic cups in a sealed reactor under 500 psig. It was felt the initial foam reaction was generated about that pressure, so the team tried to duplicate that with an outside pressure source. After a few attempts, the research team could successfully make carbon foam.

In another focus of the research the research group was asked to try to make synthetic coal tar binder pitch. This was done by dissolving coal in coal tar distillate solvents and a hydrogenating agent. At that time, researchers from WVU were invited to make a presentation of their work at the Institute for Defense Analysis (IDA). After their presentation, Major Joe Hagar from the Air Force Materials Laboratory at Wright Patterson Airforce Base, made a presentation on the properties of carbon foam; it was basically a theoretical paper. During one of the breaks, 
Dr. Alfred Stiller asked him if he had made such a foam. Major Joe Hagar said he did, but the foams were very friable. Major Joe Hagar asked Dr. Alfred Stiller if he had made such a foam; it was explained that Dr. Alfred Stiller and his research team did make a foam and found that it was found to be quite strong. Later that year, Major Joe Hagar invited the research team to come to Wright Patterson Airforce Base to make a presentation. Dr. Alfred Stiller stated that this was around the time that the Waco fire took place which gives a rough date around 1993.

Because of that presentation, researchers from WVU were invited to the Coco Beach meeting of the International Traffic in Arms Regulations (ITAR) group. The research team was able to sit in on the non-classified sessions, which was restricted from the classified sessions. The attendees were mostly industrial contractors on governmental defense contracts. That meeting was organized by the Surface Warfare Center at Cardarock, Maryland, by Dr. Mark Opeca. At that meeting, he advised the WVU researchers to meet with Tom Jusca who is a material specialist for the Navy. They met him at the ship yard at Pascagoula Miss. Tom was interested in a light weight material to replace balsawood used in ship structures. To more fully understand the properties of this material, he suggested that the research team go to the NASA facilities in Langley, Virginia. It was there where they met Dr. Satiris Kellas.

Before researchers from WVU visited the NASA facilities in Langley, Virginia, the team worked on some projects with other governmental agencies. This began another series of investigations. Dr. Stiller related the following story to me, explaining how this research was initiated. Perhaps the earliest study was the result of a demonstration made to Jim Eberhardt, who was the Director of Heavy Vehicles Division of the Department of Energy. Foam materials are porous, and as every pore in the structure is crushed, energy is absorbed. Since foams have huge numbers of these pores, it makes sense that crushing a foam would adsorb large amounts of 
energy. The purpose of that demonstration was to show the energy adsorption capability of carbon as it was crushed. The vision that utilized these properties was to make truck bumpers that would absorb the energy of impact by automobiles that underride the trucks and spare the lives of the automobile operators.

A demonstration was planned to show Jim Eberhardt how carbon foams might accomplish this challenge. During that demonstration, a 3/8-inch piece of carbon foam was placed between a piece of glass from a picture frame and a 3/32-inch piece of aluminum plate. The surface of the aluminum plate was hit by a ball peen hammer. The aluminum bent, the foam shattered, but the glass did not break. Jim wanted to see the demonstration a few more times so it was repeated. Then he said, "Yes but it is made from coal, so it will burn." The foam was calcined and had no appreciable volatiles, so it in fact would not burn. Dr. Alfred Stiller has a picture of him holding it his fingers while heating it with an oxyacetylene torch. The flame of the torch was placed on the corner of the foam piece about 1.5 inches from his thumb. It glowed white hot while it was being held in his fingers, and his fingers did not get burned. This proved the foam was not only non-combustible but also a thermal insulator. Those observations became the subjects of some research projects. Figure 1 shows Dr. Stiller holding the foam piece with the torch. 


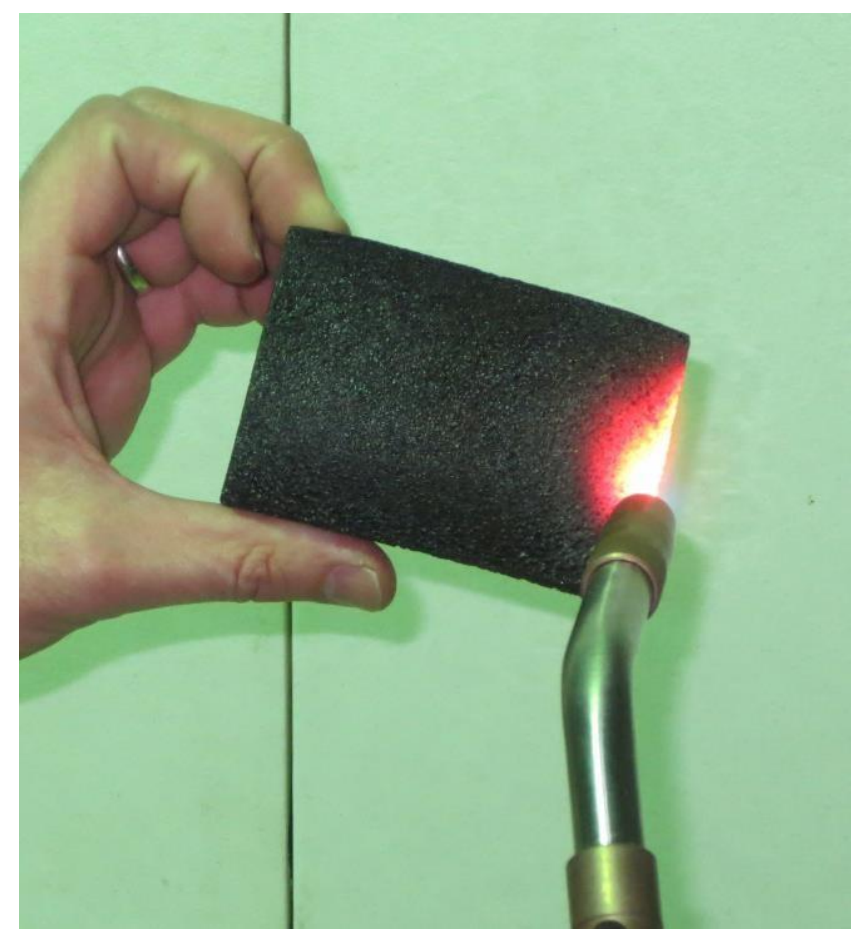

Figure 1: Carbon Foam and Oxyacetylene Torch Display

One of the first studies on the properties of carbon foam was completed in 1997 at WVU by a student in Mechanical Engineering, Denise Sral. ${ }^{[1]}$ Earlier that year, Denise and Dr. Alfred Stiller made a trip down to the NASA facility at Langley, Virginia. At that facility, they do mechanical testing of materials for the defense department and NASA. They were escorted to Dr. Sortiris Kellas, who ran the lab at the mechanical testing facility. They discussed the possibility of testing the energy absorption of carbon foams. They had brought a sample for Dr. Sortiris Kellas to run a compression test. He was very impressed with the result and an arrangement was made to Denise Sral there to do further testing of the material.

Denise performed various experiments on the carbon foam making process such as altering the manufacturing conditions as well as putting in different additives. Denise found that the changes to the manufacturing condition and the addition of additives caused the mechanical properties of the foam to vary. This analysis was completed by performing a trend analysis. 
Dr. Mark Opeka advised the WVU research group to visit the Surface Warfare Center at Carderock for a discussion with Dr. Rodger Crane. At that meeting the unique features of carbon foam were discussed, and Dr. Rodger Crane stated his willingness to fund the research group. He said he was currently doing business with a company in West Virginia and could run money through them for WVU. The company he was referring to was Touchstone Research Lab Ltd; they were basically a materials testing laboratory at the time. Dr. Rodger Crane said that he felt they could rapidly advance the foam from the research lab to the commercial stage. Most of his work is classified, so he could not directly fund the university without going through a lot of red tape; this would be a more convenient avenue. Because of this discussion, the WVU research group visited Touchstone. The group showed Touchstone some of the material and they received it enthusiastically.

At that time, it was felt that a license agreement for the intellectual property should be drawn up between Touchstone and WVU. Chairman Eugene Cilento worked with the patent attorney, Arnold Silverman, to develop a license agreement for Touchstone. A document was proposed after several meetings at the lawyer's office. Discussions with Touchstone were arranged, and an agreement was reached. A license signing celebration was planned, but at that celebration Brian Joseph, president of Touchstone, refused to sign the document. The officials of both parties had an outside meeting and developed a Memorandum of Understanding agreement which was much less binding than the previously agreed upon license agreement.

In the ensuing months, Dr. Roger Crane funded research on foams to Touchstone. Part of this money was to support research at WVU, but Touchstone felt that they had all the research they needed and could do anything in house that they would have the university do; therefore, no support was given to WVU to continue its research on carbon foams. Touchstone used part of 
this money to have an attorney write up a different carbon foam patent that eliminated any need for a relationship with WVU. The WVU patent was too narrow, so they simply went around it. Touchstone did advance carbon foam technology and brought it to commercialization in a very limited but very profitable sense.

As the Nuclear Graphite project developed to the Carbon Products Program, researchers at WVU devoted a small effort to advance the carbon foam research. The next study advanced the information from the initial study. Denise Sral's work showed that the foam was able to adsorb energy on crushing, but the non-wrapped foam pieces could not hold together during the tests. It was decided to test wrapped structures because of this.

It was during this time that we made presentations at the ITAR Coco Beach meeting and discussed the potential use of carbon foam in armor. Bullet proof vests are layered structures to absorb the energy of a projectile and minimize the impact to the target. Normally there is a silicon carbide plate followed by some impact absorbing material. These stacked plates are sandwiched in a Kevlar sheath. Kevlar reduces projectile penetration while the silicon carbide plate spreads the force over a larger area, and the impact resistant material absorbs the shock from the projectile. The team envisioned a layer of several thin carbon foam sheets enveloped in Kevlar sheets with a face plate of thin aluminum plate. Figure 2 shows stacks of the Kevlar carbon foam and aluminum plates were prepared. 

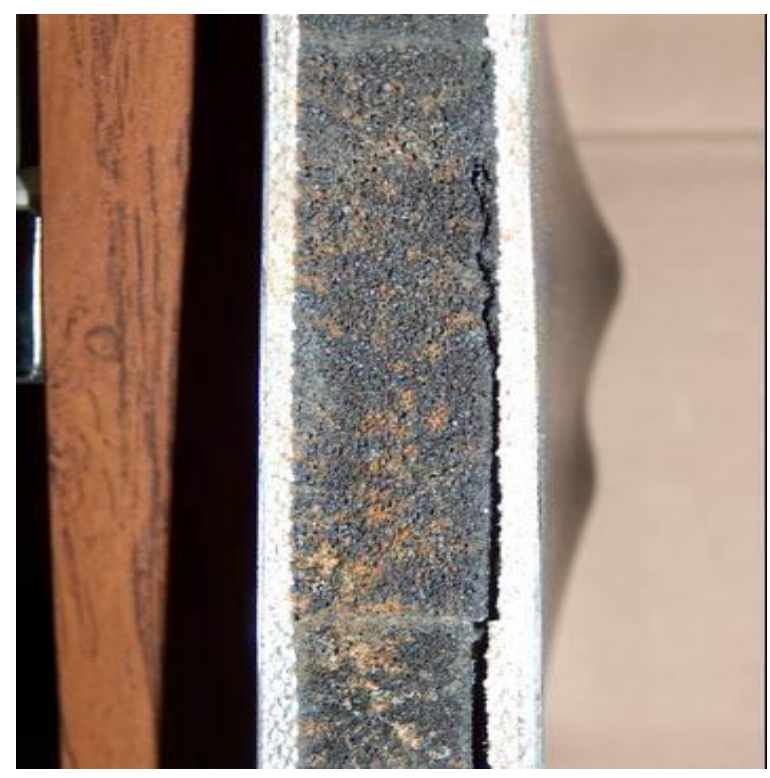

Figure 2: Stack of Kevlar Carbon Foam

They were placed in a frame that was backed with modeling clay. The clay was to simulate the response of a receiver after being shot in the armor. Each of the plates were shot using a 9mm Glock hand gun. The penetrability of the foam armor was recorded. The depthof imprint in the clay background was measured. Figure 3 shows the effects of the tests described above.

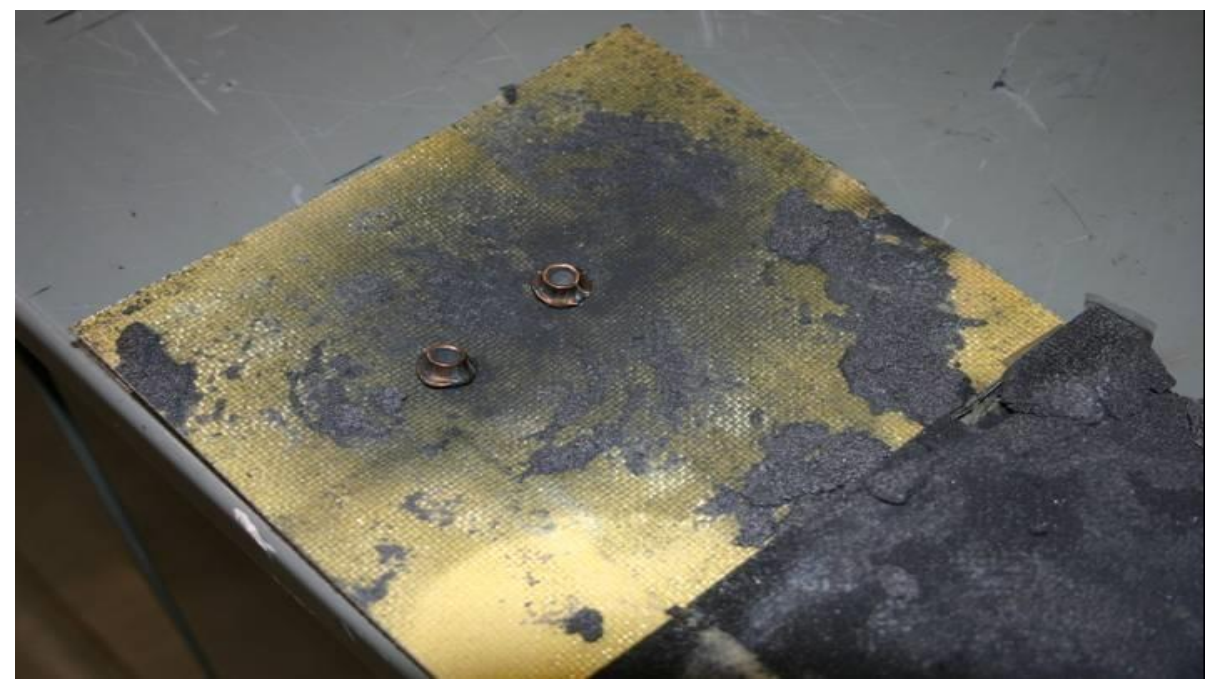

Figure 3: Kevlar Carbon Foam Penetrability Test 
From the pictures above, it can be easily seen that the projectiles did not penetrate the armor and from the diagrams of the impact depth it clearly shows that no serious injuries would have been effecting a receiver of the $9 \mathrm{~mm}$ projectiles.

This data was shown in a presentation at the ITAR meeting at Coco beach in 2002. After viewing the results, several attendees had several potential uses for this carbon foam material. Those suggestions included making baggage container for air craft, so terrorist bombs would be ineffective when exploding. Making sheathing for buildings such as embassies so street side explosions would not destroy the embassy; the shock wave would be diminished by the crushing foam. Using the carbon foam for fire walls on ships, so the heat of the fire would not be transmitted and thereby contained. Making armor planking for army trucks. This would prevent the disastrous effects of road side IEP's. Making portable quickly assembled sheds for communications in the field for soldiers; the foam is electrically conductive, so this would be a Faraday cage that could not be subjected to electronic surveillance. Tiles for the space shuttle could be made from carbon foam. Several more suggestions were given but so far none has been manufactured. The basic challenge remains: the foam manufacturing process is not easily scalable, so large pieces cannot be made and the process is too expensive for commodity applications.

\section{The New Foam Making Process}

More than 20 years have passed since the invention of carbon foam materials made from coal. The science has basically stagnated since small markets have been developed, but the expansion of carbon foams into the commodity market has never developed. The primary reason for this is the cost of manufacture is prohibitive. A new method for manufacturing needs to be developed that is far less expensive before the true value of carbon foams can be realized. A 
method for reducing the cost of the reactants, a procedure that reduces the energy required for manufacturing, and a procedure to reduce the mechanical requirements for making large scale foam pieces. An energy efficient method for calcining the foams are needed as well.

In 2015, such a procedure was conceived. First, the raw material for carbon materials for foam production had to be inexpensive. It was decided that this should be coal, rather than some refined pitch. Second, a binder is required. Originally, this was the NMP extract or reconstituted coal, and then coal tar binder pitch was used instead; however, both these materials are expensive. It was thought a possible candidate for a binder agent might be High Fructose Corn Syrup (HFCS). HFCS is very inexpensive, and when HFCS is baked, it devolatilizes and forms a weak coke like material. More importantly, HFCS has many O-H functionalities, so it can be heated by microwave energy that is tuned to the $\mathrm{O}-\mathrm{H}$ rotation mode.

This insight led to the first HFCS and coal experiments. Coal and HFCS is blended at a ratio of $30 \%$ HFCS $70 \%$ coal. The blend is poured into ceramic cups sprayed with Pam Cooking spray and exposed to microwave energy. The HFCS gets very hot which causes it to devolatilize. As the HFCS bakes, it causes the coal particles to adhere to themselves. This forms a porous solid. The HFCS is about $18 \%$ water which forms steam below this crust of fused coal particles. The release of vapors causes the fused coal to rise like a cake. This is mechanically compressed to release any pockets of trapped vapors and solidify the cake. After no more water vapor is given off, the HFCS continues to decompose. The heat given off causes the coal particles to devolatilize and form a green coke. This coke is porous and resembled a foam.

After the green foam is removed from the ceramic cups and examined, it has some strength, but needs to be calcined before it becomes truly strong. The calcination procedure has already been discussed, but the procedure is repeated here because, one task of this research is to 
modify the calcination procedure. The pieces of green foam are removed from the ceramic cups. Typically, the surface has some cracking because of the compression of the raised surface of the cake. To calcine the foams, they must be heated in an inert or reducing environment to a temperature of $900{ }^{\circ} \mathrm{C}$. A steel box was designed and fabricated by Northco Manufacturing in Westover as a favor to Dr. Stiller. The steel box is partially filled with graphitized carbon chips which were donated by GrafTech International Ltd, located in Anmoore, West Virginia. The green foam pieces are buried in these graphitized carbon chips until they are generously covered with more carbon chips to be sure the foams are completely engulfed by the chips. The steel box is topped off with steel wool. The purpose of the steel wool is to serve as an oxygen grabber and insure reducing or inert atmosphere. The steel box is placed in a large muffle furnace and the heating cycle started. The system is quickly brought to a temperature of $550{ }^{\circ} \mathrm{C}$ then slowly heated to a temperature of $900{ }^{\circ} \mathrm{C}$ at a rate of $75^{\circ} \mathrm{C}$ per hour. It remains at that temperature for 3 hours, and then is permitted to cool to room temperature. After the system is at room temperature, the pieces are dug out and examined. Normally, the pieces contract by about $30 \%$ during this calcination process. The pieces become much harder and stronger. They also become much more electrically conductive. The contraction causes internal strains which sometimes result in the pieces cracking.

It was felt that the reason the pieces contract is because the heat penetration is not uniform over the piece. The pieces are immersed in graphitized carbon chips, but the pieces themselves are thermal insulators. The heat travels from the surface of the pieces to the internal sections, and as the heat is transferred, it causes the material to devolatilize and internally crosslink by chemical bonding. The increased binding causes a contraction, so the size of the piece contracts. This is going to be the second challenge to manufacturability of carbon foam. 
Dr. Charter Stinespring of WVU had a discussion with Dr. Stiller about some of the properties of graphene. This information was sequentially transferred to the research group. Graphene is single layer graphite. It is made from puffed graphite. The puffed graphite is infused with water and then subjected to microwave energy. The microwave caused the water to become steam and radically expands the graphite. In order to make graphene, the radically expanded graphite is emulsified in a blender using NMP as a dispersing liquid, and the mixture is sonicated with an ultrasonic horn. The condition important for this research is that in the microwave the graphene gets white hot. It appears the fine graphite and or graphene absorbs microwave energy. Since graphite is a conductor, the microwave creates eddy currents within the system which causes heating and the temperature rise of the material.

It was hypothesized that fine graphite could be emulsified in HFCS and then mixed with coal to make foams in the microwave. It was expected that the graphite would get hot well before the HFCS and cause it to decompose as well as cause the coal to form a green coke foam. A major portion of this research in the thesis tests that hypothesis.

As discussed above, calcination of carbon foams, using the tried and true usual method, causes internal strains within the foam structure that sometimes leads to failure. It was felt that this is the direct result of a temperature gradient caused by the insulating features of the foam. The foam gets hot at the outside while the internal portion remains cool. Reactions take place at the hot zones causing a change in dimension. This occurs before the more central insulated portions get hot. The resulting strain can cause failure. To prevent that from occurring, the foam must be heated uniformly. That process cannot occur by relying on conductive heat transfer. It was hypothesized that radiant heat transfer may possibly be able to accomplish the task. In the system being tested, the coal is not directly affected by the microwave energy; however, the 
graphite material that is homogeneously dispersed throughout the carbon foam is an absorber of the microwave energy. Not only the graphitic material at the surface is affected, but the graphite material throughout the entire piece has the ability to absorb the microwave energy. If this hypothesis is correct, by exposing pieces of carbon foam infused with graphitic material to microwave energy, the entire piece should be uniformly heated. There is no directional heating with the consequential chemical changes that are responsible for the change in dimension or contraction. This should be able to calcine the carbon foam with minimal change in dimension and eliminate the source of failure in the pieces. A second task of the research for this thesis is the testing of that hypothesis.

The main objective of this research is to decrease the manufacturing costs for carbon foam so that this material has the possibility to enter the commodities market. There are two approaches to accomplishing that goal:

(1) to decrease the energy costs of manufacturing.

a. This is attempted by using microwave energy as the principle tool in the formation of carbon foams.

(2) to reduce the cost of the chemical reactants involved in that manufacturing.

a. Instead of using expensive pitches or reconstituted coal as the primary foaming material, the use of low volatile bituminous coal and/or high volatile bituminous coals as the primary source of carbon would significantly decrease the cost of foam manufacture.

The employment of microwave heating should dramatically decrease the energy costs for making carbon foams. HFCS is the secondary binding agent or flux in the proposed process. Even though HFCS is a low-cost material that adsorbs microwave energy by dielectric effects of 
the $\mathrm{OH}$ rotations; it is proposed that additions of powdered graphite, that adsorbs microwave energy by eddy current processes, would more effectively foam the precursors. Since graphite eddy current heating is being used rather than relying on the dielectric properties of HFCS, other potential binding agents can be examined.

The energy costs for foam manufacture could be further reduced if microwave or inductive field energy could be used to calcine the green foam rather than the tradition convective heat process. Radiation that is uniformly exposed to the foam material would prevent the fracturing common to the traditional calcining procedure. The time required for total conversion should be dramatically reduced, and therefore the energy cost should be dramatically reduced.

The use of HFCS as a low-cost binder along with the use of ground coal would decrease the chemical costs for making carbon foams. There are other potential candidates for binder materials which would further decrease the chemical costs. One potential candidate is the lignin waste from paper mills. Lignin is the binding agent that holds the cellulosic fibers together in hard wood materials. Basically, it is a complex blend of variously substituted propyl benzene polymers. In paper manufacturing, lignin, along with various other resins and carbohydrates, are mixed as a waste solution which is generically described as black liquor. This is either burned on site in a fired heater or landfilled. One of the tasks of this research is to test the viability of using black liquor as a binding agent in carbon foam manufacture. Graphitic material was dispersed in Black liquor which was blended with ground coal and subjected to microwave energy to determine if carbon foam was produced.

As described earlier, since the revelation of the new carbon foam manufacturing process, several companies have expressed an interest in the material. WVU has very limited capabilities 
for testing such a material. An interested company has agreed to do fire testing of carbon foams that the research team can produce; however, the foam piece must be $1 \mathrm{ft} X 1 \mathrm{ft}$. It will be tested for flammability and insulation properties. The last task of this research is to prepare that sample.

To reiterate, the recently patented foam manufacturing process has none of the previously mentioned drawbacks. Instead of using solvent extracted coal pitches, or coal binder pitch only high fructose corn syrup is used. The only requirement for the coal used is that it must be a caking coal. The energy transfer is by radiant heat transfer rather than by convective heat transfer, so the thermal efficiency is much higher. The time required for the foam making process is in minutes rather than in hours. The process is run at atmospheric pressure, so it requires no pressurization. It is expected that this method should be much more economically attractive then previous processes and has the interest of several companies currently.

American Gypsum has expressed interest in carbon foam that can be massed produced to form sheets of insulation which would replace current types of commodity construction materials. The largest issue with modern insulation is that it is relatively flammable which promotes the destruction of buildings by fires. With the increase in mass wild fires that have been sweeping the western regions of the United States, the development of a material such as carbon foam that has the properties of a thermal insulator with the benefit of not being able to burn would have a massive market that would be successful nationally and most likely globally as a modern insulation replacement.

Harbison Walker International Refractory Products has also expressed interest in carbon foams. Their goal would be to use the carbon foams to make bricks to replace their current refractory bricks that are used in high temperature furnaces. Similar to the applications stated with American Gypsum, carbon foam is a thermal insulator that does not burn when in the 
presence of relatively high temperatures. The production cost of making carbon foam is predicted to be lower than that of refractory brick as well.

Poco graphite has expressed an interest in the foam making process. Poco commercially produces carbon foams. Their foams are made using high cost mesophase pitch. The uniqueness of their foams is that their foams are highly thermally conductive. Originally, they were interested in making the mesophase pitch, but when they saw the development of the new carbon foam process they developed an interest in the new method.

Mason Industries also expressed an interest in the new carbon foams. They are an international carbon product manufacturing company and when they saw the new foam manufacturing process they showed an interest in the new foams, as the materials that might be important for their future industry development. 


\section{Experimental Overview}

The research that was conducted on this topic was the first ever recorded experiments expanding upon the previous patent work; this thesis evaluates and defines process improvements on the production of carbon foam. The samples produced in this research were sent to interested companies for their evaluation. WVU does not have the necessary tools for such analysis and some of the procedures are proprietary. The research is divided into five primary tasks:

(1) An evaluation of the effect of addition of graphite into the production system of carbon foam to increase heat transfer within the microwave heating system.

(2) Testing the potential for graphite assisted calcination of carbon foamusing microwave energy.

(3) Exploration of different substitutes as fluxing agents to be used in place of the high fructose corn syrup in carbon foam production.

(4) The use of an inductive heater to calcination of carbon foam.

(5) Making $1 \mathrm{ft}^{2}$ pieces for clients

\section{Task 1: Evaluation of the Addition of Graphite}

The purpose of task 1 is to test the viability of graphite assisted carbon foam production. Samples of carbon foam were made using

(1) three different quantities of graphite in the fluxing blend.

(2) three different power levels of the microwave.

(3) four particle sizes of the coal.

(4) two coal types: high volatile and low volatile bituminous coals. 
The graphite percentage is defined by weight percent of the mixture. The high graphite is $5 \%$ of the total weight, the low graphite uses $1 \%$, and no graphite $0 \%$. The power settings are set on the microwave. These are $100 \%$ for the high power, $50 \%$ for the middle power, and $20 \%$ for the low power. The microwave has an on or off control for the inner antenna, so the power setting can vary by changing the amount of time that the sample is exposed to the radiation. For example, if a foam sample is heated for 1 minute in total using the $50 \%$ power setting, the sample was exposed to the radiation for 10 seconds and then the antenna was turned off for an interval of 10 seconds. This cycles till the total time equals 1 minute. This means that overall the sample was exposed to 30 seconds worth of total radiation. The particle sizes are as follows: (a) 20-35 mesh, (b) 35-60 mesh, (c) 60-100 mesh, and (d) >100 mesh. As the mesh size increases, the particle size decreases.

Samples of low volatile bituminous coal were obtained from Rosebub Mining Corp from Clarien County, PA. Samples of high volatile bituminous coal were obtained from Anker Energy Monongahelia County, WV. The samples were ground using the equipment in the Mining Engineering Department of West Virginia University. The ground samples were stored in 5gallon plastic buckets until use. Portions of the ground coal were separated into size fractions by Rototap screen trains in Room 312 of the Engineering research building at WVU. The sized samples were stored is sealed plastic buckets until use.

High Fructose Corn Syrup was purchased from Mann Lake Bee supply house. HFCS is found in apricots and is used to feed bees during periods of dearth. Because bees require specific viscosities, it is understood that the purchased HFCS contain significant quantities of water. A weighted sample of the HFCS was put in a drying oven with its temperature set at $110{ }^{\circ} \mathrm{C}$. It was determined from the remains that the water content was $21 \%$ by weight. 
Graphite powder was obtained from Alpha Aesar. It was analytical grade. The powder was sized using a colter counter at Coats Toner Corp- in Wilks Barre Pa. The median size was 6 microns.

\section{Sample Preparation Procedure:}

Blends of the previously described samples were prepared by hand mixing the components in cleaned beakers using a spatula until the blends were homogenous. Weighted portions of the blends were poured into ceramic cups. The cups had previously been sprayed using Pam cooking spray to prevent the carbon foams from sticking to the ceramic sidewalls of the cups. The samples were placed in the microwave ovens and covered with a piece of ceramic tile to act as a lid, both the ceramic cups and ceramic tile covers were tested to determine that they did not heat up in the microwave oven.

As described earlier, when making carbon foam using the HFCS flux method the process occurs in steps. To reiterate these steps:

(1) The HFCS is exposed to the energy of the microwave.

(2) The HFCS devolatilizes.

(3) The vapors cause the coal to rise like a cake.

(4) The coal is compressed to release the vapors and to help solidify the cake.

(5) The compression is repeated till the HFCS begins to decompose.

(6) The decomposition of HFCS cause the coal particles to devolatilize and form a coke.

The samples were exposed to the microwave in small increments to allow them to be taken out and compressed. This process is repeated until the sample hardens. The time was recorded when the sample was completely solid and ready for calcination. 


\section{Microwave Standard Operating Procedure}

The operating procedure for the microwave is as follows:

(1) Open the microwave door, place the sample inside, and close the door.

(2) Choose the power option to operate at.

(3) Select the time increment to operate. Typically, a range of 1-5 minute increments is recommended.

(4) After each increment, take the sample out and check to see if it has risen.

(5) If it has risen, use a clean beaker or tool with a flat surface to compress the sample.

(6) Continue repeating steps 3-5 till the sample has solidified and no longer rises.

Figure 4 and 5 both show pictures of typical foam samples manufactured using this process.

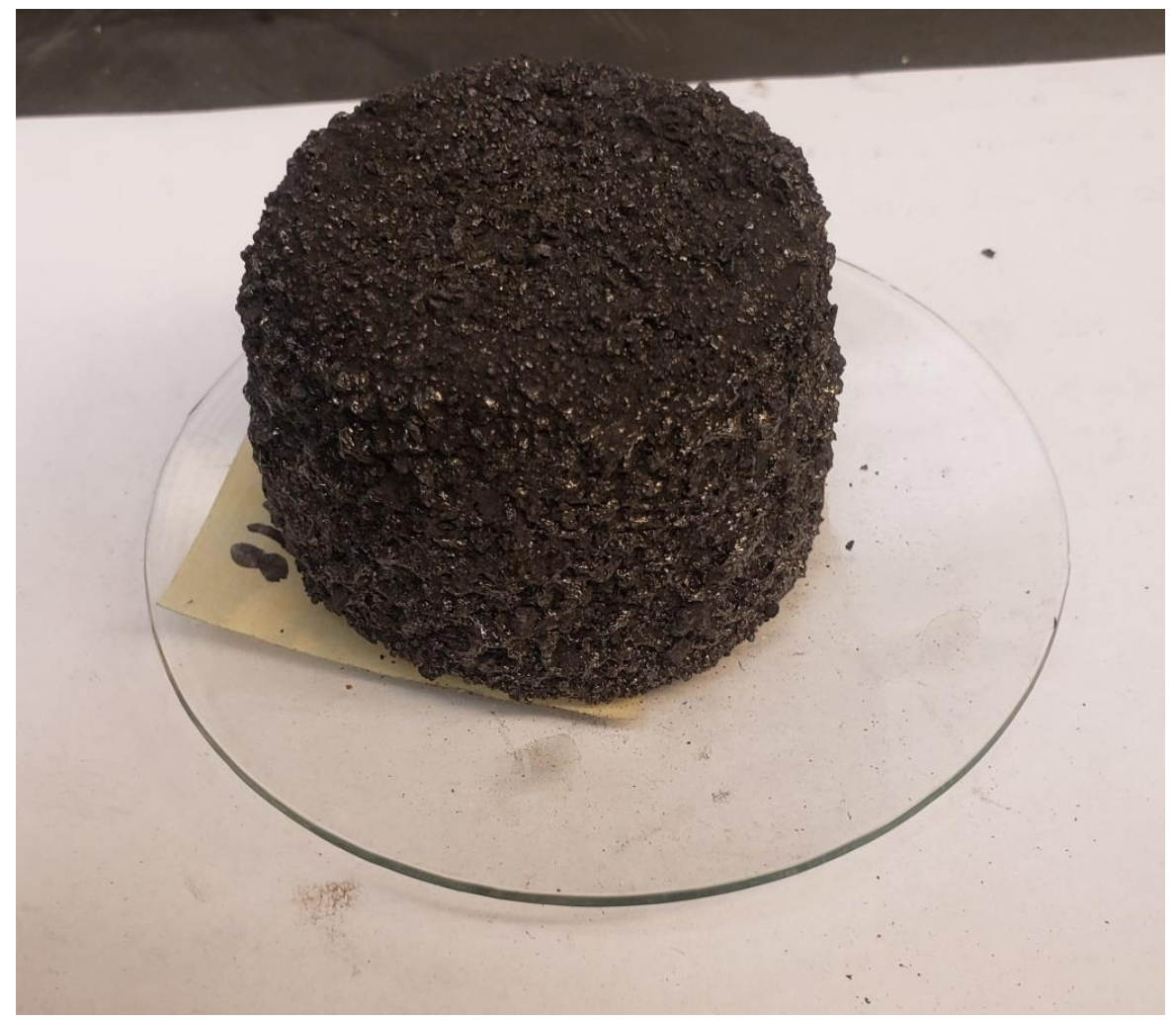


Figure 4: Standard Carbon Foam Sample (Large Particle Size)

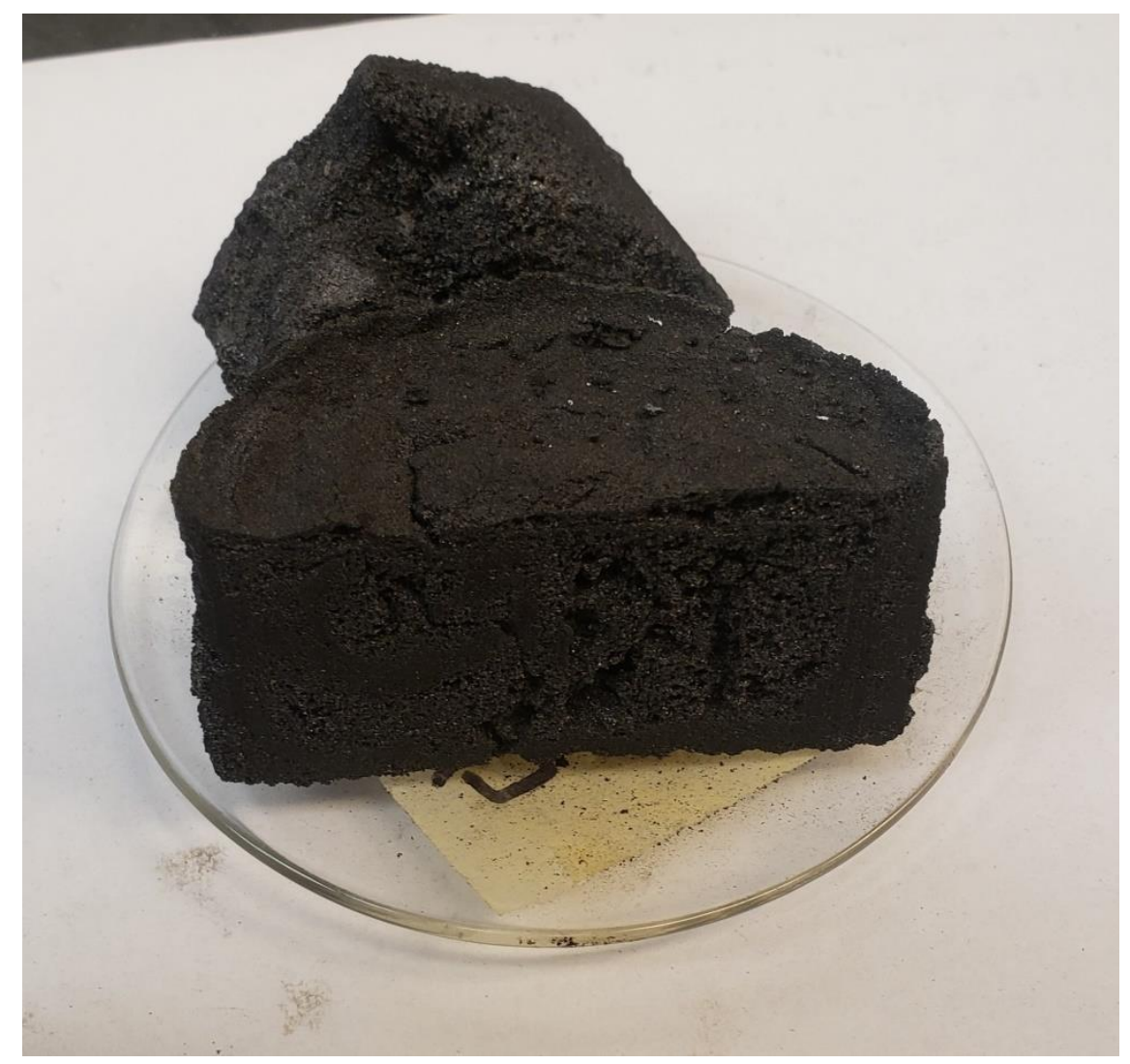

Figure 5: Cross Section of a Standard Carbon Foam Sample (Medium/Small Particle Size)

\section{Task 2: Testing the Potential for Graphite Assisted Calcination}

When the manufactured carbon foams made in the patent process have solidified in the microwave, they are considered Green Coke. Green coke is nonconductive and has relatively low crush strength. Conductivity is indicative of the calcination process. The standard process for calcining samples is described in The New Foam Making Process section of the Background. To summarize, a carbon foam sample is calcined by burying it in a steel box filled with graphite chips. After the sample is sufficiently covered by the graphite chips, a layer of steel wool is placed on top between the layer of chips and the lid. The box is then placed in a kiln and heated 
up to $900{ }^{\circ} \mathrm{C}$. The sample then cools till it is room temperature. This standard method causes the samples to shrink.

To avoid the issues with the standard calcination method, it has been hypothesized that the carbon foam samples can be calcined using the radiant heat from the microwave. The samples need to contain graphite to allow the mixture to get to the desired calcination temperatures.

\section{Procedure:}

The procedure for testing the samples is quite simple. The sample is tested with a multimeter to see if there is any conductivity. The sample is then heated in the microwave in 5 minute intervals till 1 hour of total exposure time. After the 1 hour, the sample is evaluated to see if there is a change in conductivity.

\section{Task 3: Exploration of Various Flux Agents}

As stated previously, to make carbon foam using the current patented process, a caking coal and a flux agent must be mixed together and heated in a microwave. HFCS was the standard flux that was used because of its effectiveness and availability. It is quite easy to get HFCS and it is affordable for a small laboratory. After some discussions and brainstorming with Dr. Stiller, it was hypothesized that lignin could be an effective binding agent because it is essentially the natural binding agent that holds the cellulose structures together in wood.

Large quantities or lignin are currently produced in the paper industry, specifically from the pulping process, as a waste product. The solution is considered "Black Liquor" and is currently just burned in a fired heater due to its lack of value. Lignin was thought to be a good 
candidate to investigate because generally, when a process can use a waste stream as a feedstock, there is a major increase in potential profit.

The Forestry Department of WVU was contacted, and an agreement was made to get a small amount of lignin to be tested. The lignin was provided in a liquid form as sodium lignosulfonate. The sodium lignosulfonate was taken directly from a paper mill located in Luke, Maryland.

\section{Procedure:}

The procedure is the same as that from the patented process. Sieved coal is measured out and mixed with an amount of the lignosulfonate mixture. The combined mixture is thoroughly mixed till it is homogenous. The mixture is measured out into a ceramic mug that has been sprayed with Pam non-stick spray. The ceramic mug is then placed in the microwave and covered with a ceramic tile to act as a lid. The microwave is turned on and ran in segments.

\section{Task 4: The Use of an Inductive Heater for Calcination of Carbon Foam}

In the traditional calcining procedure, shrinkage of the foam artifacts during calcination may cause catastrophic failures of the foams. It is believed that this may be due to nonlinear heating. In essence, the artifact is heated from the surface to the interior at unequal rates. This is the direct result of conductive heating; thus, the alterations occur from the surface to the interior at unequal rates. If the powdered graphite homogeneously dispersed through the foam artifact acts as the heat source through microwave heating or radiant heat transfer by exposing the artifact to microwave radiation, the entire foam piece should be heated uniformly, and the shrinkage should be relatively small; therefore, no significant distortion and resulting strain should occur. The power of the microwave should easily heat the artifact to calcination temperatures. This may cause the entire piece to become electrically conductive and cause 
sparking in the system Therefore heating by inductive fields may be more suitable. If calcination without distortion can be made to occur in an inductive field, then the manufacture of carbon foam could be very economic and fast.

\section{Procedure}

Already manufactured carbon foam pieces are taken to an area to test the surface for conductivity using a basic multimeter. The products are then place into the space between the coils in the inductive heater. The inductive heater is turned on for about 30 seconds. The carbon foam sample is then removed and tested again by the multimeter to see if the sample has increased in conductivity. The process is relatively short due to the depth of penetration of the inductive fields.

\section{Task 5: Making $1 \mathrm{ft}^{2}$ Samples for Clients}

In the laboratory, only small pieces of foam have been made until recently. These pieces are up to 1 inch thick and have a radius of 3.5 inches. Some of the potential customers would like $1 \mathrm{ft}^{2}$ pieces for underwriter's fire testing. To make such test materials a new microwave oven with a heating area of over $1 \mathrm{ft}^{2}$ was purchased. This oven had to come equipped with a rotating antenna rather than a rotating table. A wooden framework encasing a ceramic tile floor and sides were constructed. Samples of flux and coal of significant quantity must be prepared. The form must be filled to a depth of $3 / 4$ inch and then heated in the microwave until foam is produced. That foam sample must be calcined by one of our partner companies due to the unavailability of large enough furnaces, and the resulting calcined foam $1 \mathrm{ft}^{2}$ piece must be sent for testing because WVU doesn't not have the analytical tools necessary for the specific characterization.

\section{Procedure:}


The samples are manufactured using the same methods as the ceramic mug samples. The difference is that the coal, HFCS, and graphite are measured out and placed in a large mixing bowl. A commercial mixer is used to mix the sample into a homogenous state, and the sample is placed into the wooden framework. The process has to be repeated twice to get enough material to make the sample, due to the size limit of the bowl and mixer. Once the sample is filled in the wooden framework, it is placed into the microwave and follows the same procedure as in the ceramic cup samples, which is described in the Task 1 Experimental Overview section. 


\section{Results and Discussion}

In this study, the hypothesis for each task is listed below:

(1) Task 1: The addition of graphite increases the heat transfer rate of the carbon flux mixture which decreases the carbon foam manufacturing time.

(2) Task 2: After a finite amount of time, carbon foam samples manufactured with graphite can be calcined by only using the radiant heat transfer of the microwave.

(3) Task 3: A carbon foam sample can be created using lignin as the binding agent in place of HFCS.

(4) Task 4: An Inductive heater can be used in place of a microwave to heat the carbon foam samples.

(5) Task 5: $1 \mathrm{ft}^{2}$ samples can be manufactured and prepared for clients following the same patent.

\section{Task 1: Evaluation of the Addition of Graphite Results}

Figure 6 shows the results of foaming with different initial coaltypes. 


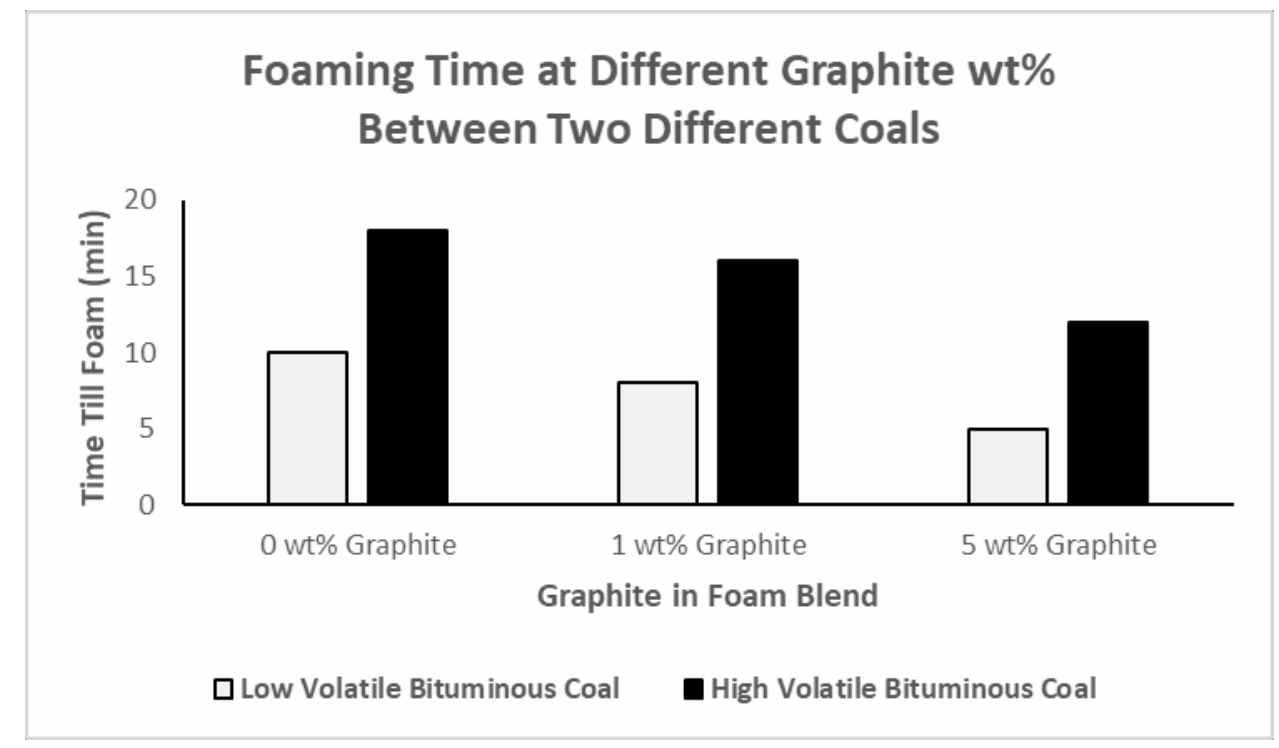

Figure 6: Varying Graphite wt\% and Two Different Coals Using 20-35 mesh Particle Size / 100\% Total Microwave Power

Figure 6 shows that the high volatile bituminous coals took more time to foam than comparable samples of low volatile bituminous coals. This is probably due to the fact that the devolatilization process consumed more energy, hence more time needed for the high volatile coals to foam than the low volatile coals, in which this effect would be less.

In virtually all cases, the presence of graphite decreased the foaming time for all comparable samples. As expected, graphite is a heat transfer agent, and without that agent, foaming was the result of HFCS decomposition heat transfer. The graphite seems to be a better transfer agent.

Figure 7 details the effects of the change of particle size to the foaming time. 


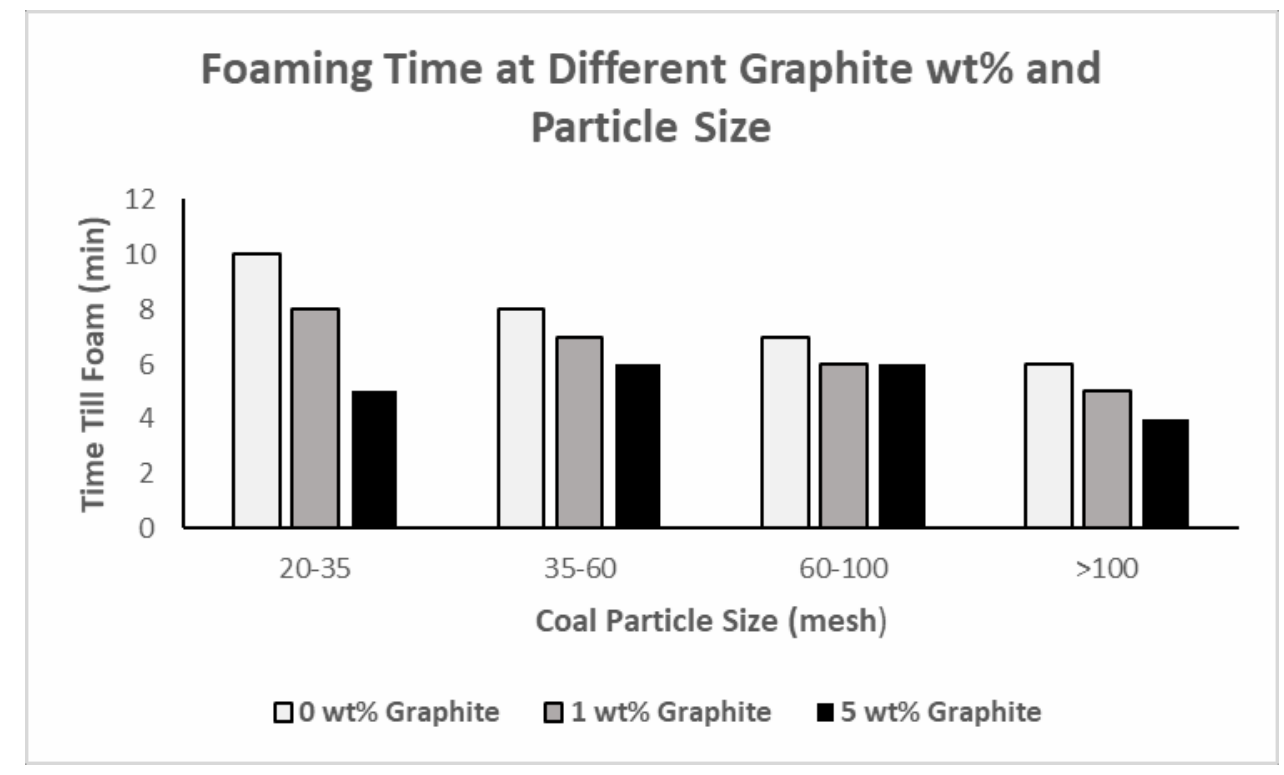

Figure 7: Low Volatile Bituminous Coal Using 100\% Total Microwave Power While Varying Coal Particle Size and wt\% Graphite

The particle size only seemed to make a slight difference with the low volatile coal which the differences between most of the samples being relatively insignificant.

The biggest effect was realized with increase in the microwave energy. The higher the power setting, the faster the foam was produced. This is not surprising as the total energy supplied to the system was in the foam of microwaves.

The power settings in the microwave were $100 \%$; $50 \%$; and $20 \%$. If the conversion of power to foam was linear, one would expect the times to be in the ration of $1: 1 / 2$ to $1 / 5$. Differences from that ratio might be due to experimental error or different reactivities of different particle sizes. The differences between high power and medium power seem to fit that approximation, however the difference between high power and low power are significantly outside what would seem reasonable. It is most probable that the power at the low range was insufficient to follow the same reaction pathway as the high and medium power processes. 
The trend analysis data for the evaluation of graphite can be seen in Figures 8-11.

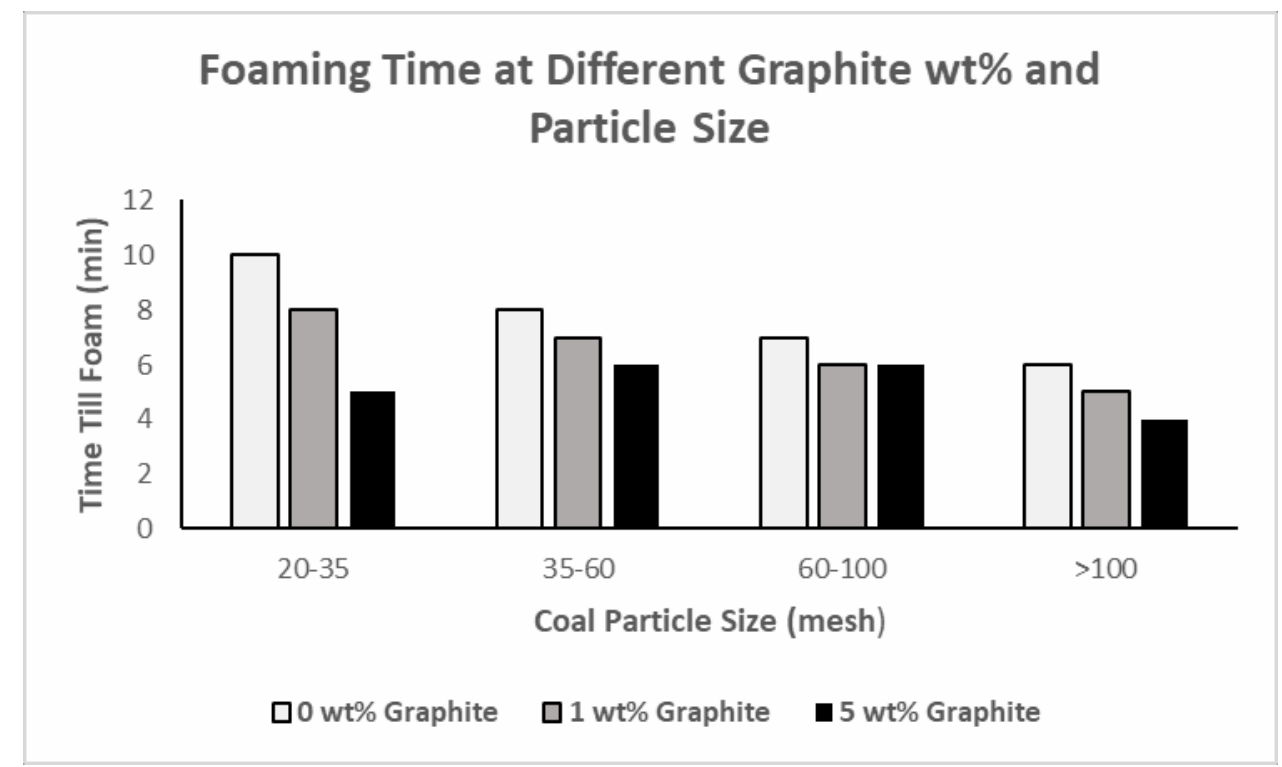

Figure 8: Low Volatile Bituminous Coal and 100\% Microwave Power

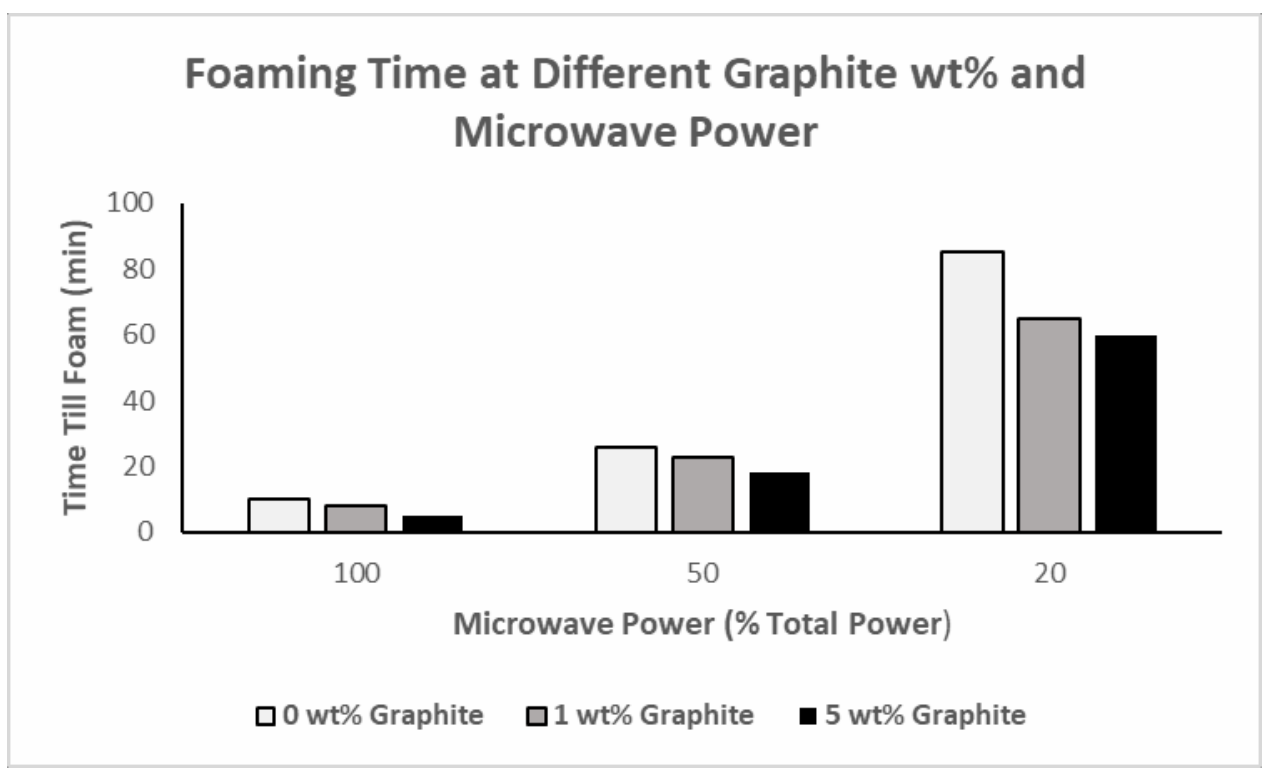

Figure 9: Low Volatile Bituminous Coal and 20-35 mesh Coal Particle Size 


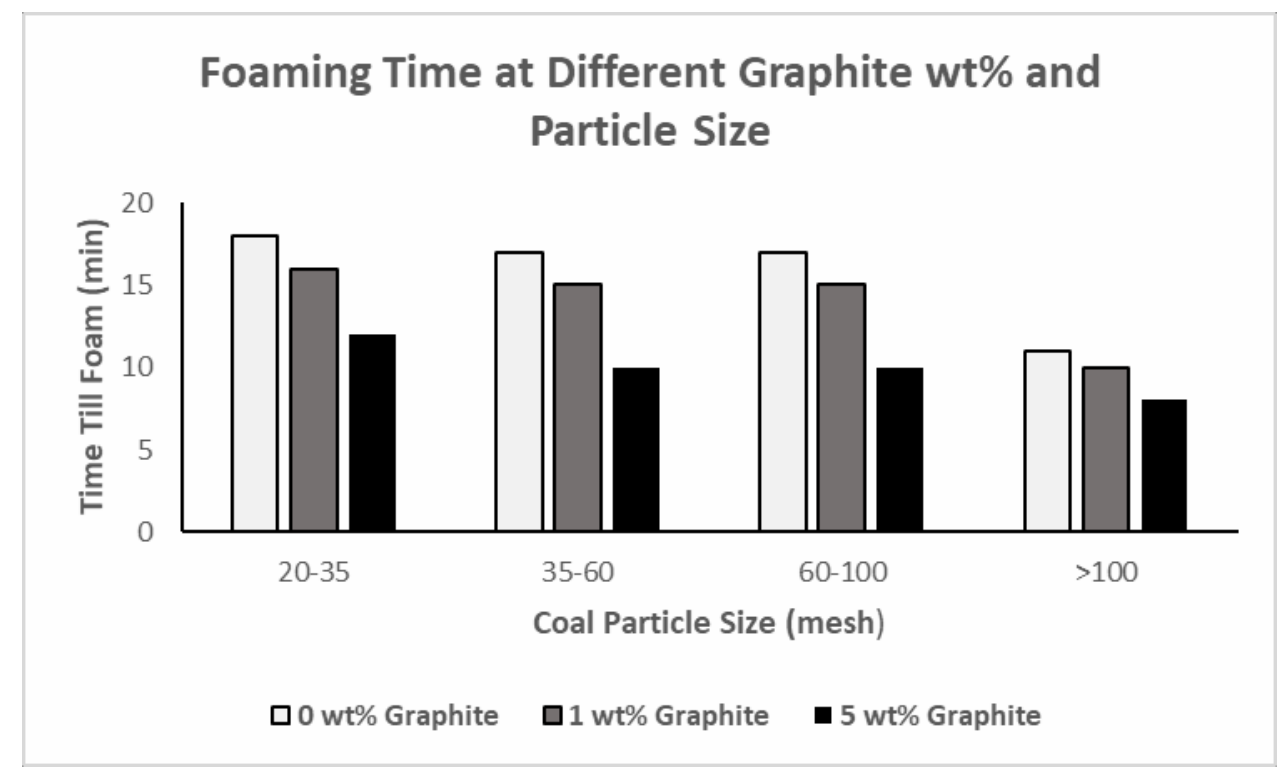

Figure 10: High Volatile Bituminous Coal and 100\% Microwave Power

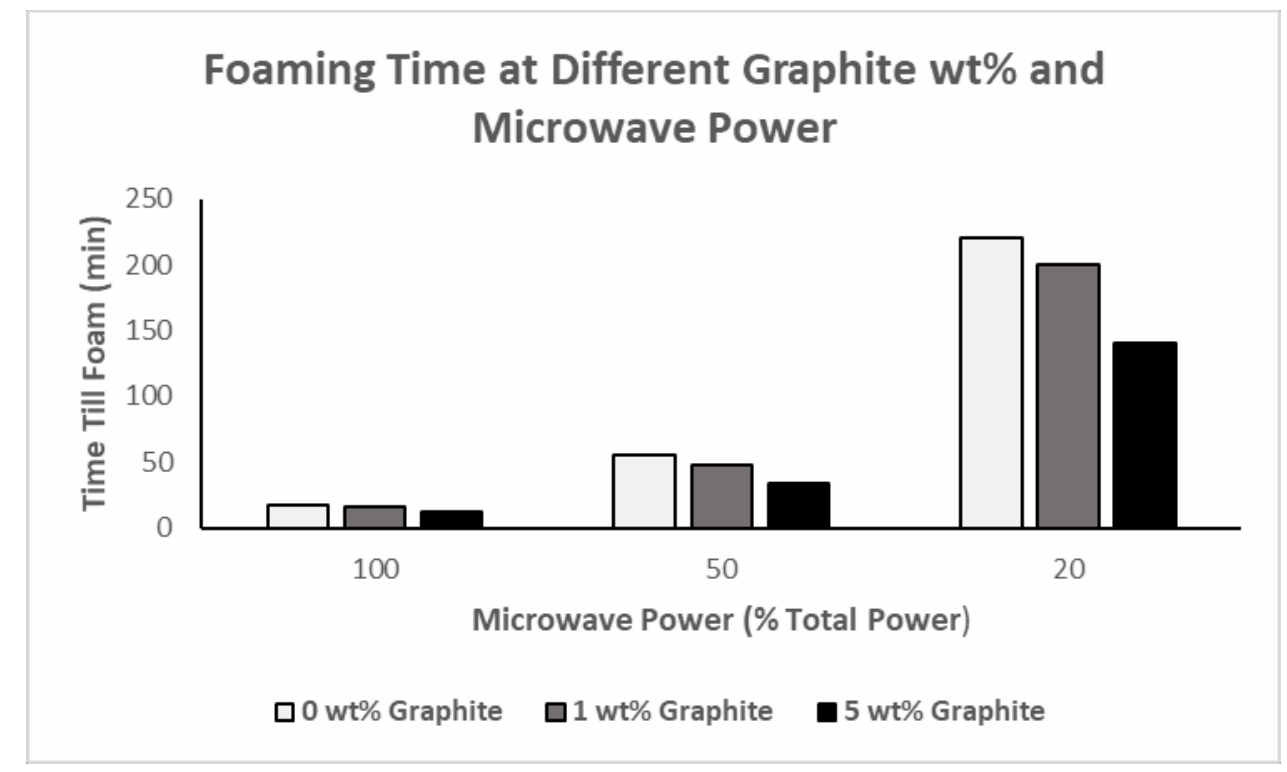

Figure 11: High Volatile Bituminous Coal and 20-35 mesh Coal Particle Size 
The data found in Figures 8-11 show the graphite wt\% varying next to either the percentage of the total microwave power or the coal particle size at each time that it takes for the foam to become a solid after being exposed to the radiant heat of the microwave. Every chart associated with the table's data points can be found in the Appendix: Trend Analysis section.

The results were consistent across each trial. Adding graphite to the system from $0 \%$ to $1 \%$ greatly decreased the time which it took the coal/HFCS mixtures to harden into a green foam. The values were fairly consistent across the varying particle size while the effects of adding the graphite were significantly increased at the lower power settings. The reason for this is because at the lower power settings the samples have a much harder time reaching the temperatures required to devolatilize the HFCS; the increase in graphite causes the system to be at a much higher temperature than the no graphite samples.

The data also show that increasing the change in the amount of graphite from $1 \%$ to $5 \%$ does decrease the time it takes for the coal/HFCS mixtures to turn into a green foam, but not at as much as the change from $0 \%$ graphite to $1 \%$ graphite makes. The different coal types, low volatile bituminous coal and high volatile bituminous coal, also show the same trend for each increase in graphite percentage which can be seen by comparing the scales of time for two of the charts with different coal types.

\section{Task 2: Testing the Potential for Graphite Assisted Calcination Results}

Three samples followed the testing procedure found in Task 2: Testing the Potential for Graphite Assisted Calcination in the Experimental Overview section. All three samples had an increase in conductivity which proves that calcination is possible by only using a microwave. 
Two samples that were prepared without graphite were also tested, and both samples were not conductive after the 1 hour of exposure.

\section{Task 3: Exploration of Various Flux Agents Results}

Carbon foam was produced by using lignin as the binding agent. The procedure followed the standard process from the patent but with the substitution of lignin in place of the HFCS. The sample looked similar to the coal/HFCS standard sample, but the lignin mixture was less viscous. After exposing the mixture to the normal microwave procedure, the sample solidified after about 4 minutes of total microwave time. A solid was formed, but the solid was not as structurally strong as the standard samples. Figure 12 shows a picture of a carbon foam sample made from a coal and lignin mixture.

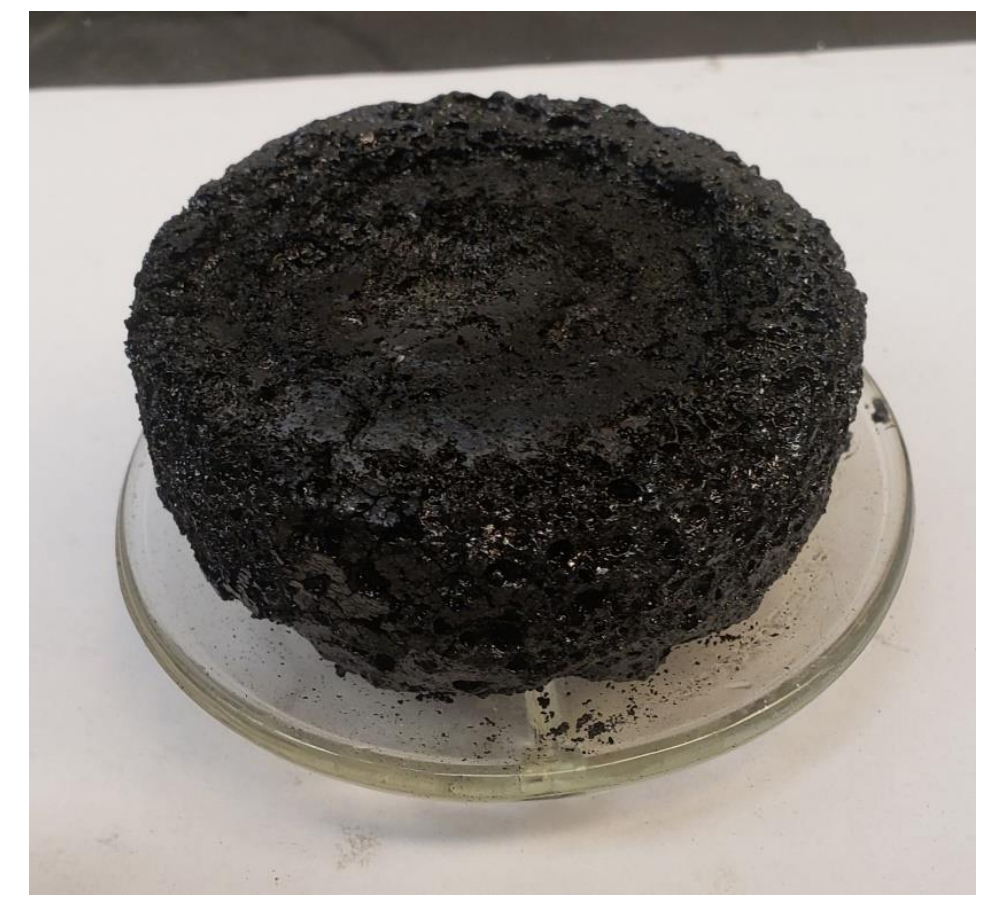

Figure 12: Carbon Foam Sample Manufactured Using Lignin 


\section{Task 4: The Use of an Inductive Heater for Calcination of Carbon Foam Results}

The inductive heater was assembled, and a carbon foam sample was selected to be tested. The carbon foam used a high volatile coal that was created with coal particles of size 20-35 mesh mixed with HFCS and graphite. Figure 13 shows what the sample looked like before being introduced to the inductive field.

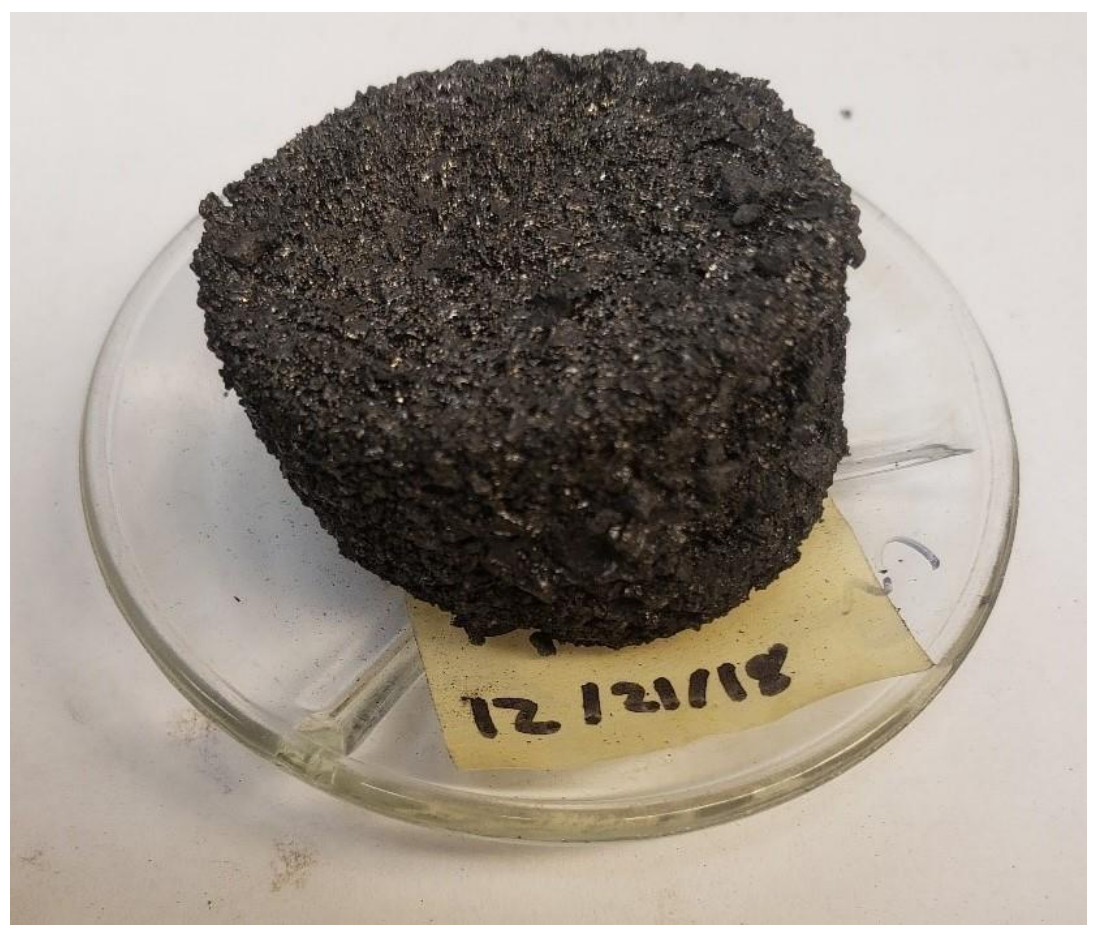

Figure 13: Carbon Foam Before Inductive Heating

The sample was placed in the coils of the inductive heater by resting on top of a ceramic cup. It was important to have the sample held by a material that was unaffected by the inductive field but could deal with the expected rapid temperature increase of the carbon foam sample.

Before turning the inductive field, a multimeter was used to check the rough conductivity of the sample. Figure 14 shows what the sample looked like after being exposed to the inductive heater for about 30 seconds. 


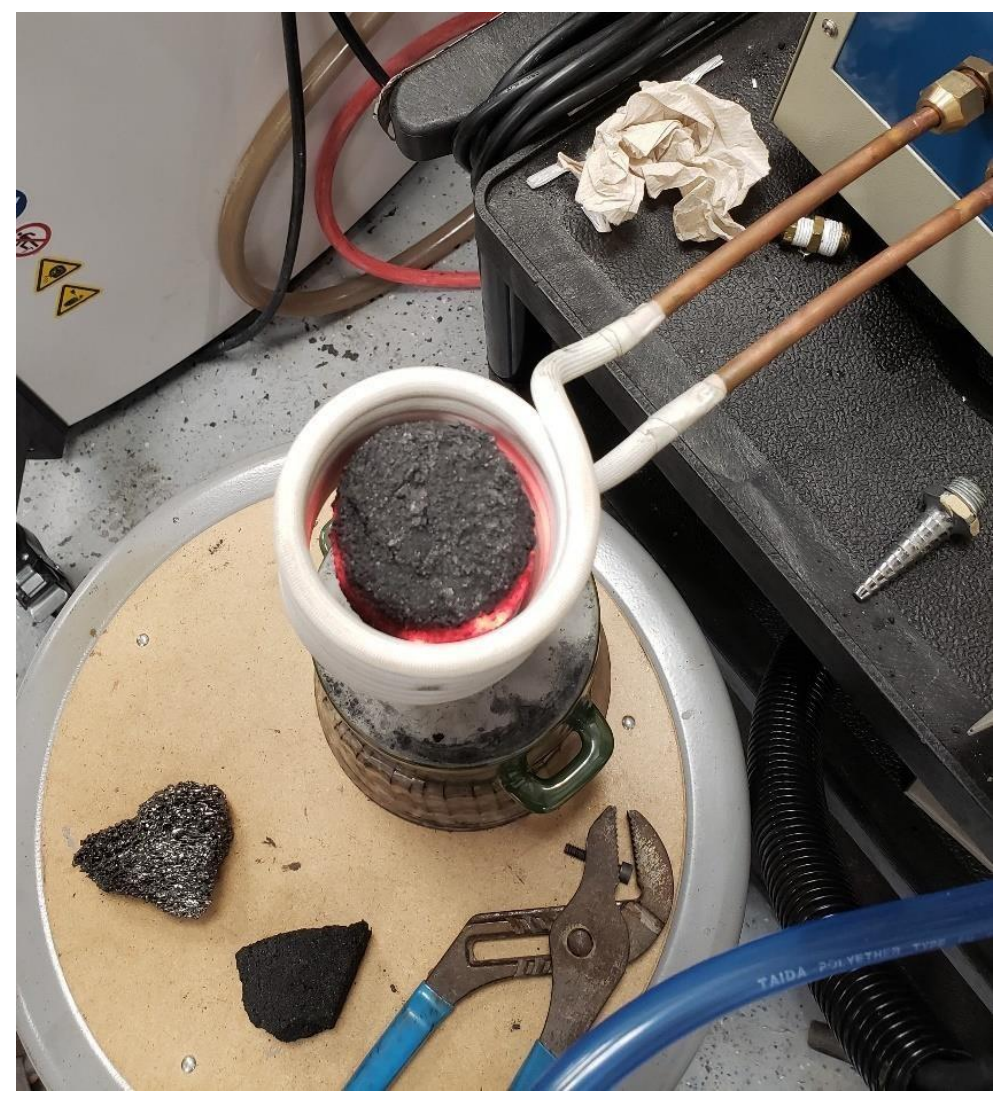

Figure 14: Carbon Foam After Inductive Heating

As seen in the Figure 14 the lower section of the sample has become red hot after being exposed to the inductive field for only 30 seconds. The sample was remeasured with the multimeter and proved to have an increase in conductivity. This proves that the carbon foam could be calcined if it sat in the inductive heater for longer amounts of time.

\section{Task 5: Making $1 \mathrm{ft}^{2}$ Samples for Clients Results}

Four large $1 \mathrm{ft}^{2}$ samples were prepared using the same sample preparation process and microwave procedure as described in Task 5 and Task 1 in the Experimental Overview section. Figure 15 shows what the sample looked like before heating in the microwave. 


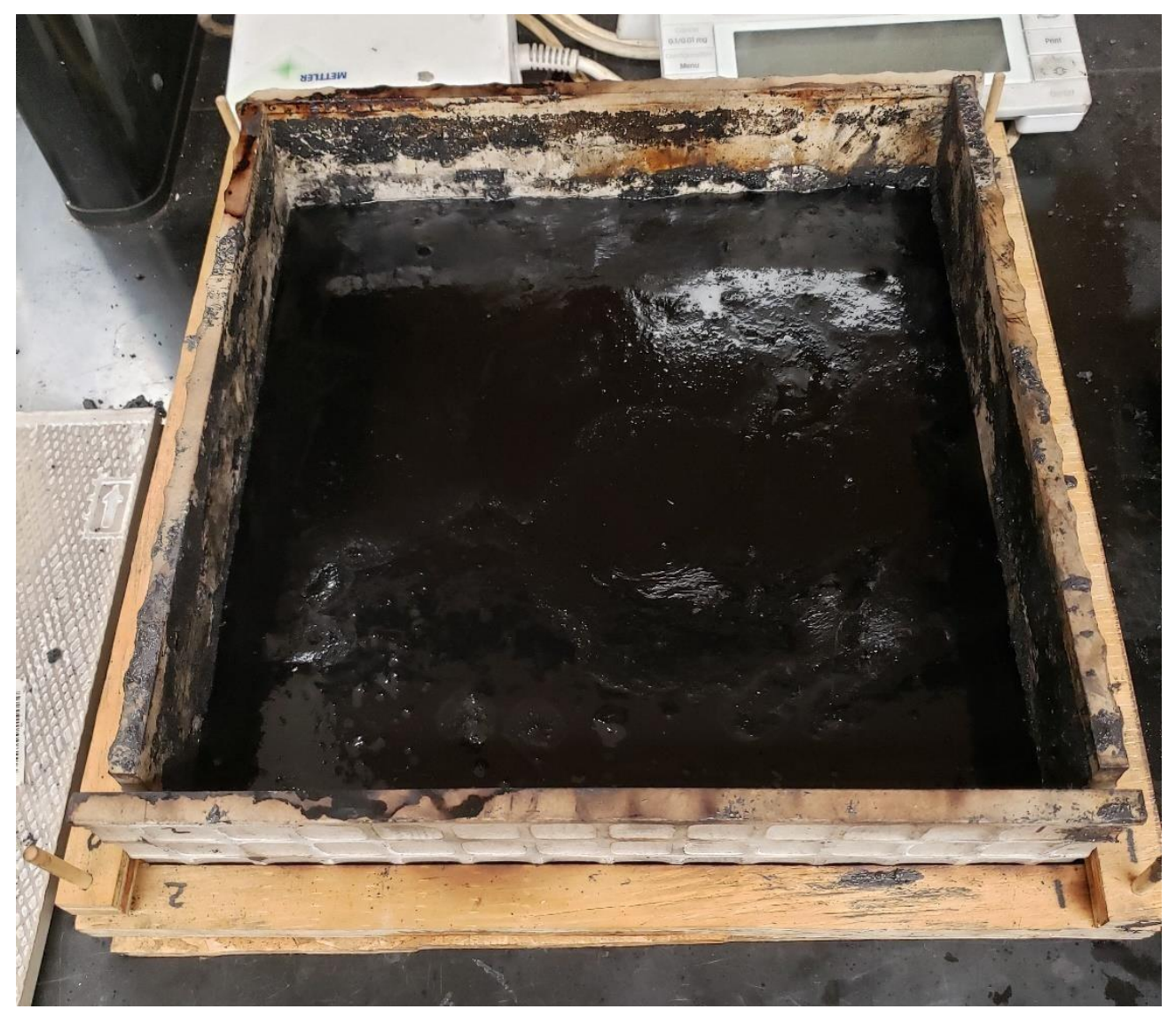

Figure 15: Large Test Piece Before Microwave Exposure

The large piece looked the same as the samples that were made for the small ceramic mugs. Figure 16 shows what the piece looks like after following the microwave procedure. 


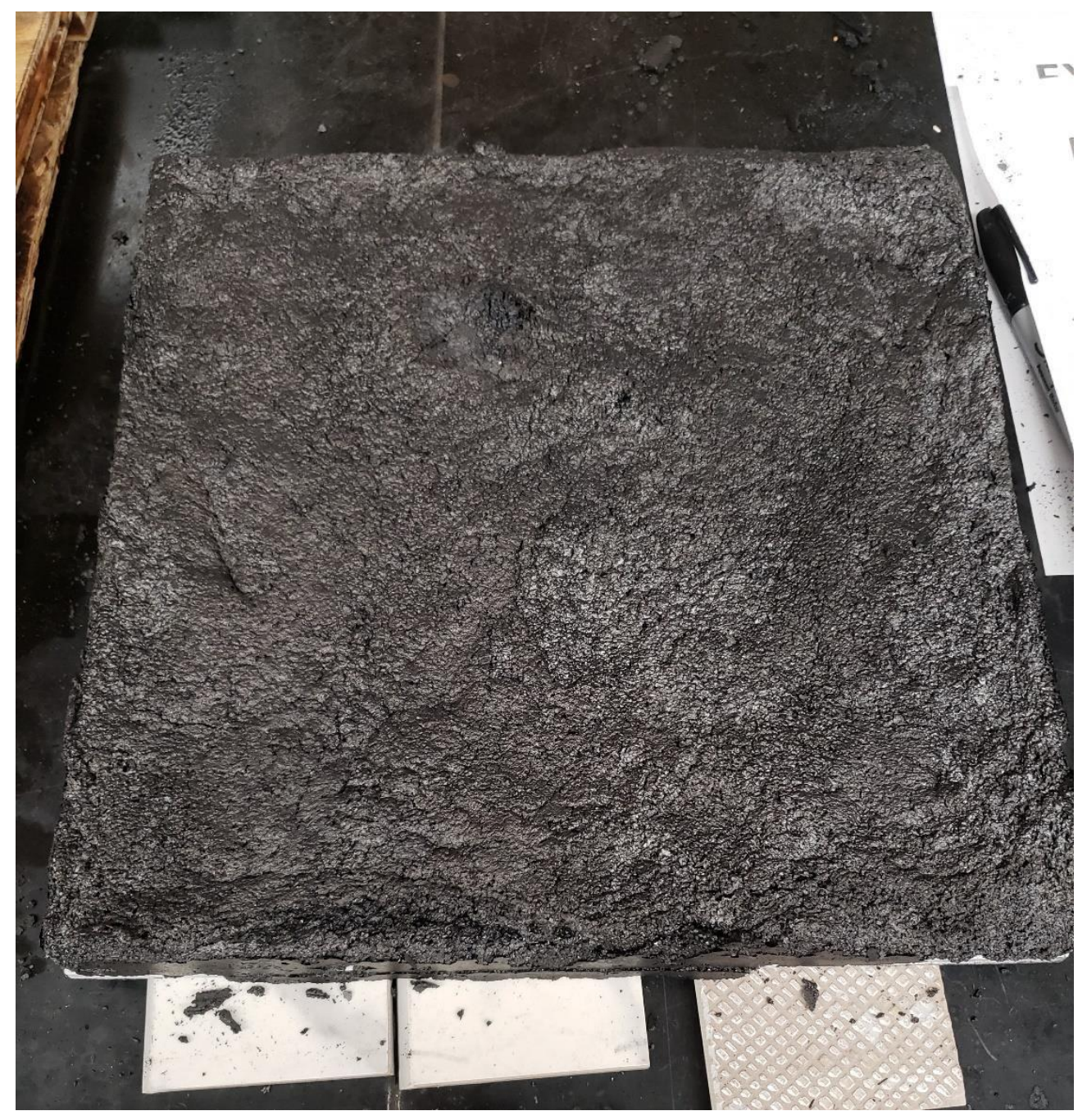

Figure 16: Large Test Piece After Microwave Exposure

The large piece solidified and became a relatively uniform solid. This proved that the creation of large pieces was possible. All ofthe manufactured large pieces were packaged and sent out to clients for testing. 


\section{Conclusions}

\section{General Conclusions}

(1) The addition of graphite into the carbon foam manufacturing process greatly decreases the time required to turn the coal/flux agent mixtures into a carbon foam using a microwave.

(2) Carbon foam samples made with graphite can be calcined using the radiant heat transfer from a microwave alone.

(3) Lignin can be used as a binding agent in place of the high fructose corn syrup in the carbon foam manufacturing process.

(4) An inductive field can be used to calcine carbon foam samples in place of a microwave.

(5) Large test pieces of carbon foam can be manufactured.

\section{Trend Analysis Conclusions}

The effect of the addition of graphite to the carbon foam manufacturing process significantly decreases the time required to form a green foam compared to samples without the graphite additive. The increase in graphite $\%$ also decreases the time required to form a green foam, but the significance is not as large as the step from $0 \%$ graphite to $1 \%$ graphite. The additions of the graphite overall increases the efficiency of the carbon foam manufacturing process. 


\section{Recommendations}

1. The analysis completed in the thesis was trend analysis only. An analysis on all of the manufacturing variables would be necessary to get a more optimized carbon manufacturing process. A Box-Behnken experimental design would be appropriate for this optimization. This is a three-level design in which each parameter can be altered.

2. Limitations with the equipment that was used caused minimal data to be obtained on determining if the samples could be calcined by microwave alone. Although the hypothesis that it is possible was proven to be correct, a thorough investigation should be completed to test the full scope of the process.

3. The laboratory was only able to get access to a small supply of lignin. Sodium Lignosulfonate was the only mixture that was tested. Different lignin mixtures should be investigated.

4. Only preliminary experiments were complete using the inductive heater. The few experiments that were ran showed that the heating is possible but does not quantify those results with data. 


\section{References}

[1] Sral, D. M. (1997). The Effect of Additives and Manufacturing Conditions on the Mechanical Properties of Carbon Foams (Unpublished master's thesis). West Virginia University. 


\section{Appendix A}

Trend Analysis 
Low Volatile Bituminous Coal: 100\% Microwave Power

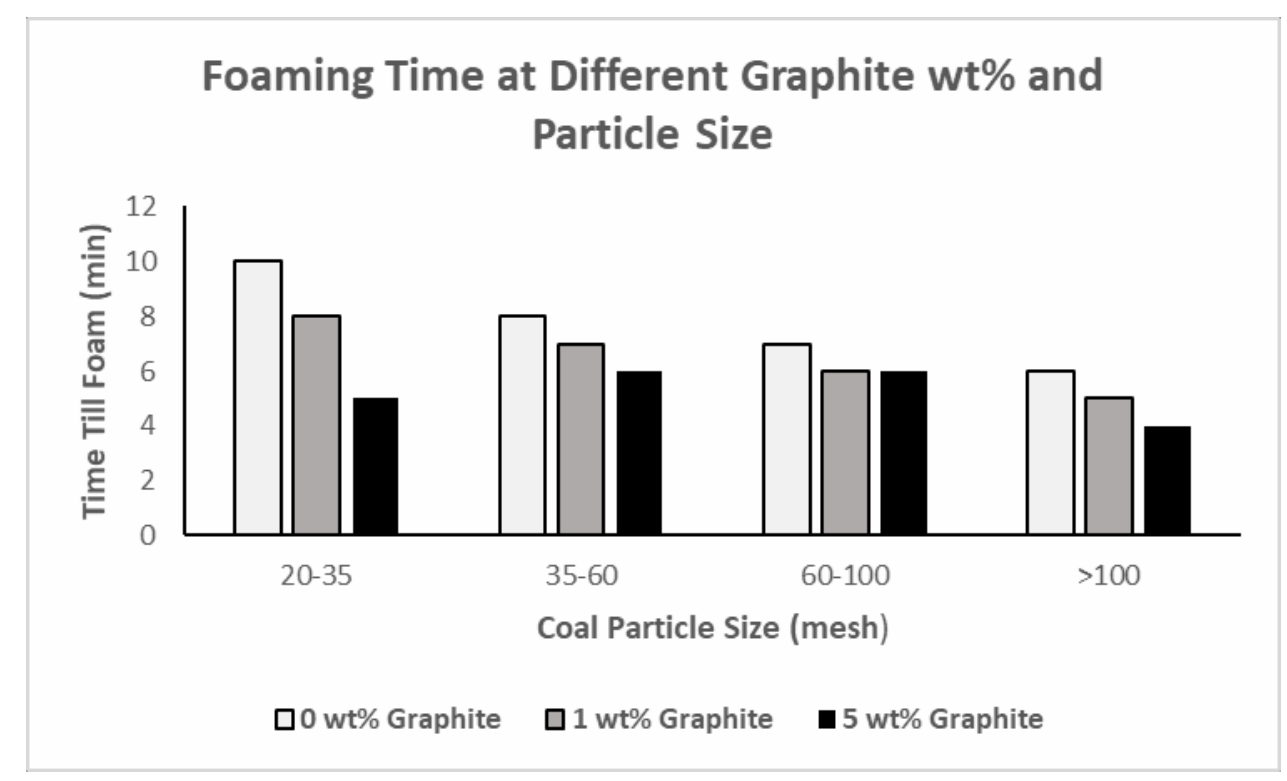

Low Volatile Bituminous Coal: 50\% Microwave Power

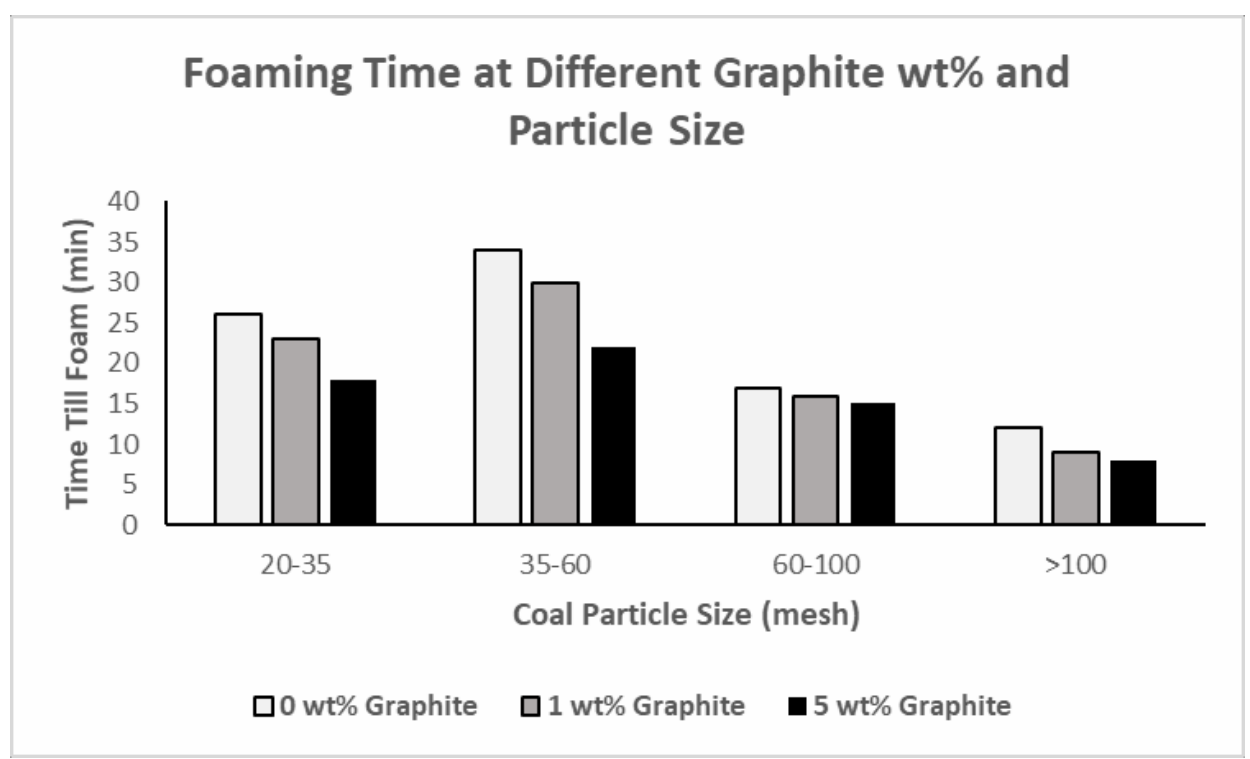


Low Volatile Bituminous Coal: 20\% Microwave Power

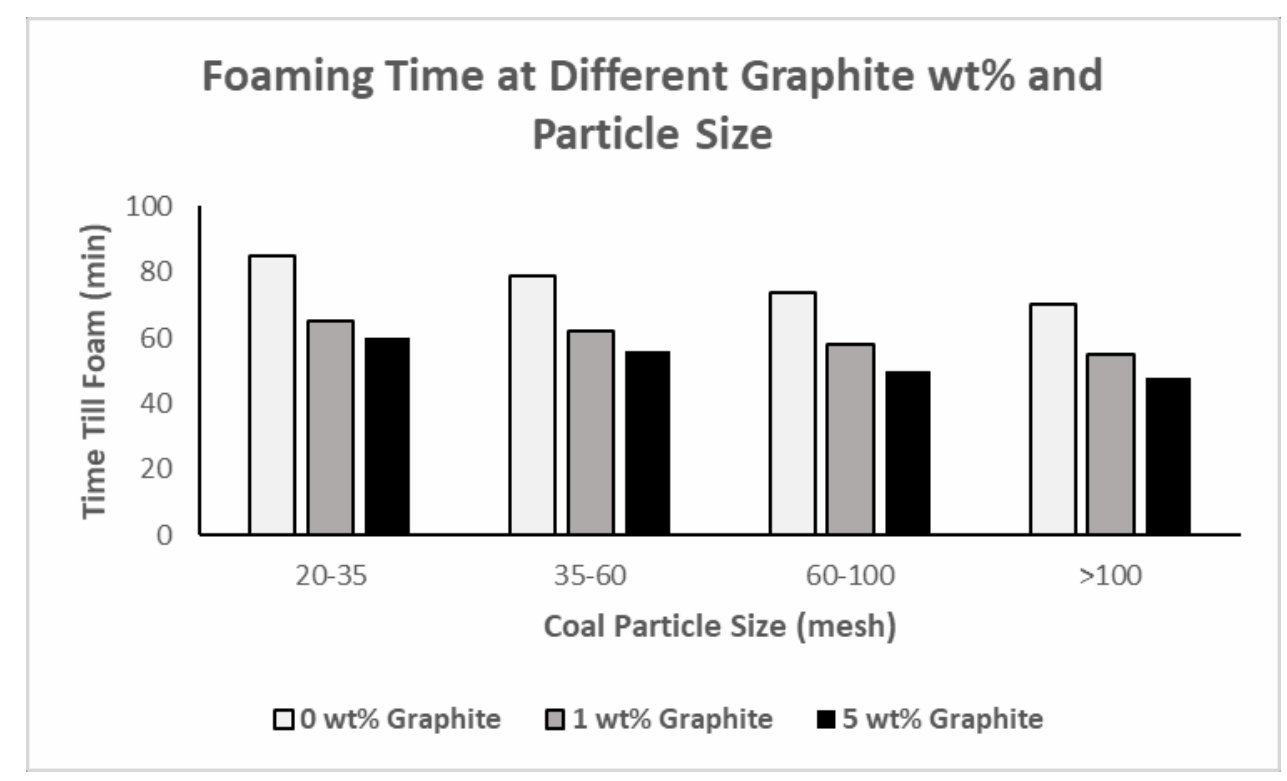

High Volatile Bituminous Coal: 100\% Microwave Power

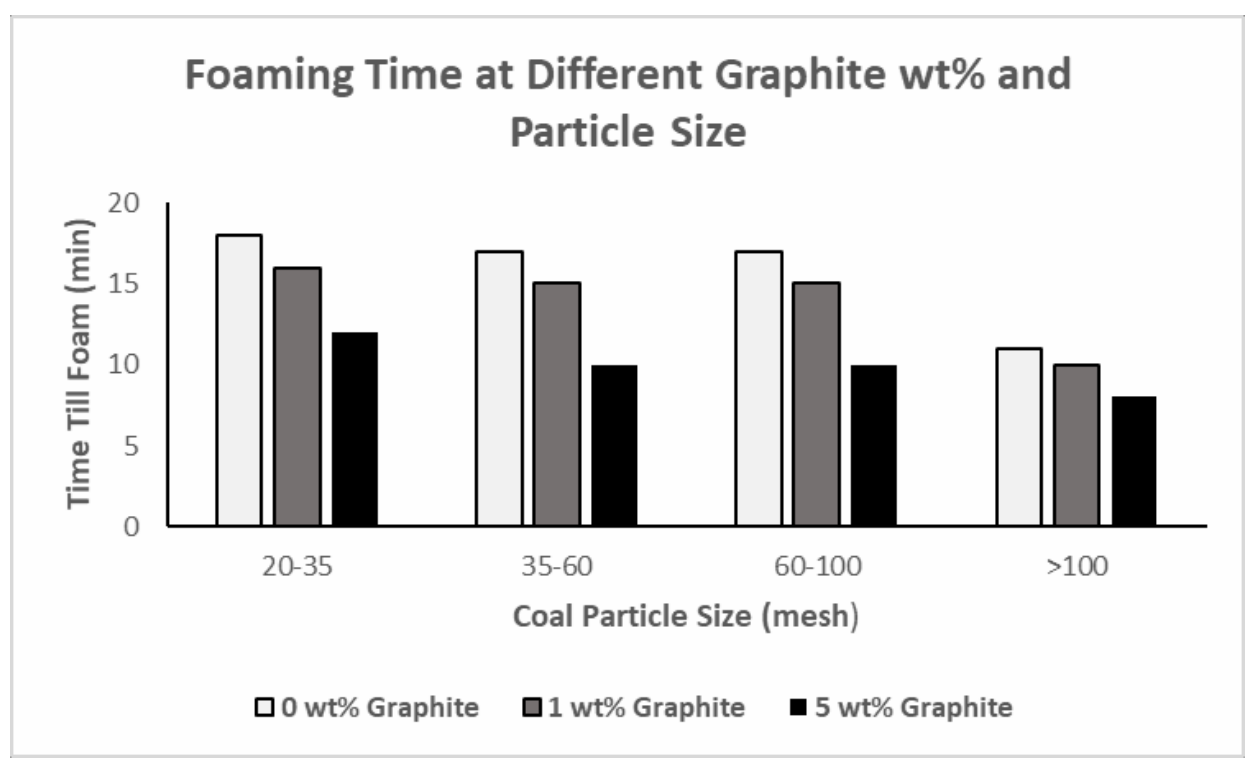


High Volatile Bituminous Coal: 50\% Microwave Power

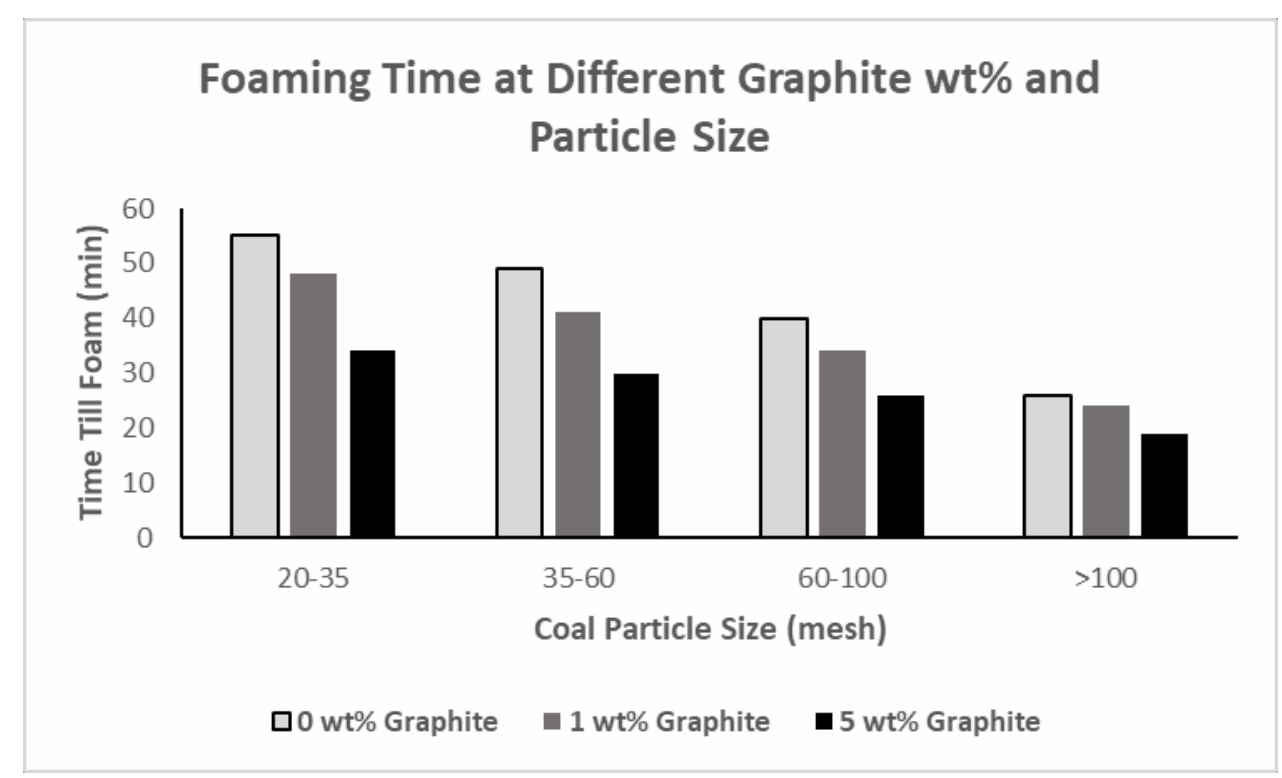

High Volatile Bituminous Coal: 20\% Microwave Power

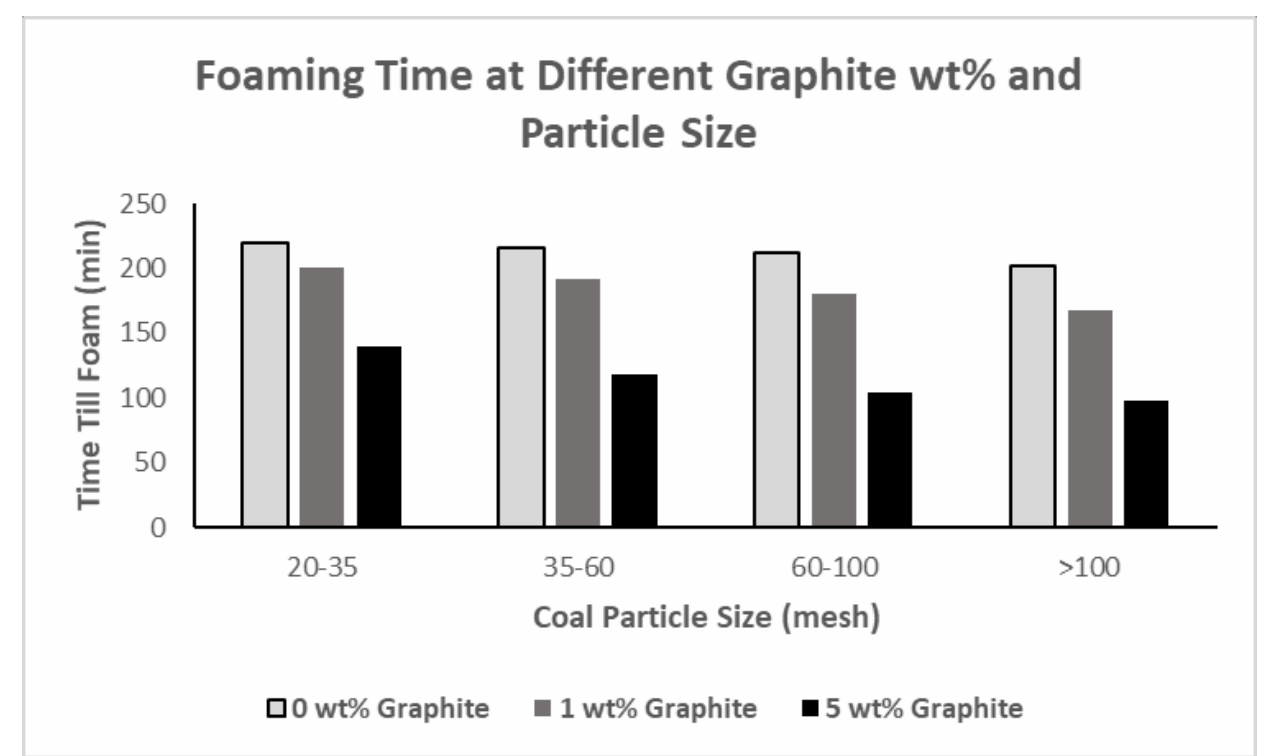


Low Volatile Bituminous Coal: 20-35 mesh Coal Particle Size

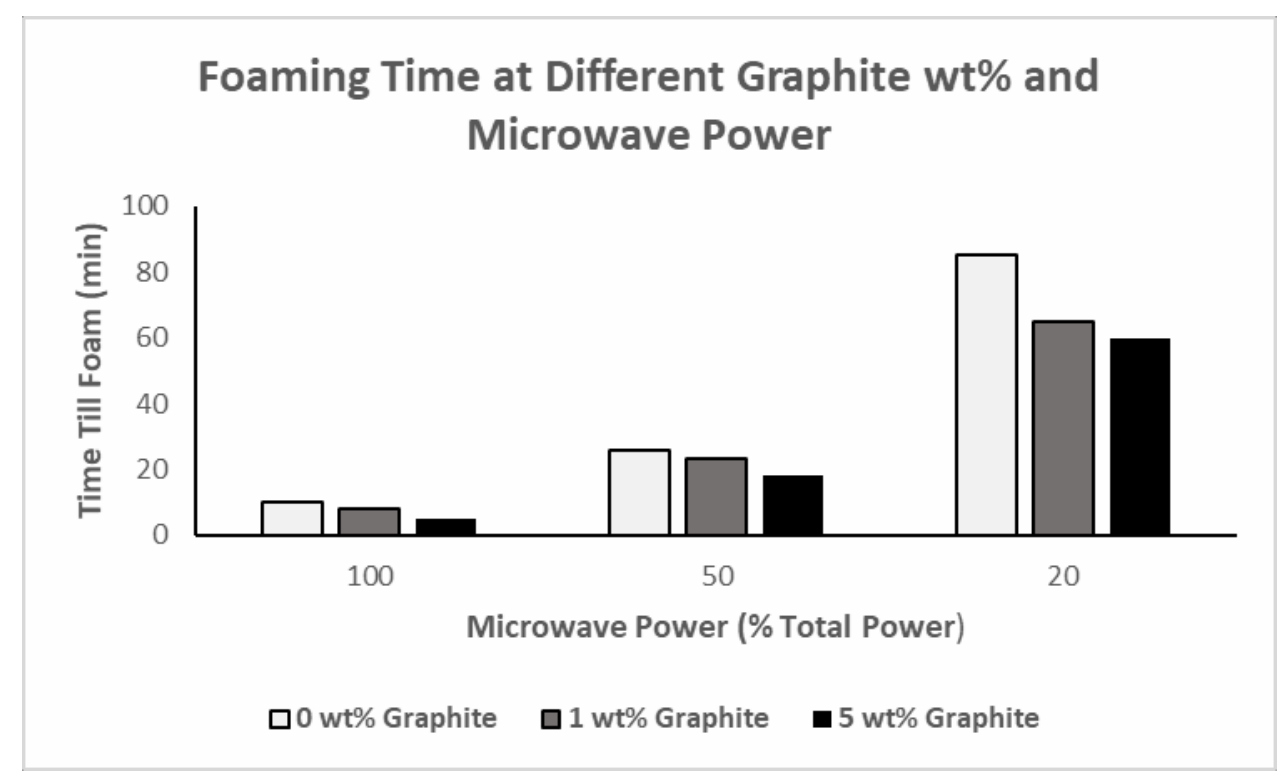

Low Volatile Bituminous Coal: 35-60 mesh Coal Particle Size

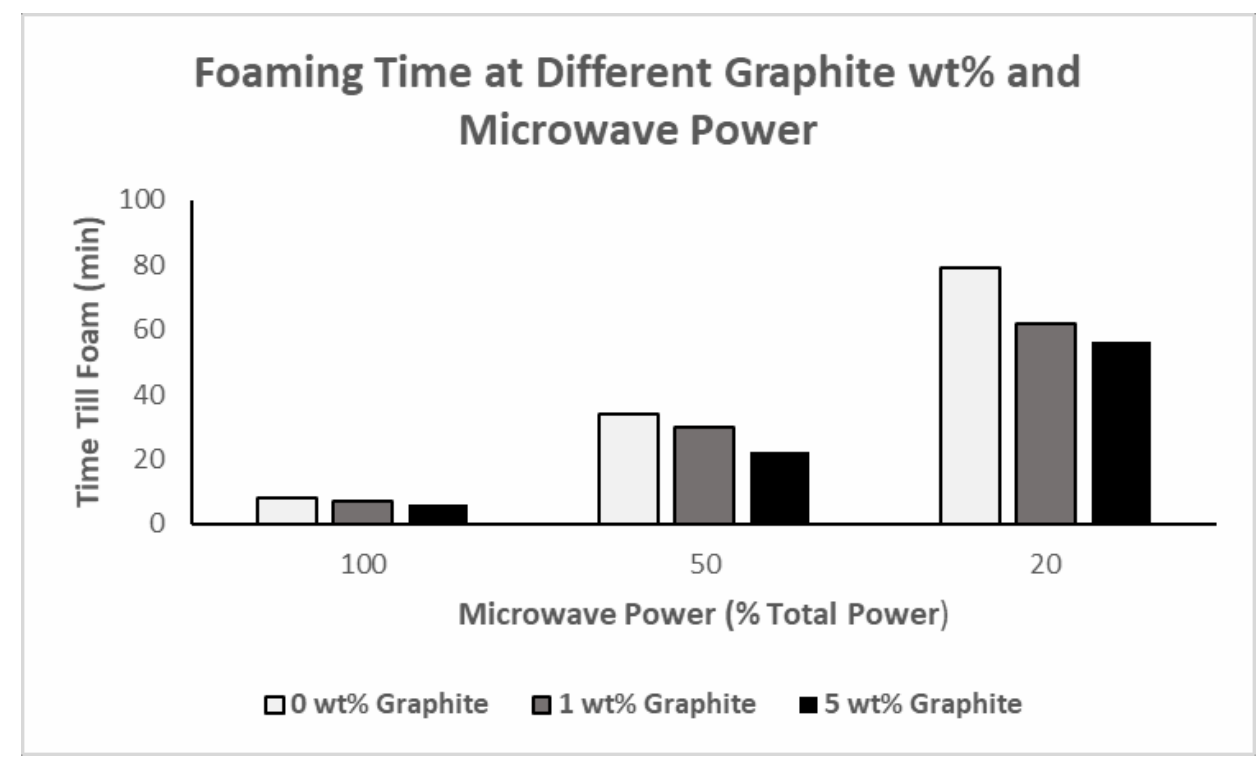


Low Volatile Bituminous Coal: 60-100 mesh Coal Particle Size

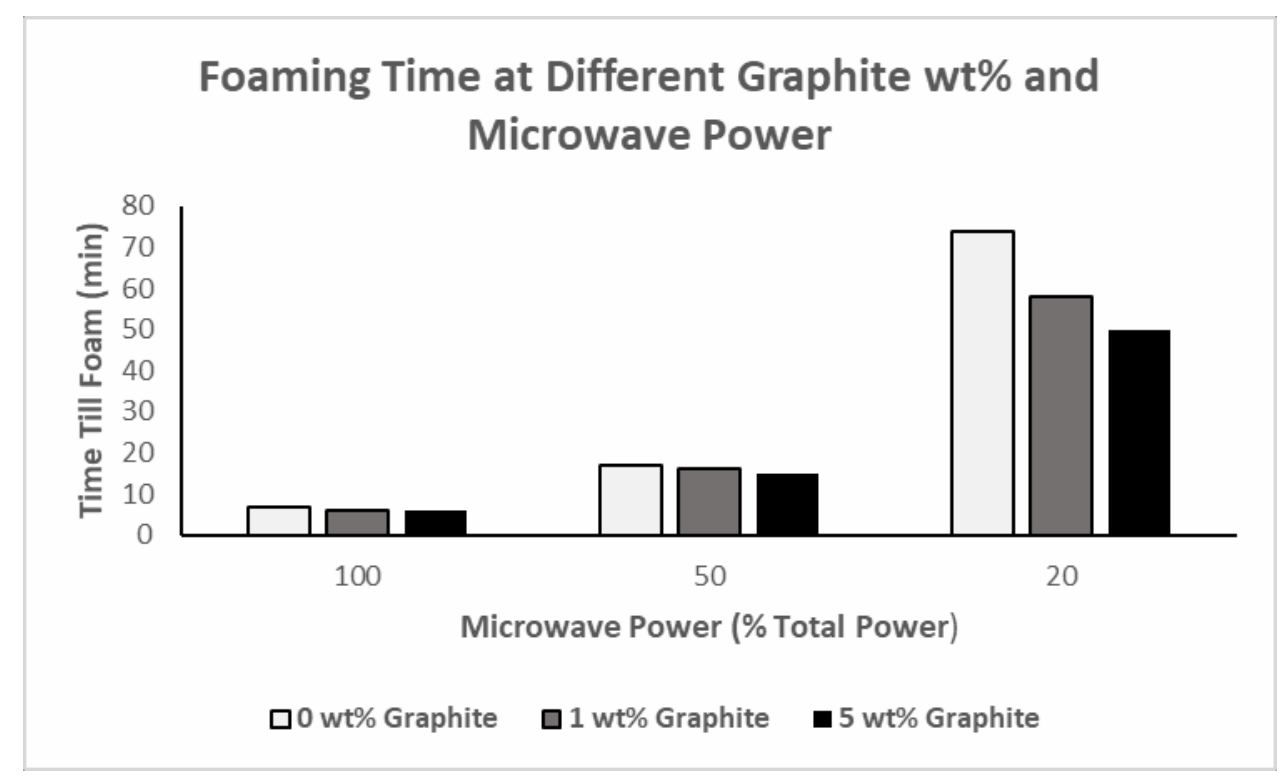

Low Volatile Bituminous Coal: >100 mesh Coal Particle Size

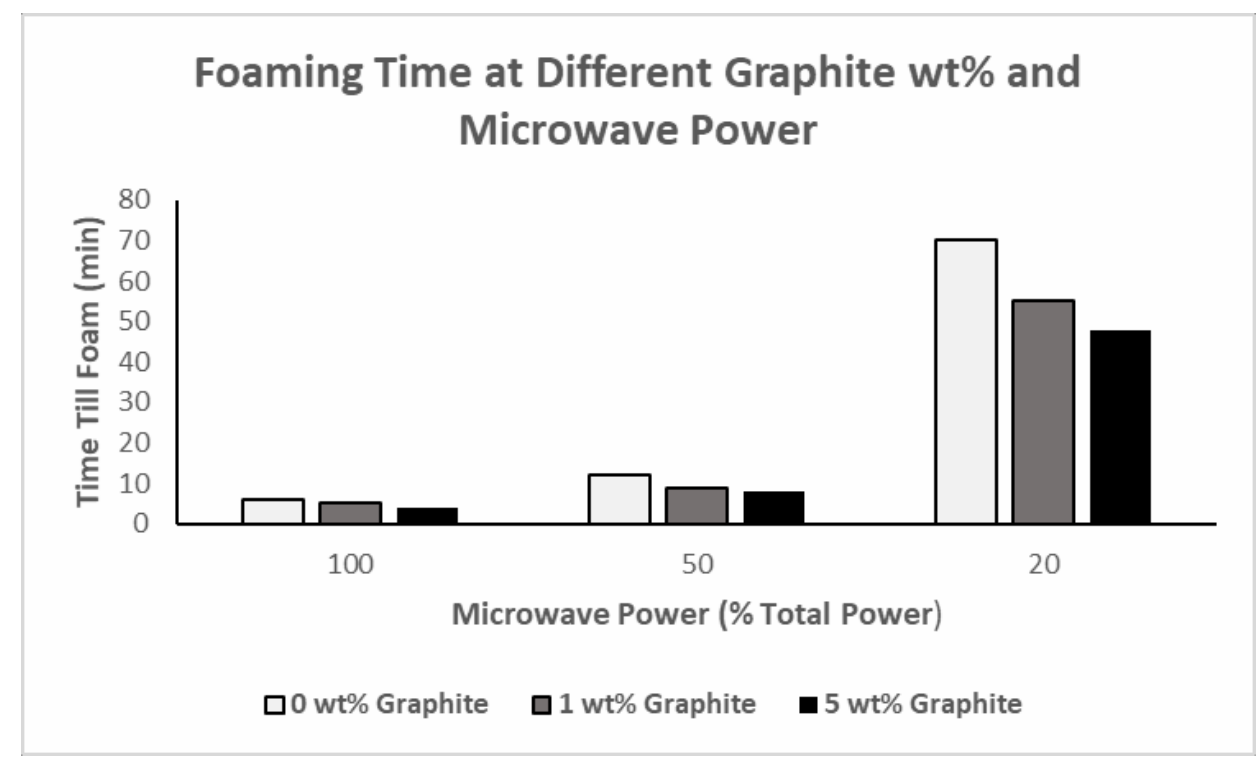


High Volatile Bituminous Coal: 20-35 mesh Coal Particle Size

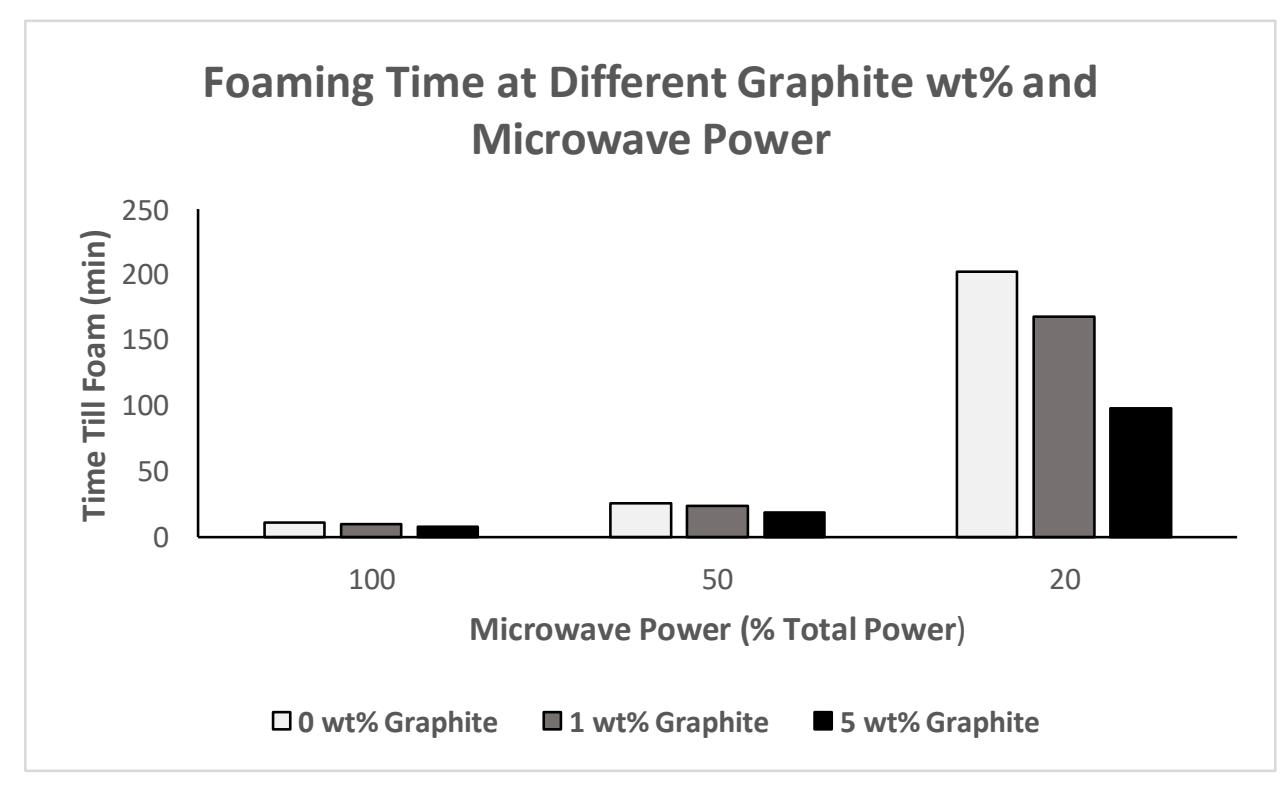

High Volatile Bituminous Coal: 35-60 mesh Coal Particle Size

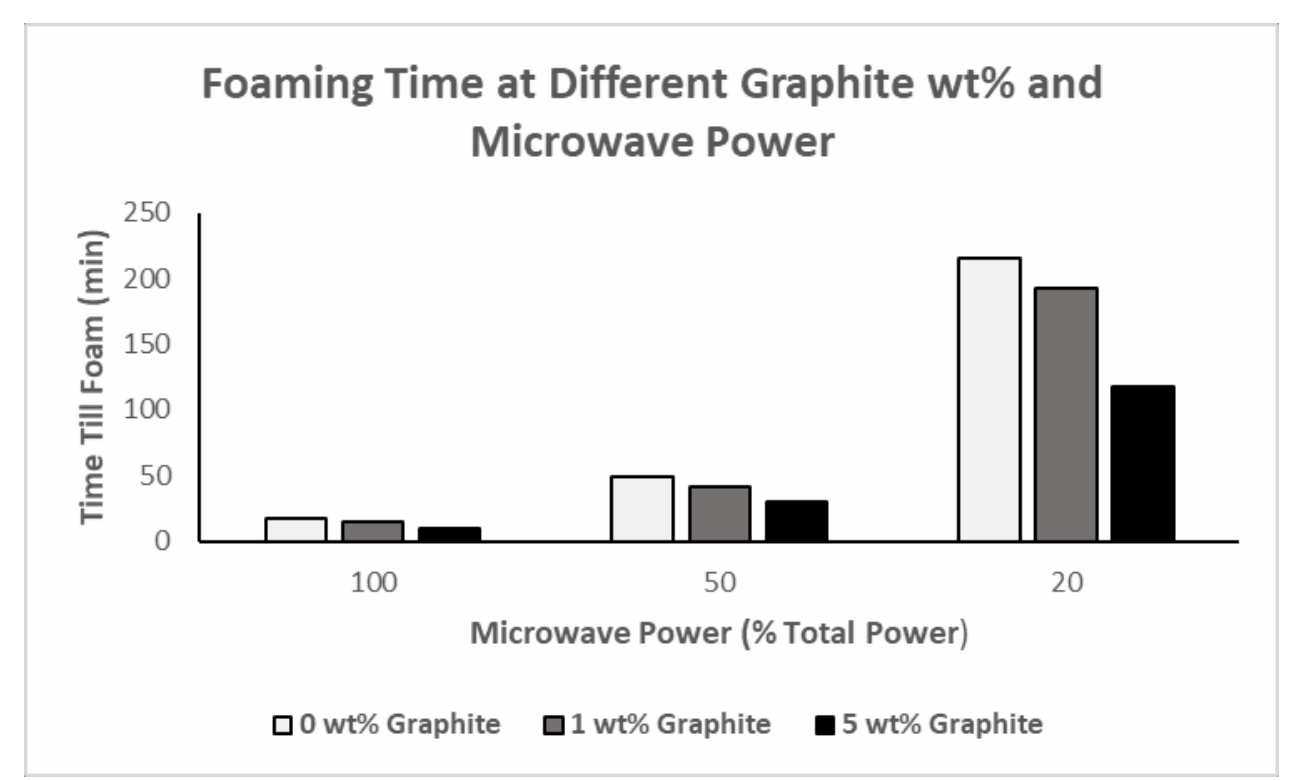


High Volatile Bituminous Coal: 60-100 mesh Coal Particle Size

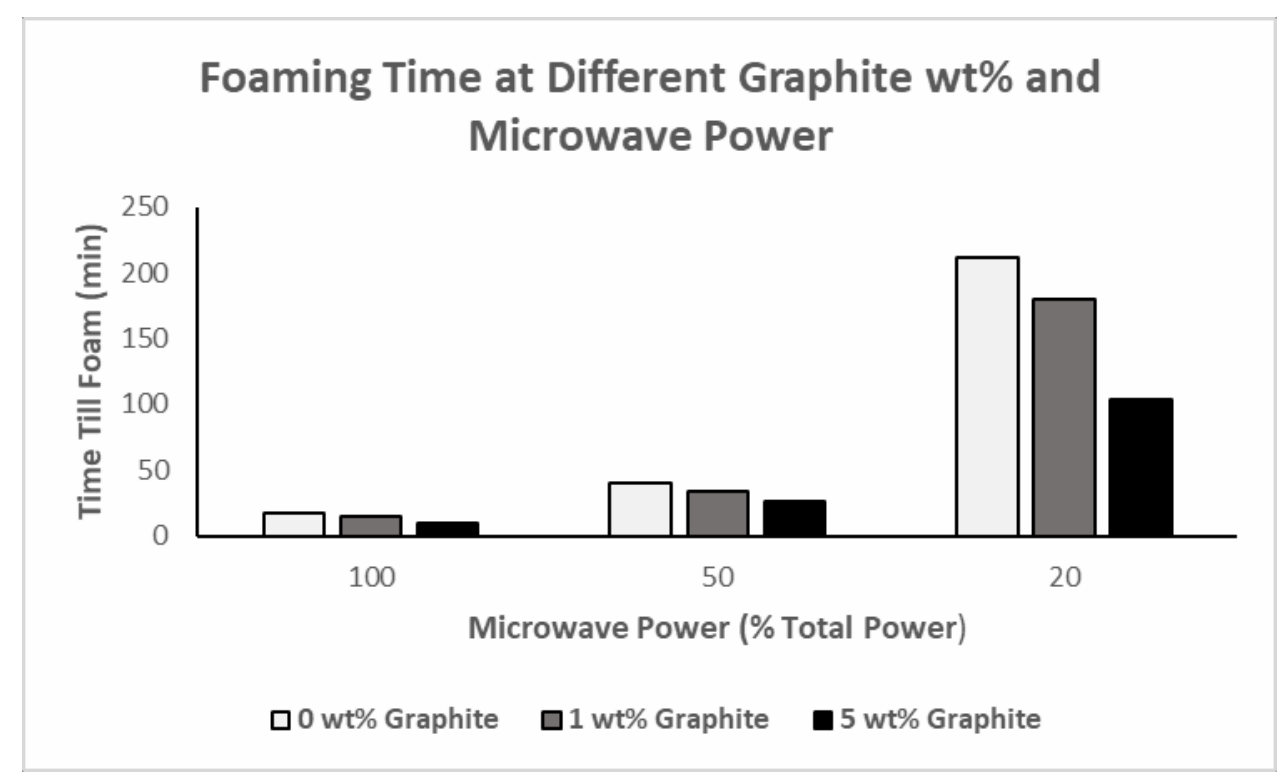

High Volatile Bituminous Coal: >100 mesh Coal Particle Size

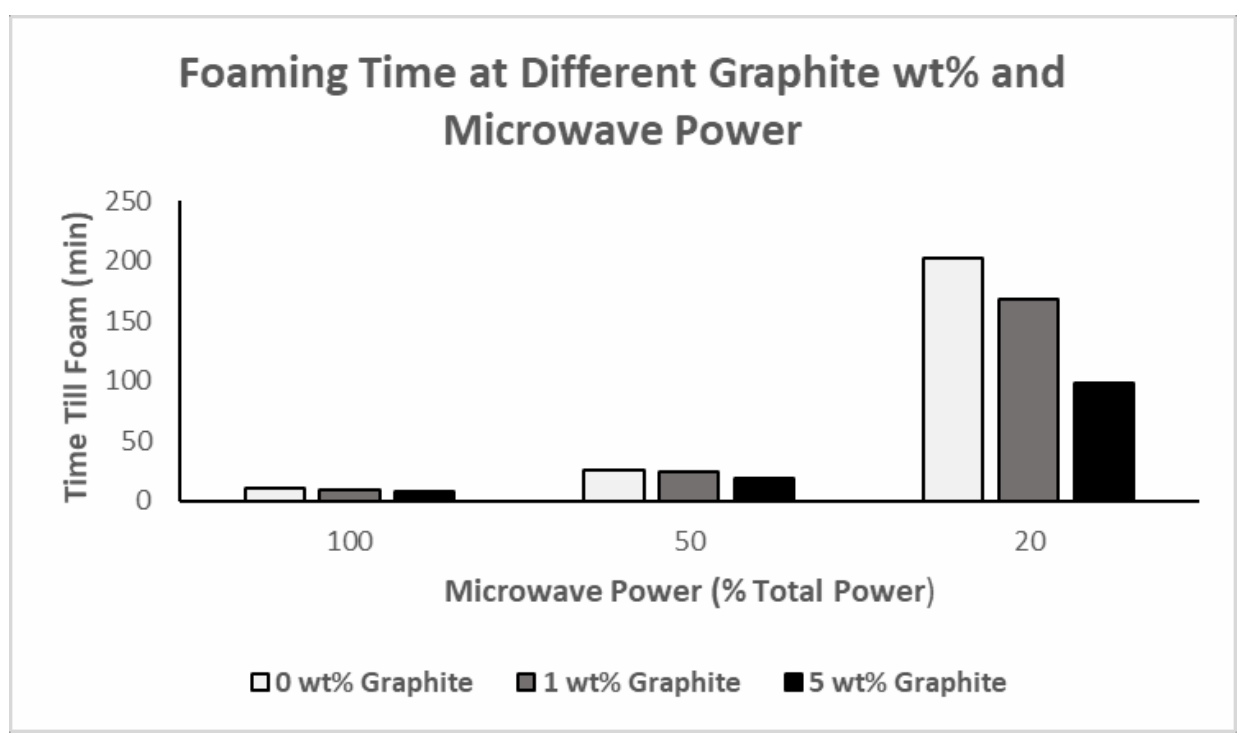




\section{Low Volatile Bituminous Coal: 0 wt\% Graphite}

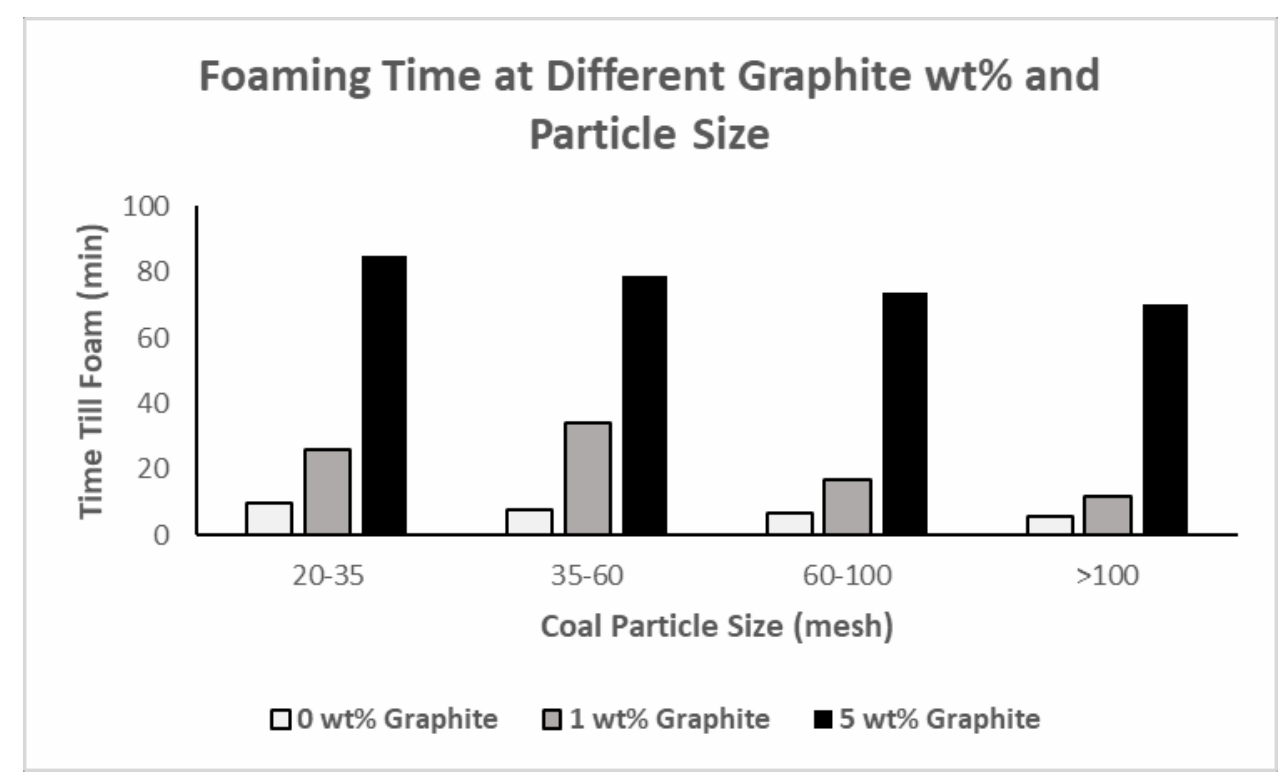

Low Volatile Bituminous Coal: 1 wt\% Graphite

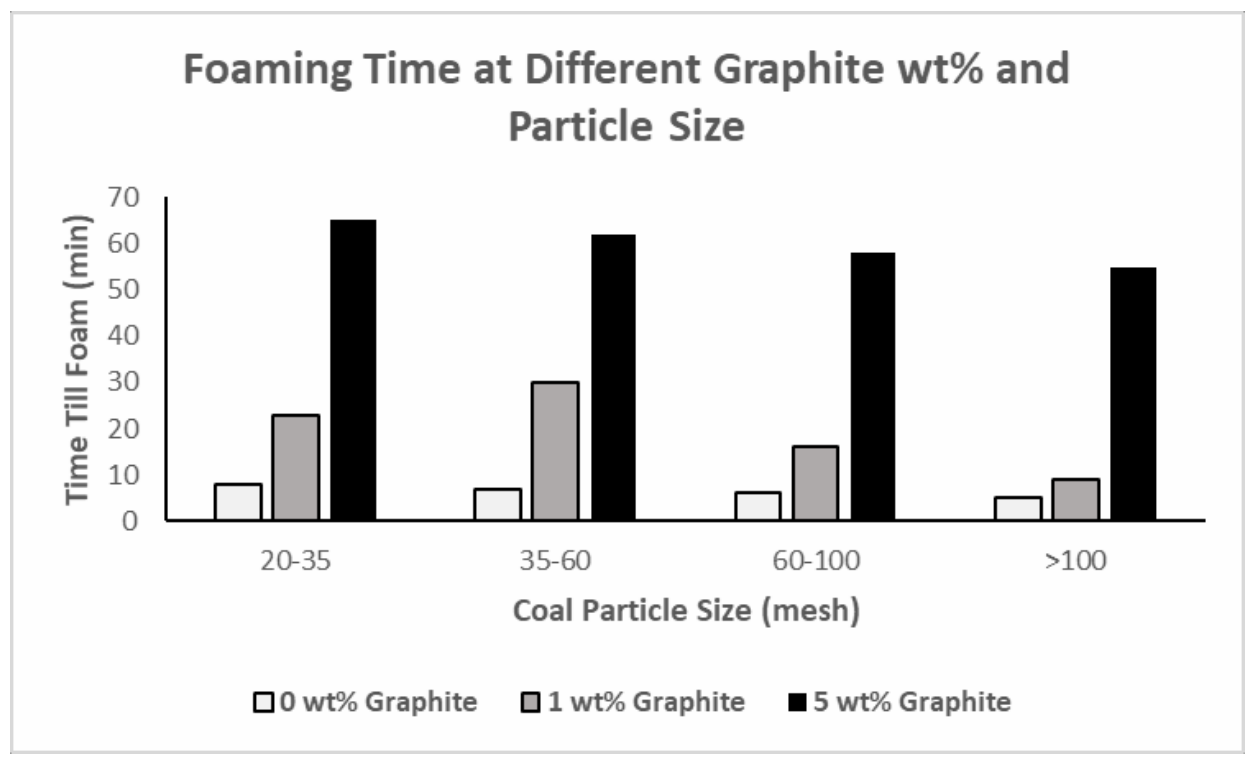


Low Volatile Bituminous Coal: 5 wt \% Graphite

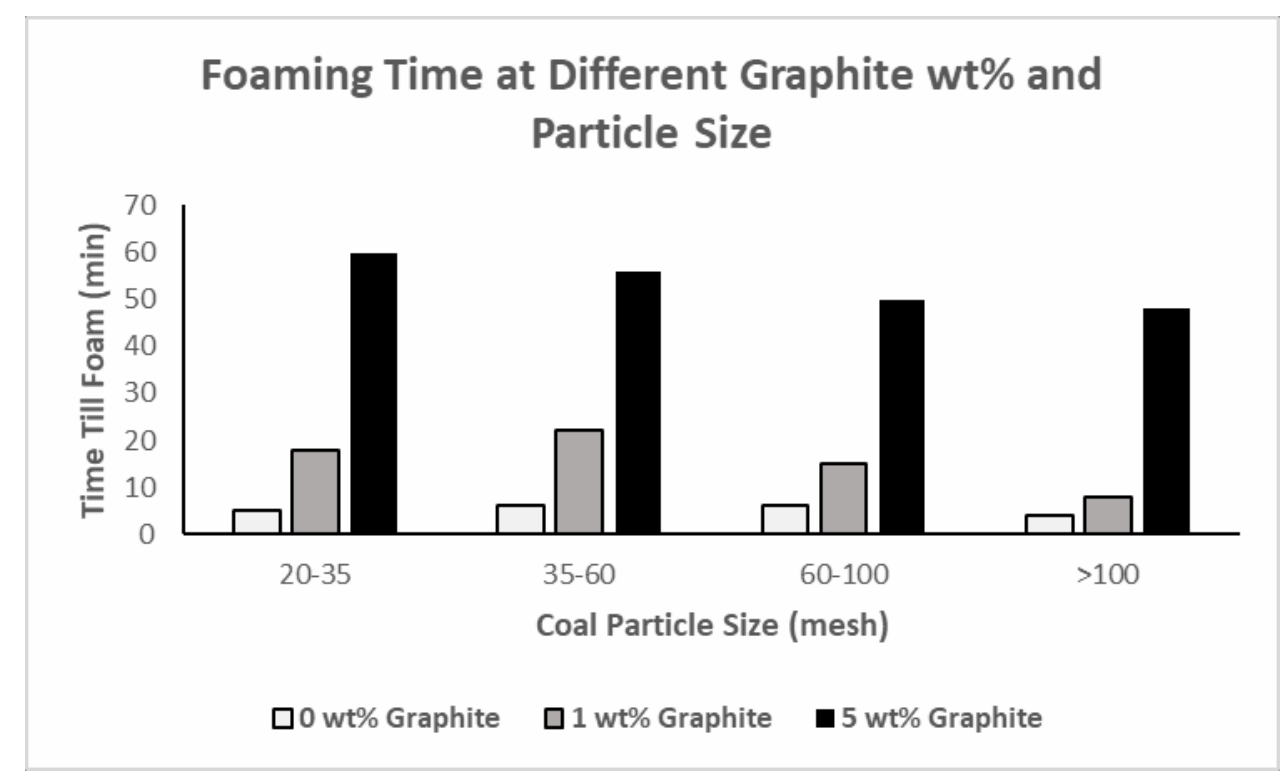

High Volatile Bituminous Coal: 0 wt \% Graphite

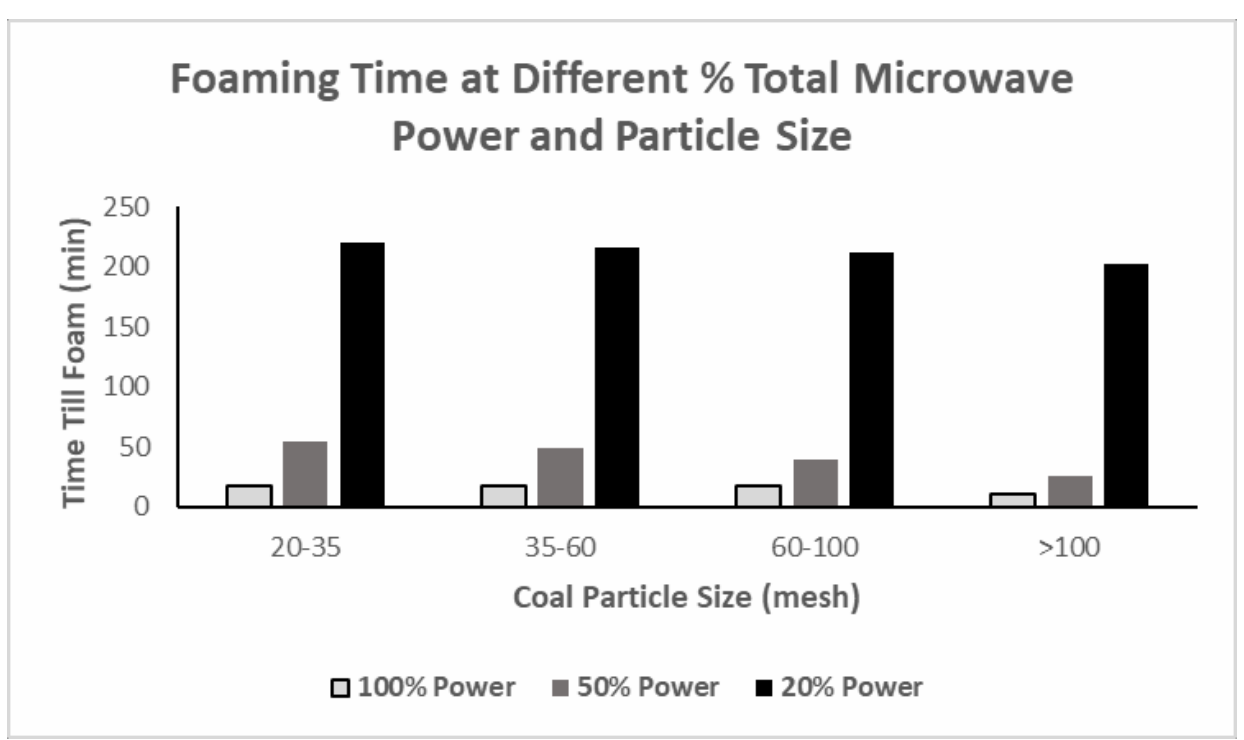


High Volatile Bituminous Coal: 1 wt\% Graphite

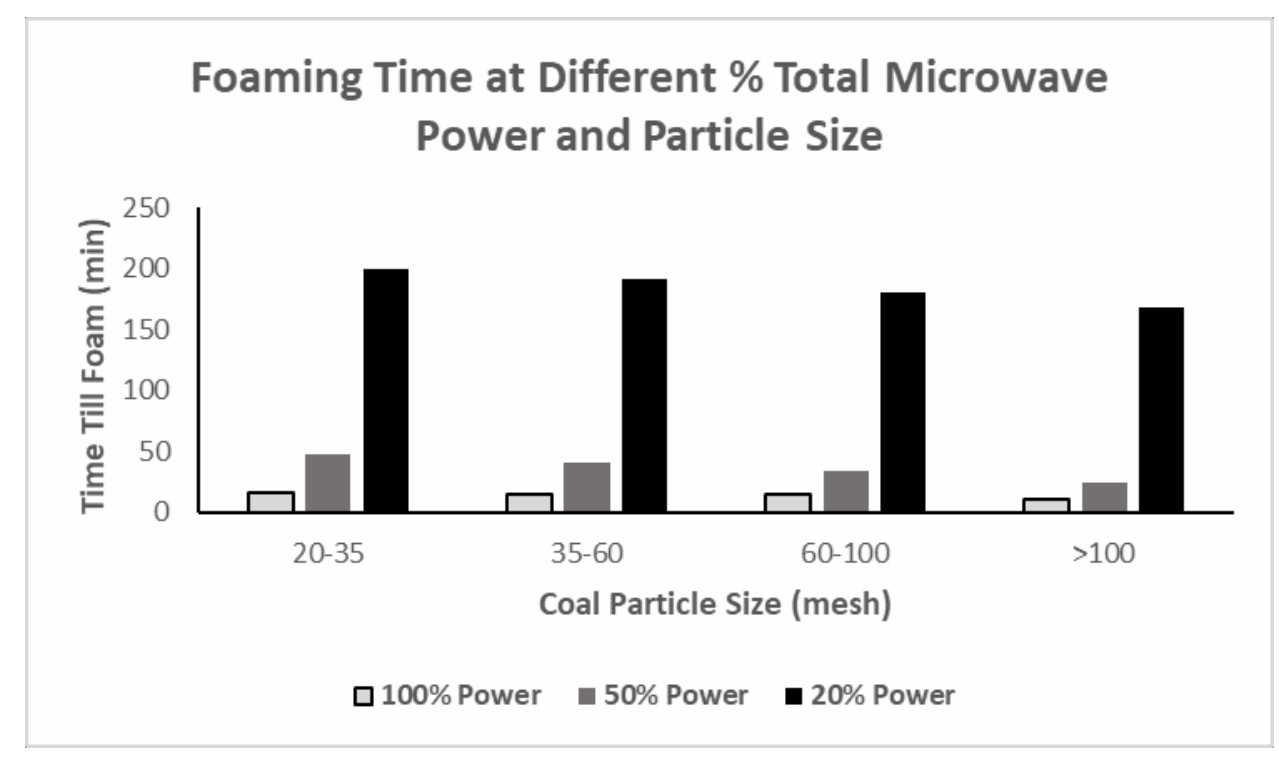

High Volatile Bituminous Coal: 5 wt\% Graphite

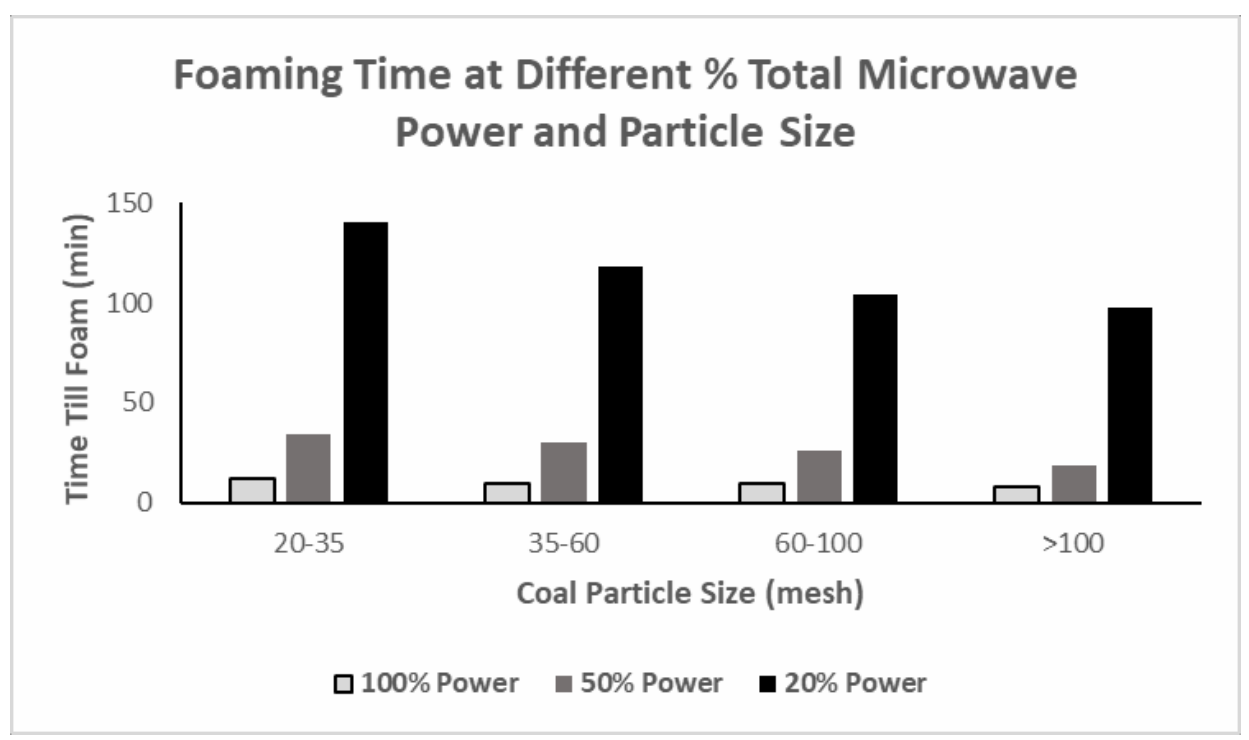


20-35 mesh Particle Size / 100\% Total Microwave Power

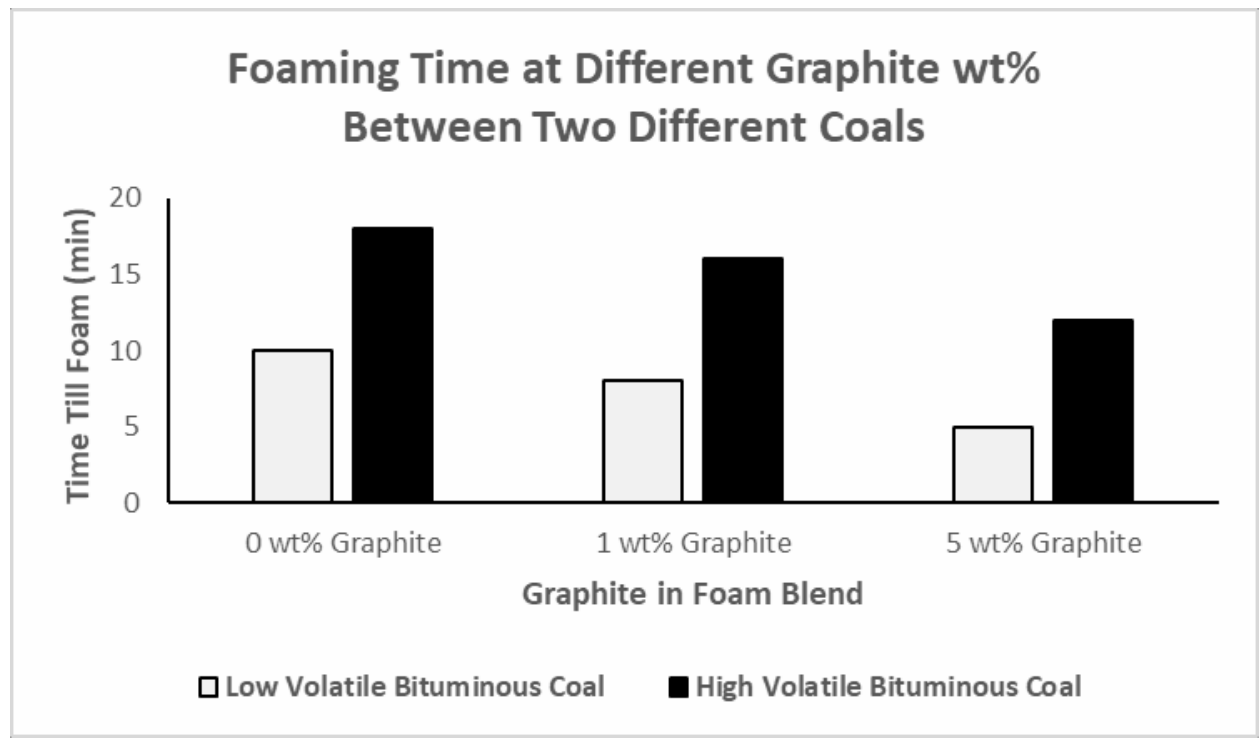

20-35 mesh Particle Size / 50\% Total Microwave Power

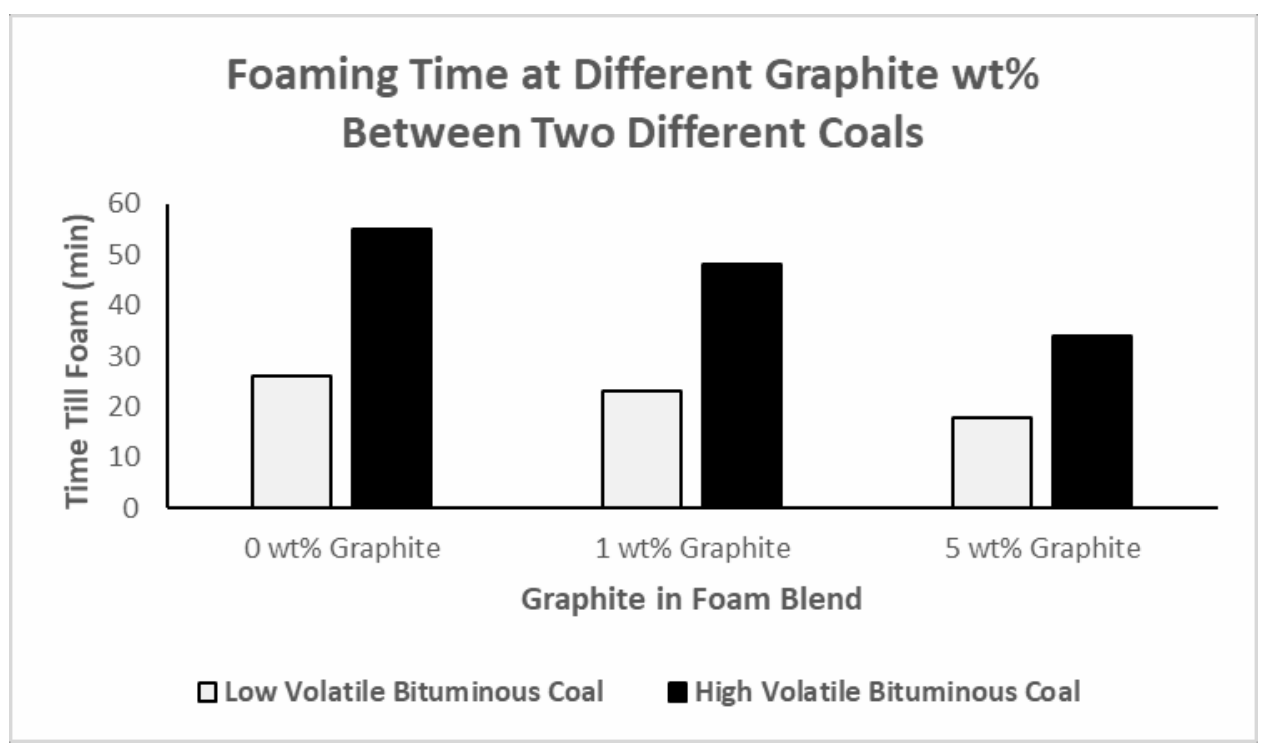


20-35 mesh Particle Size / 20\% Total Microwave Power

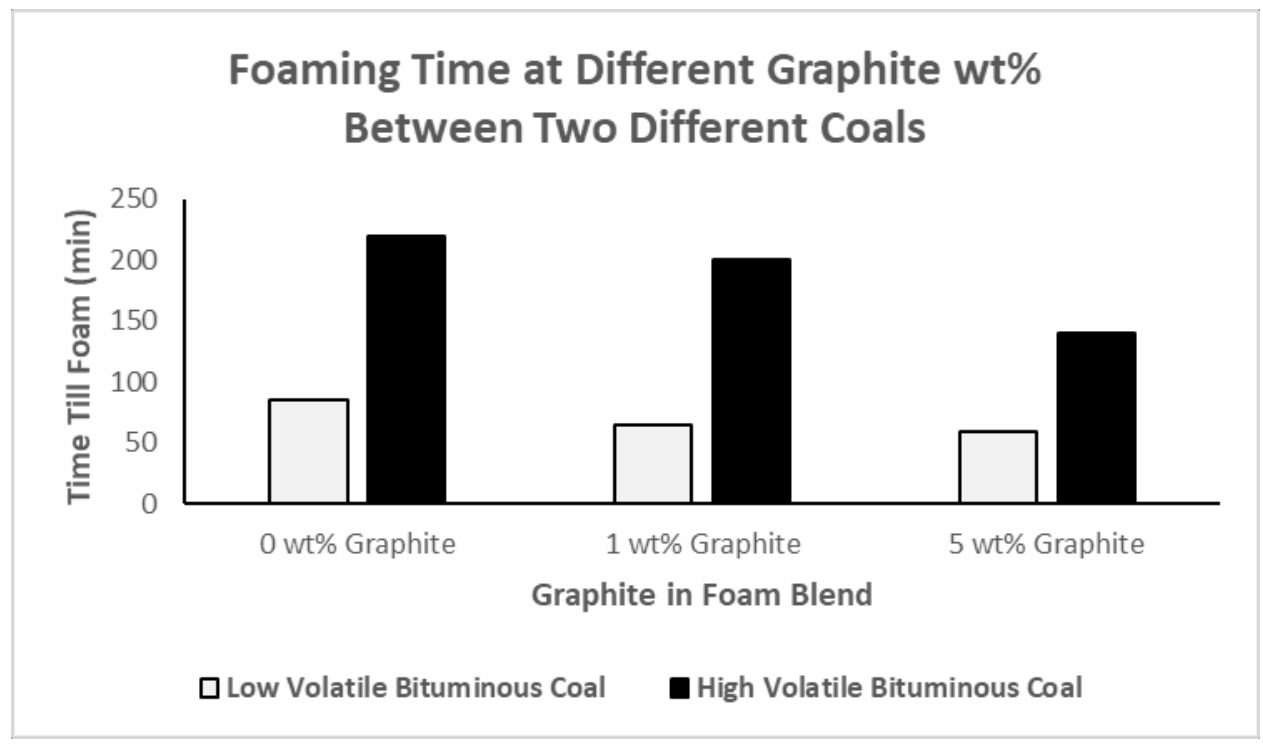

35-60 mesh Particle Size / 100\% Total Microwave Power

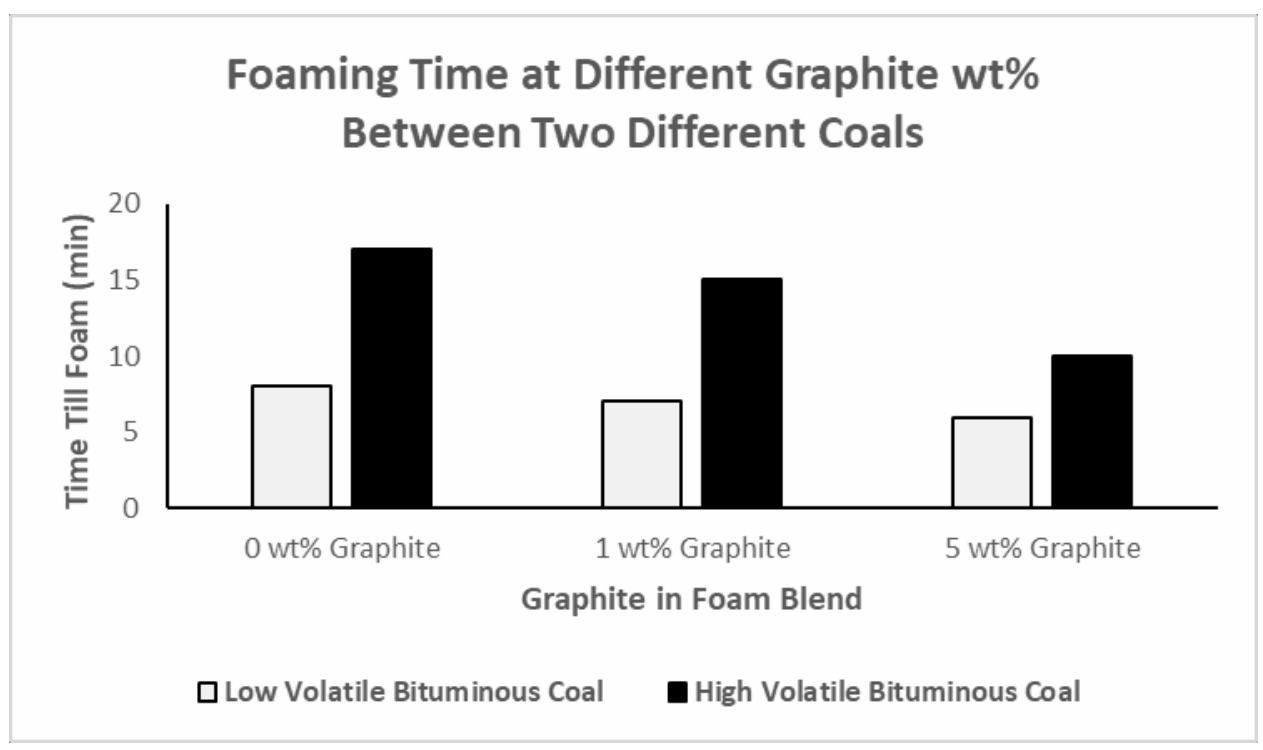


35-60 mesh Particle Size / 50\% Total Microwave Power

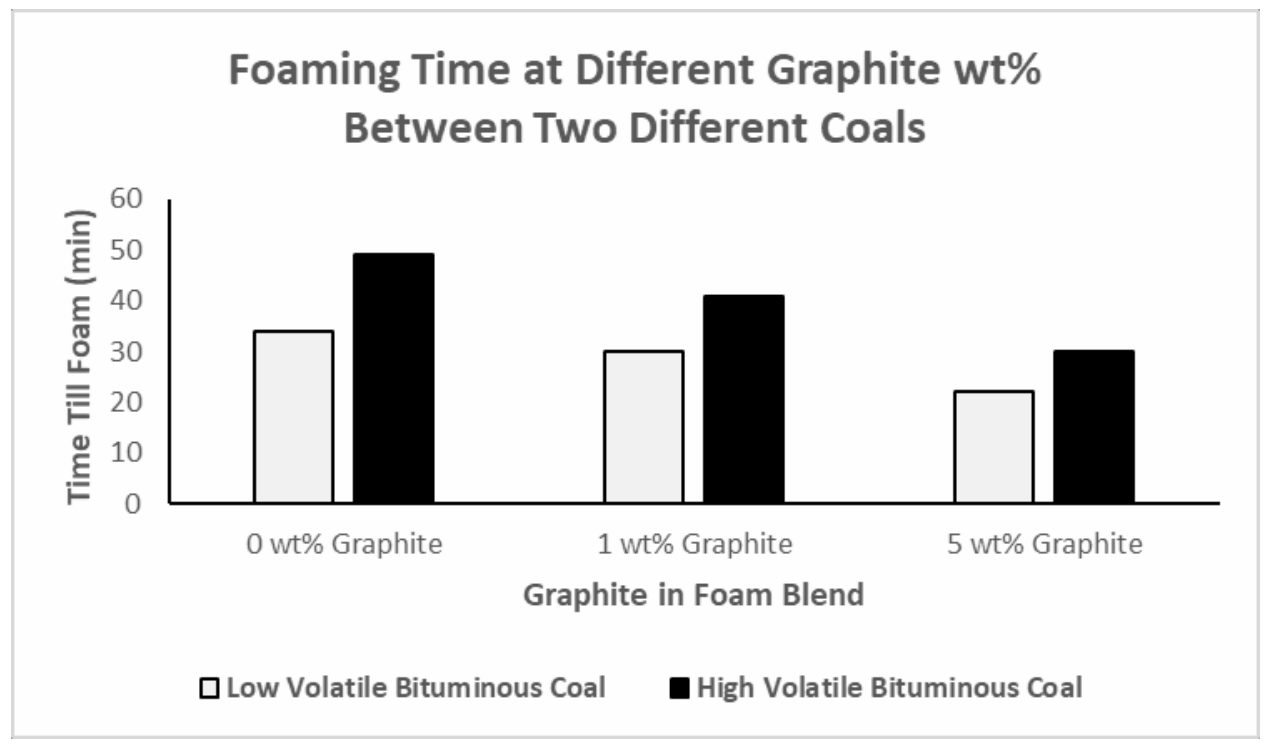

35-60 mesh Particle Size / 20\% Total Microwave Power

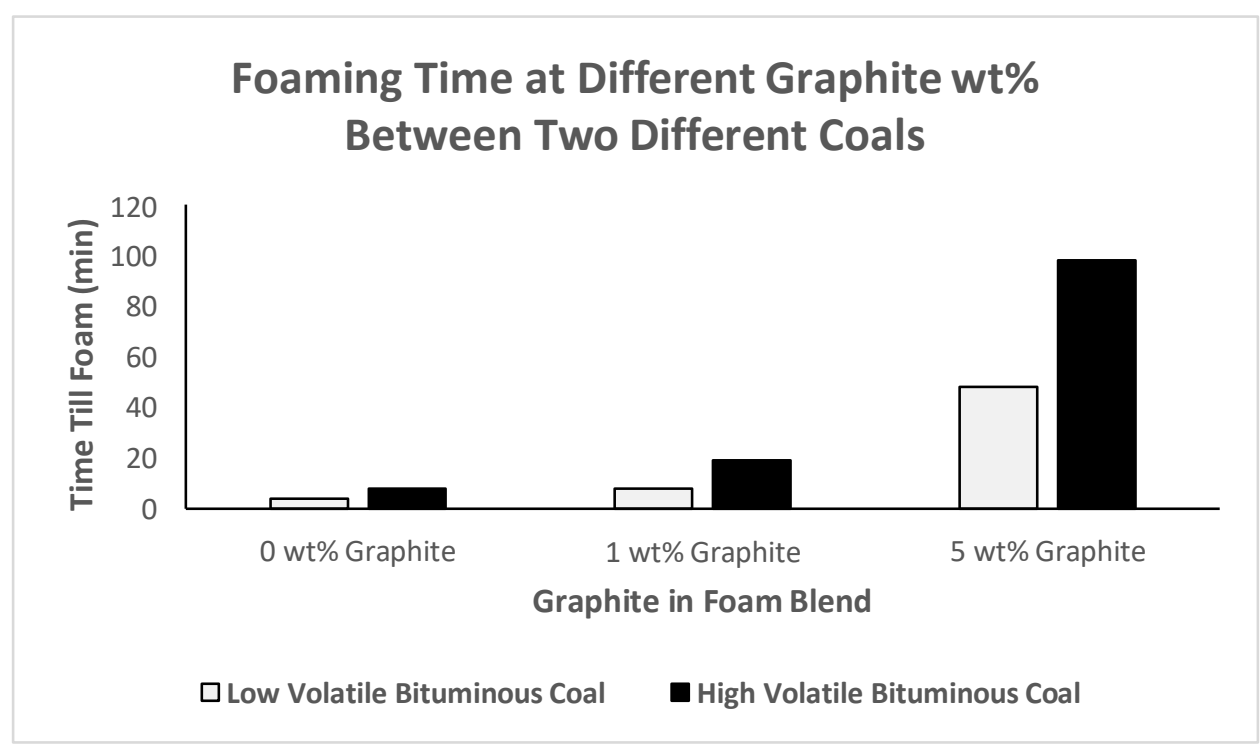


60-100 mesh Particle Size / 100\% Total Microwave Power

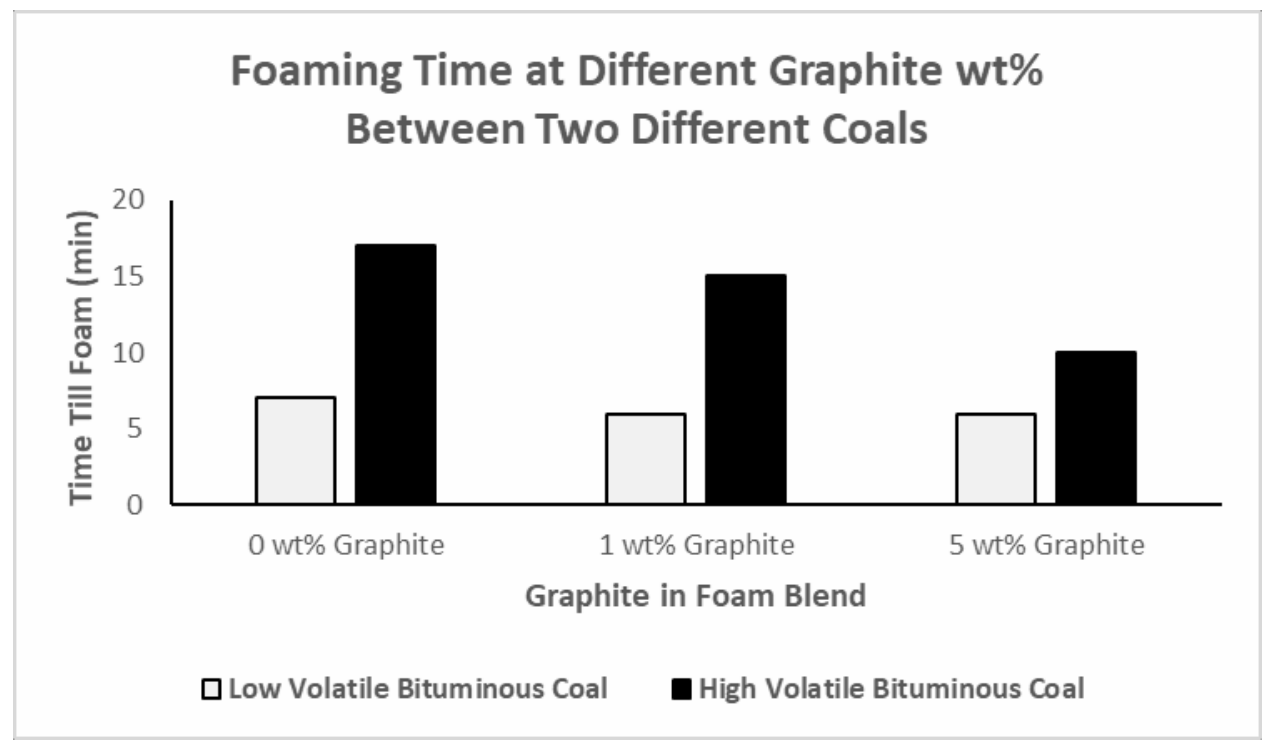

60-100 mesh Particle Size / 50\% Total Microwave Power

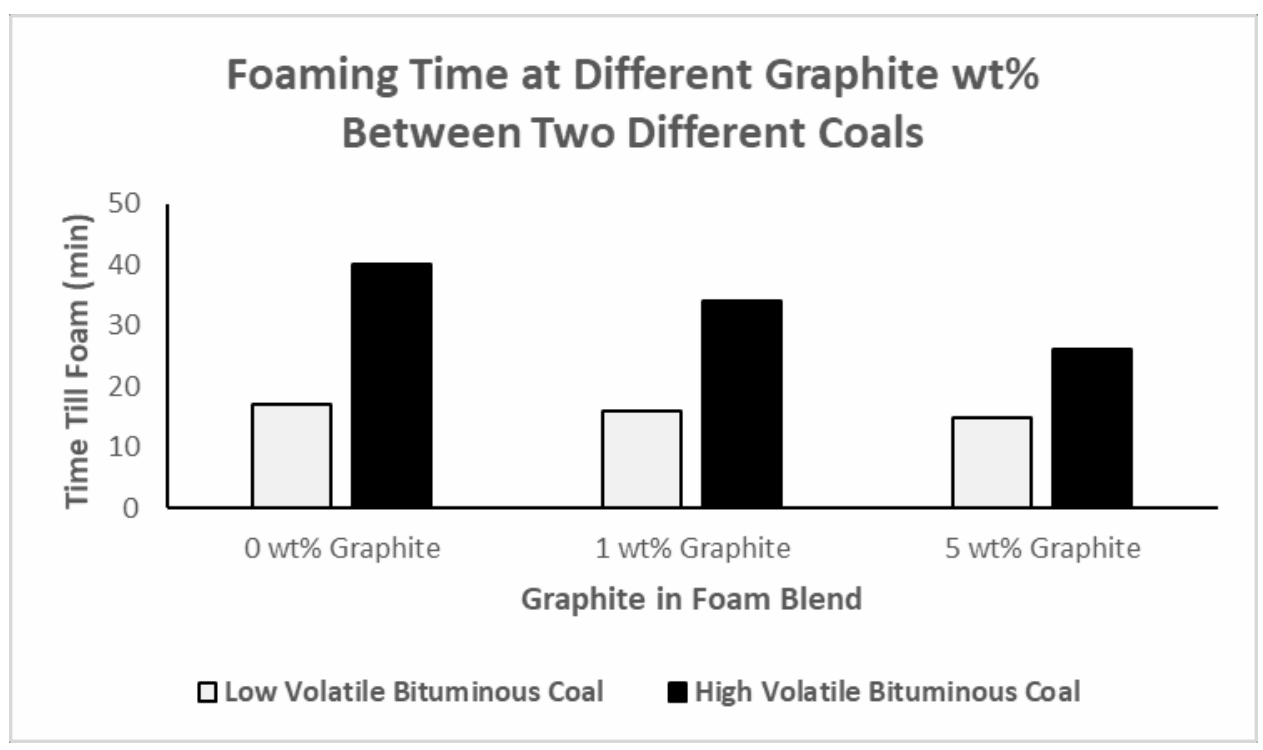


60-100 mesh Particle Size / 20\% Total Microwave Power

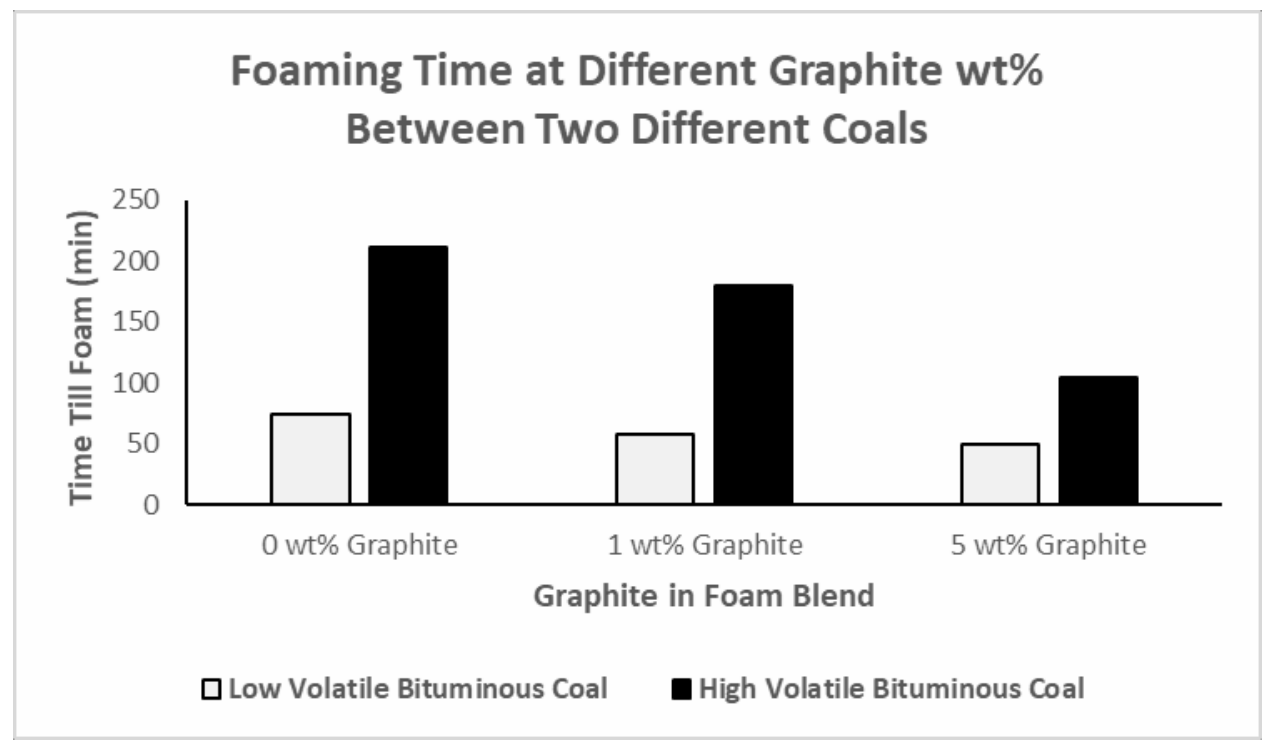

>100 mesh Particle Size / 100\% Total Microwave Power

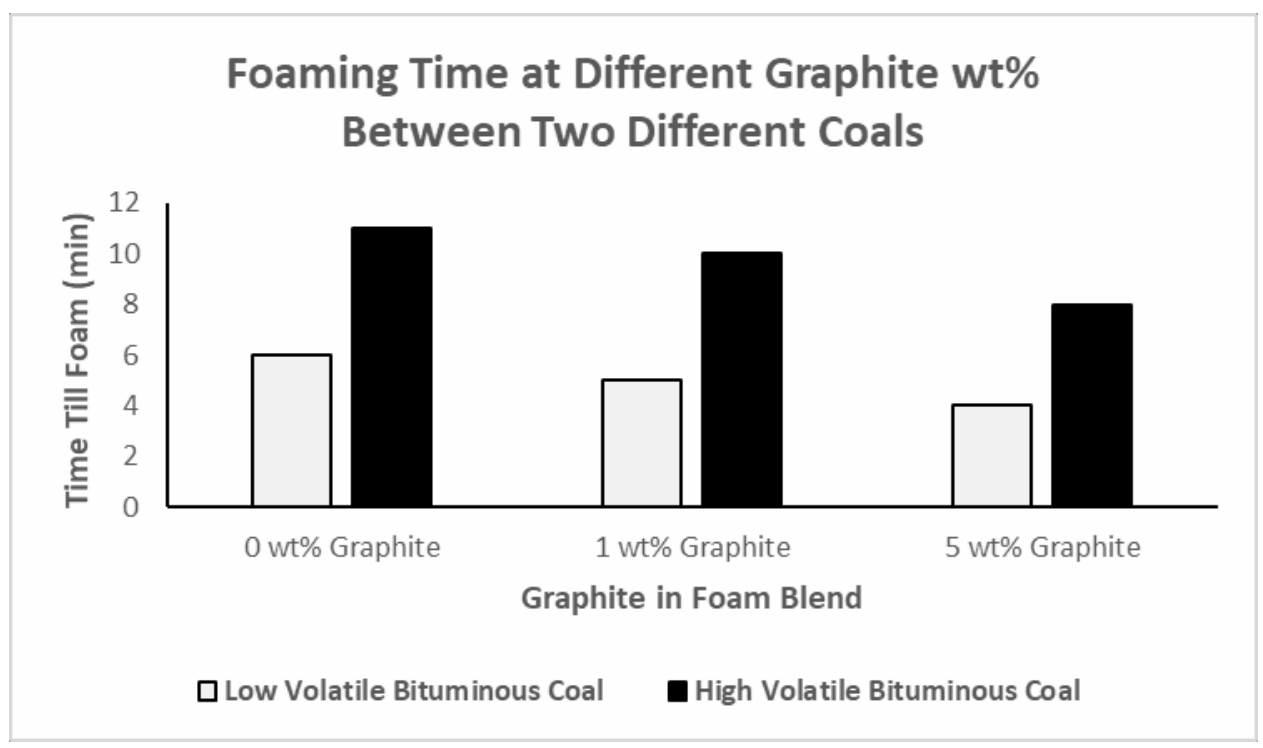


>100 mesh Particle Size / 50\% Total Microwave Power

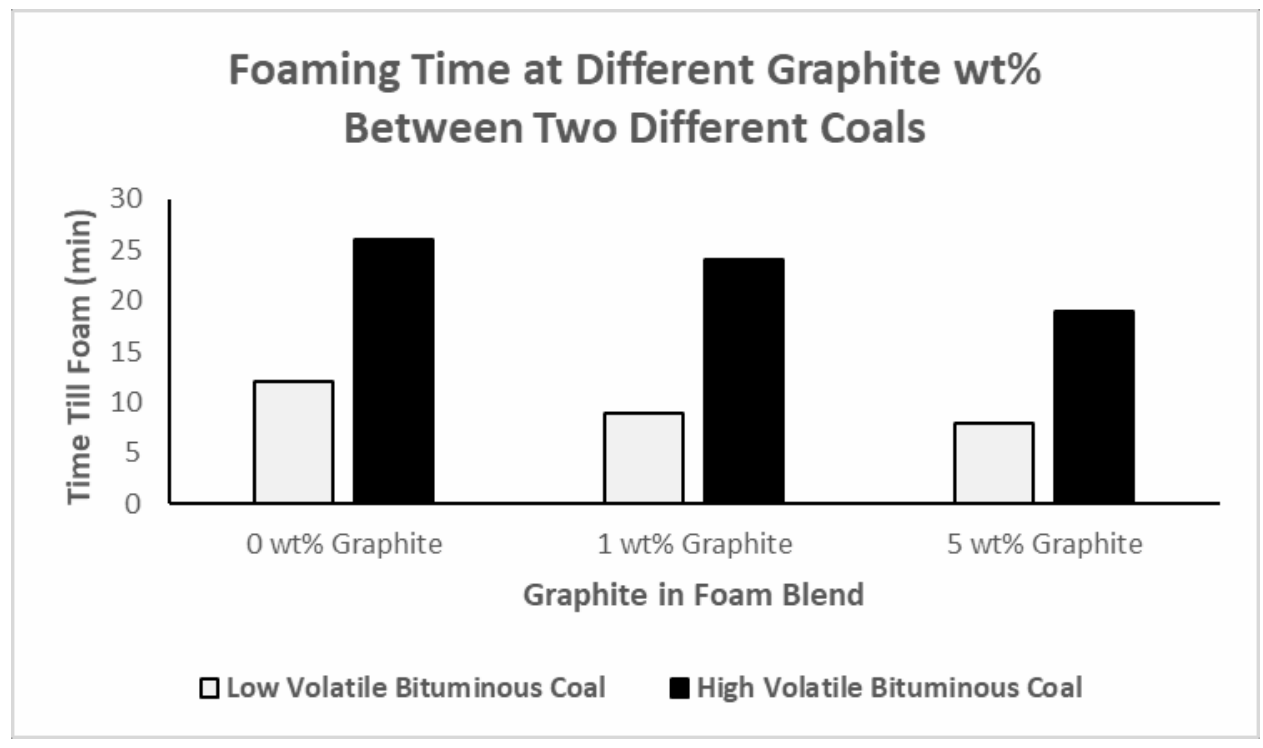

>100 mesh Particle Size / 20\% Total Microwave Power

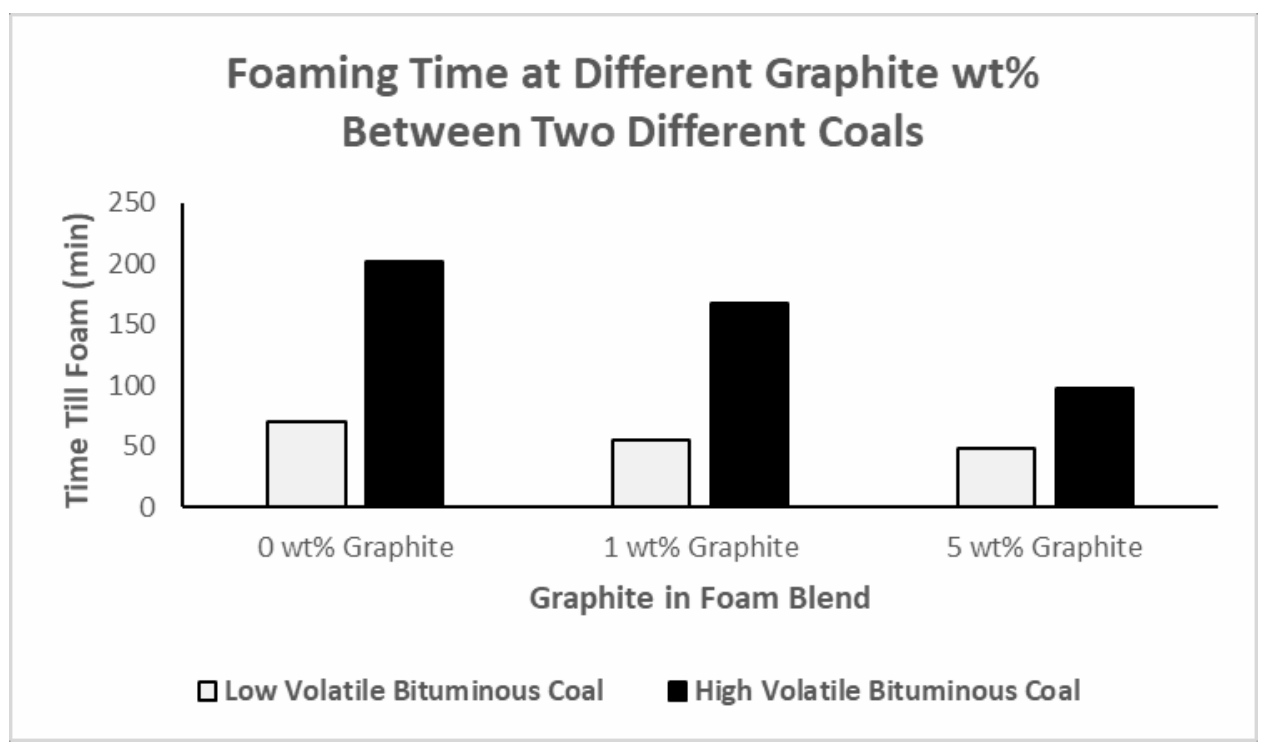


0 wt\% Graphite / 100\% Total Microwave Power

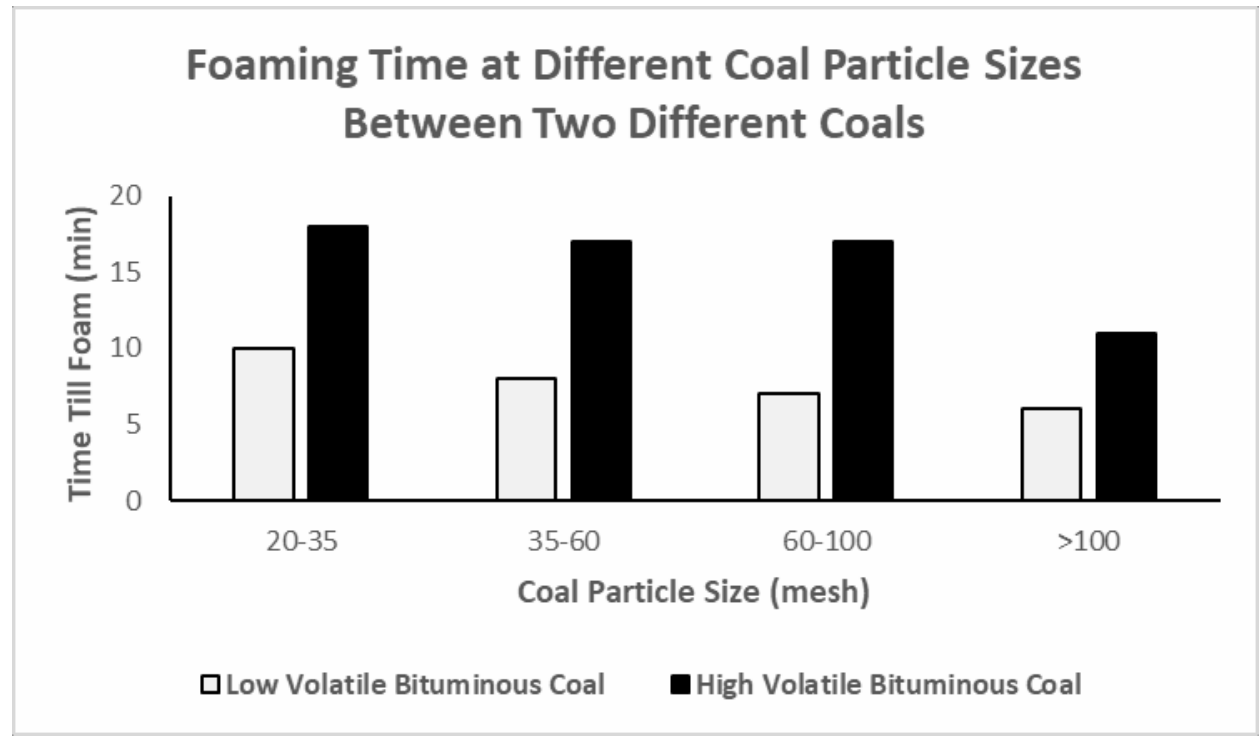

0 wt \% Graphite / 50\% Total Microwave Power

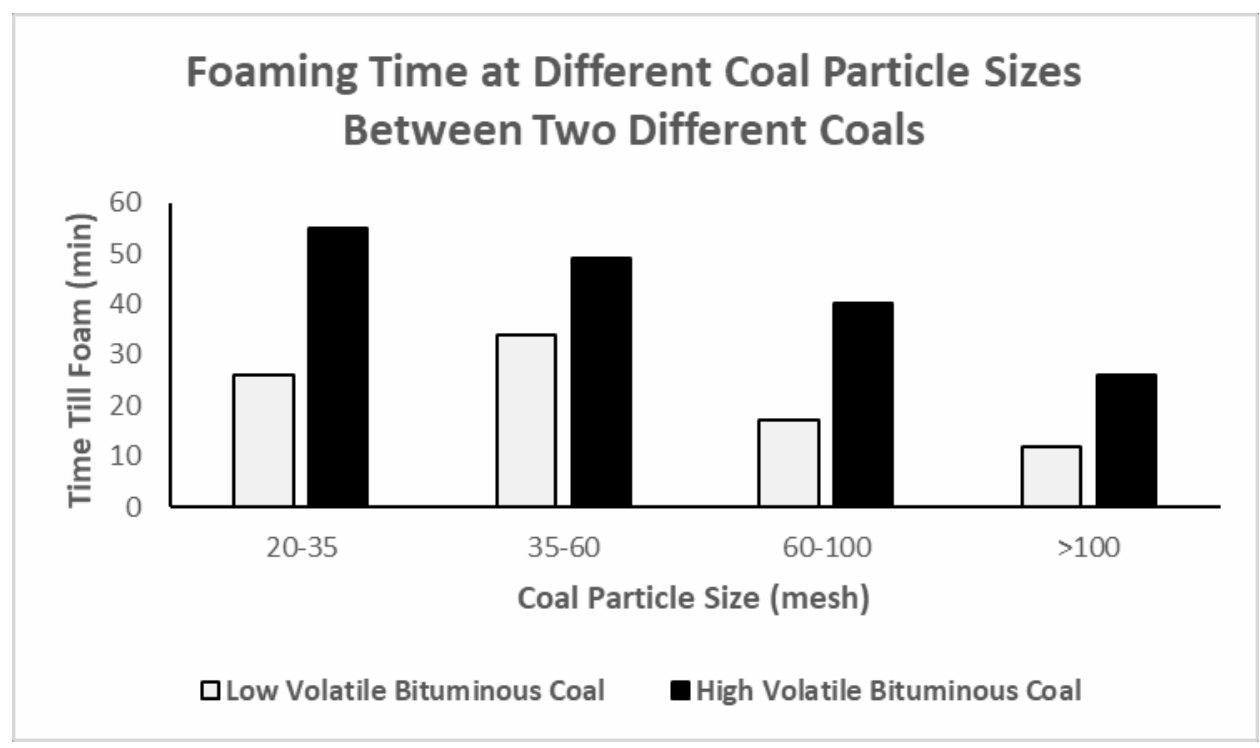


0 wt\% Graphite / 20\% Total Microwave Power

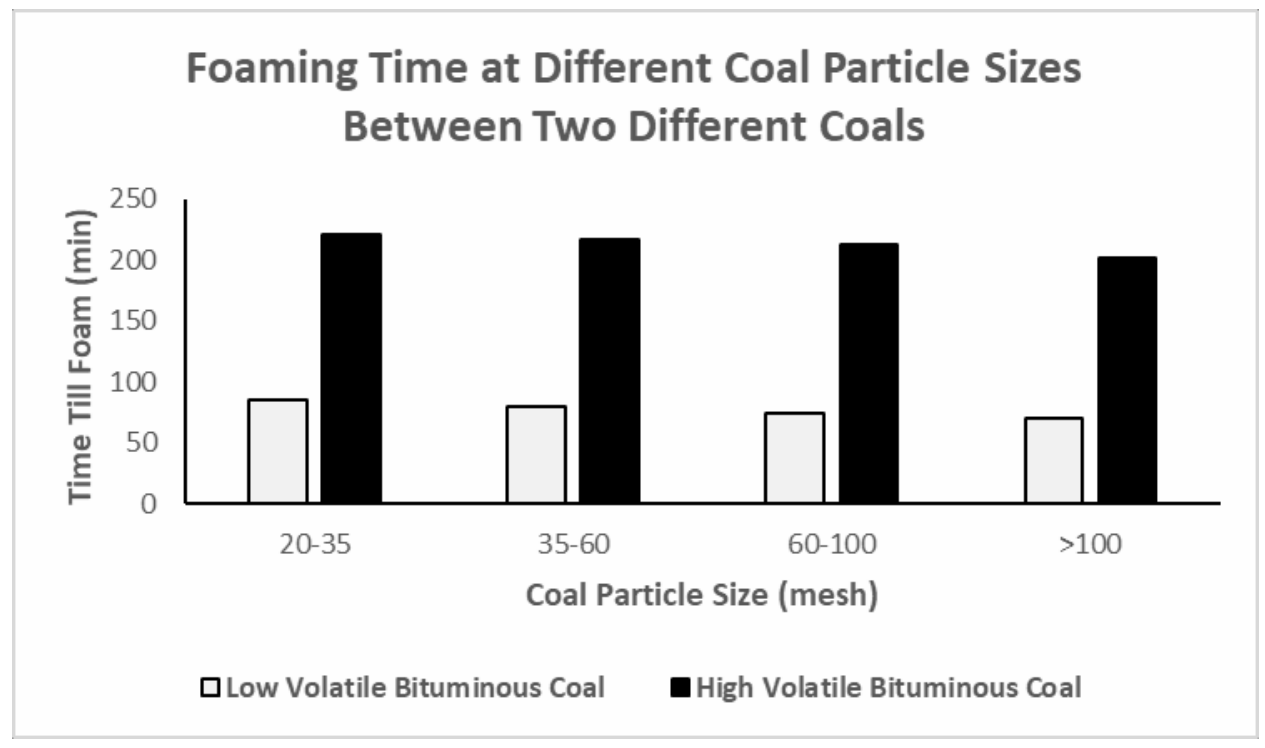

1 wt\% Graphite / 100\% Total Microwave Power

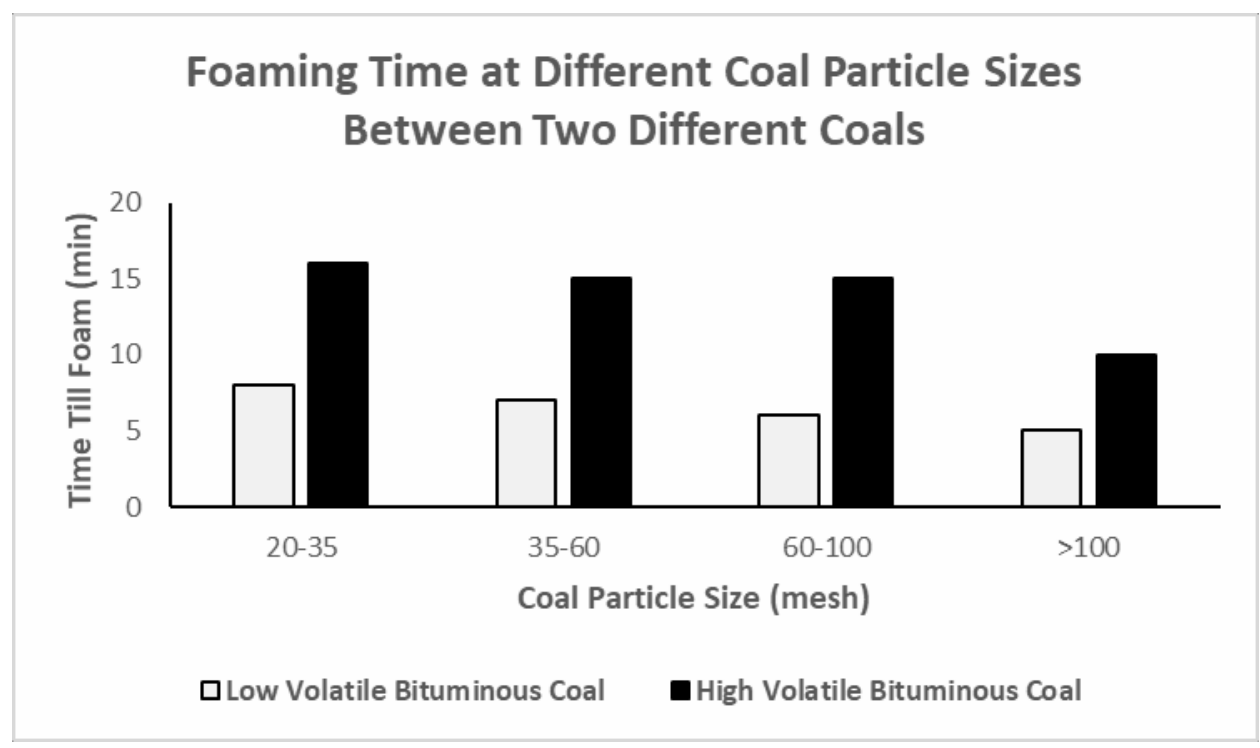


1 wt\% Graphite / 50\% Total Microwave Power

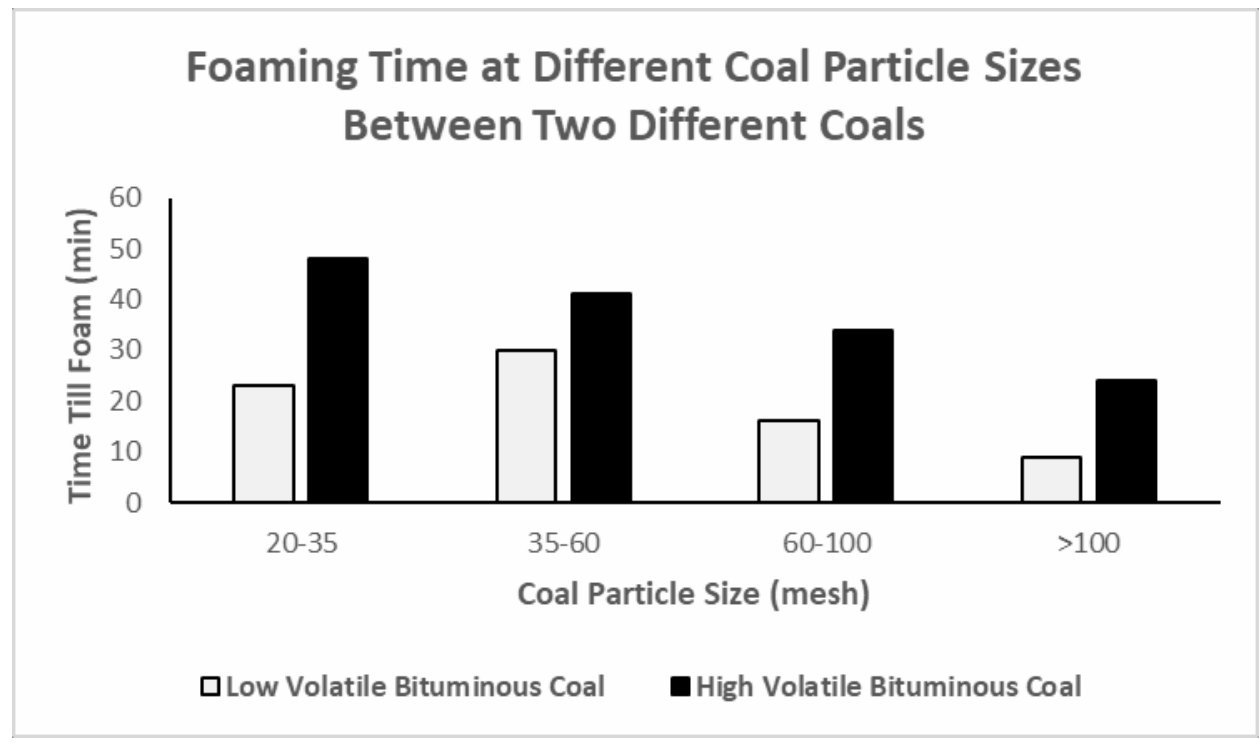

1 wt\% Graphite / 20\% Total Microwave Power

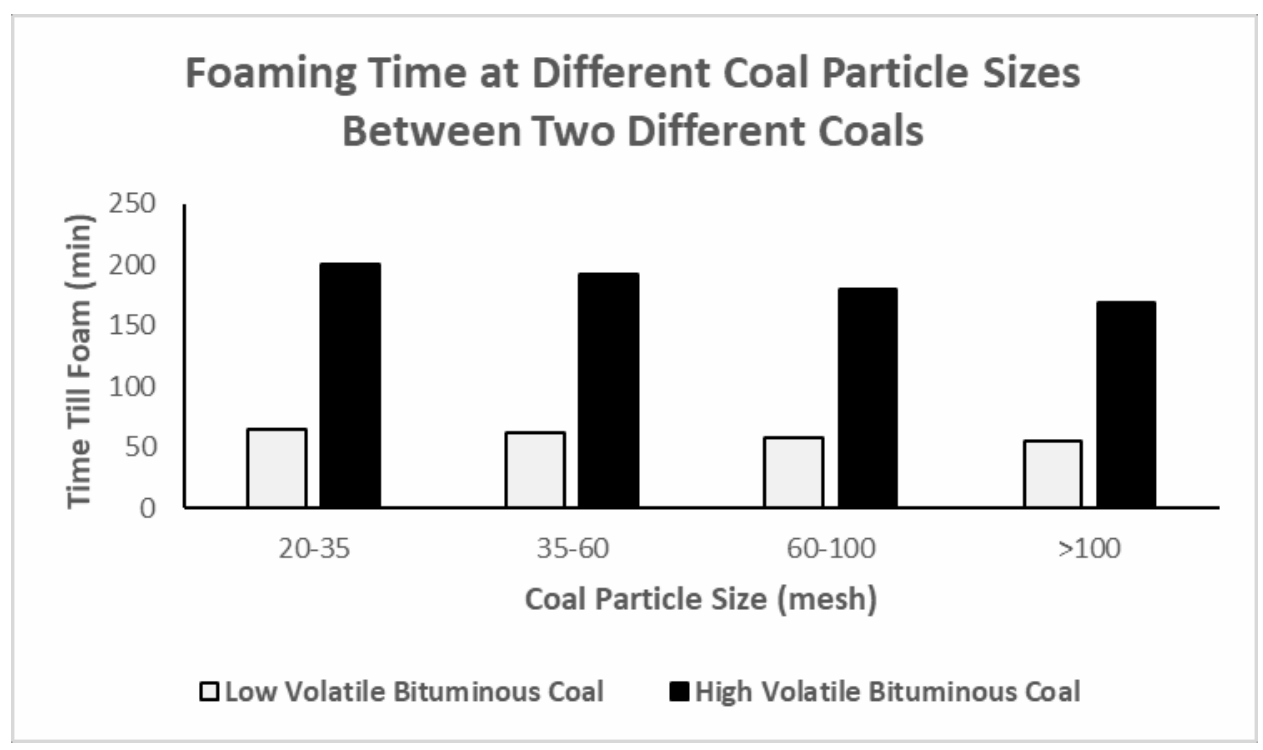


5 wt \% Graphite / 100\% Total Microwave Power

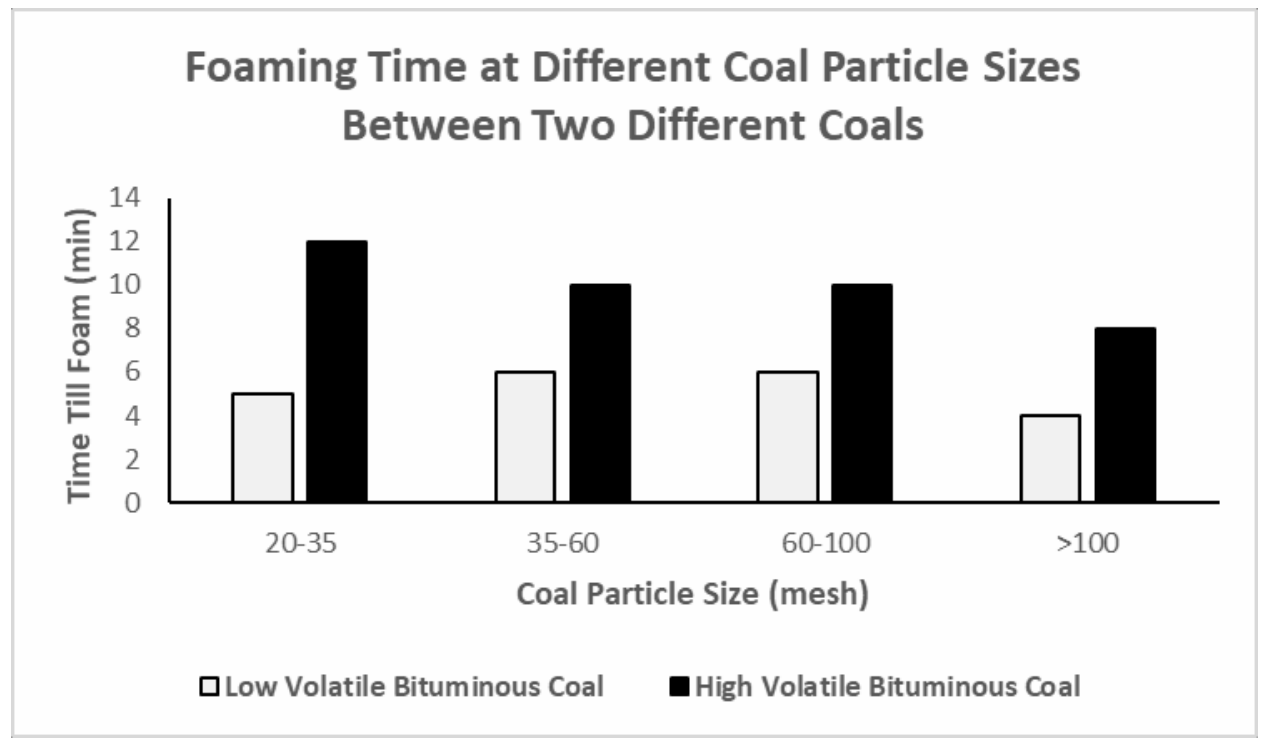

5 wt \% Graphite / 50\% Total Microwave Power

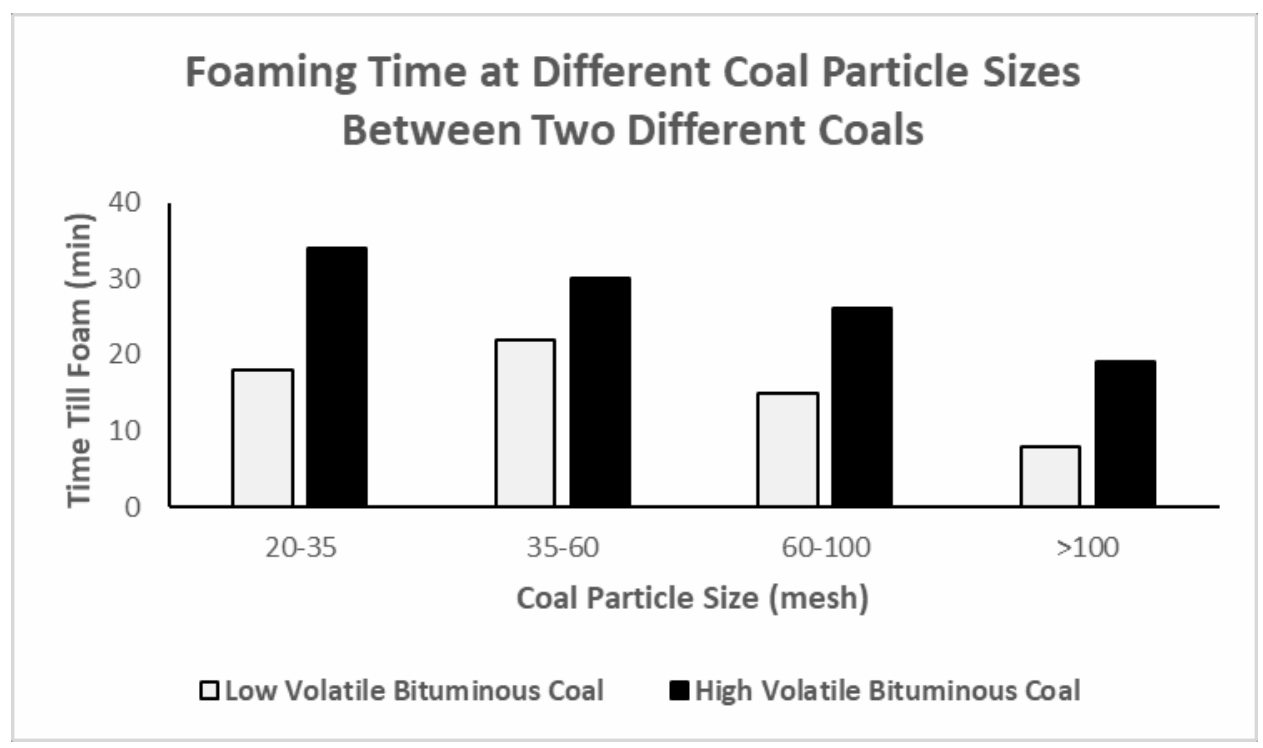


5 wt \% Graphite / 20\% Total Microwave Power

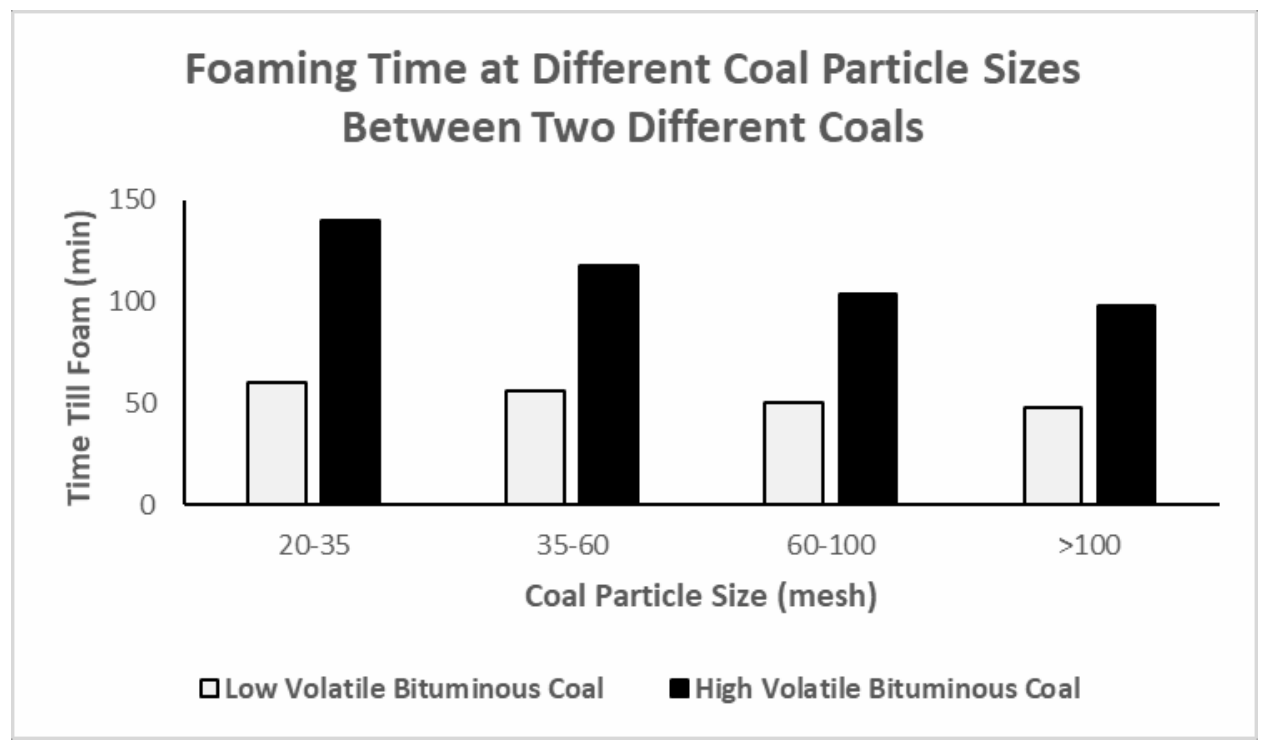

20-35 mesh Particle Size / 0 wt\% Graphite

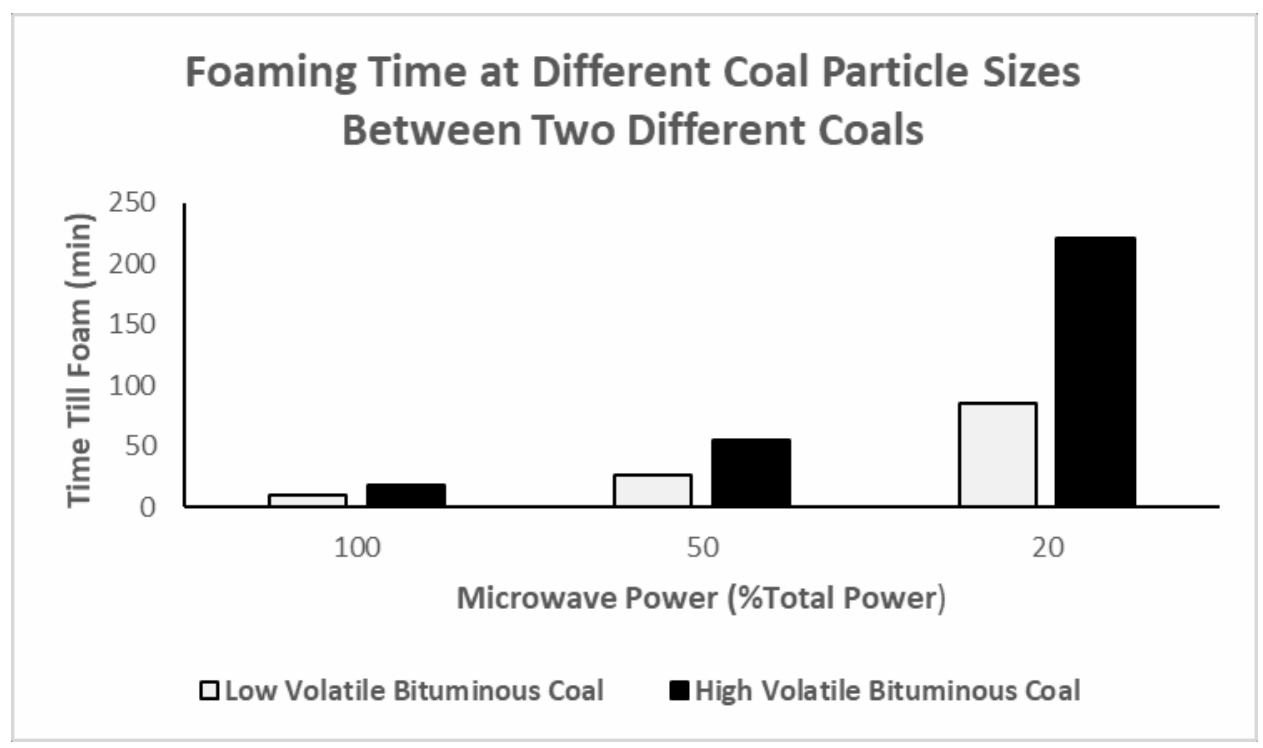


20-35 mesh Particle Size / 1 wt\% Graphite

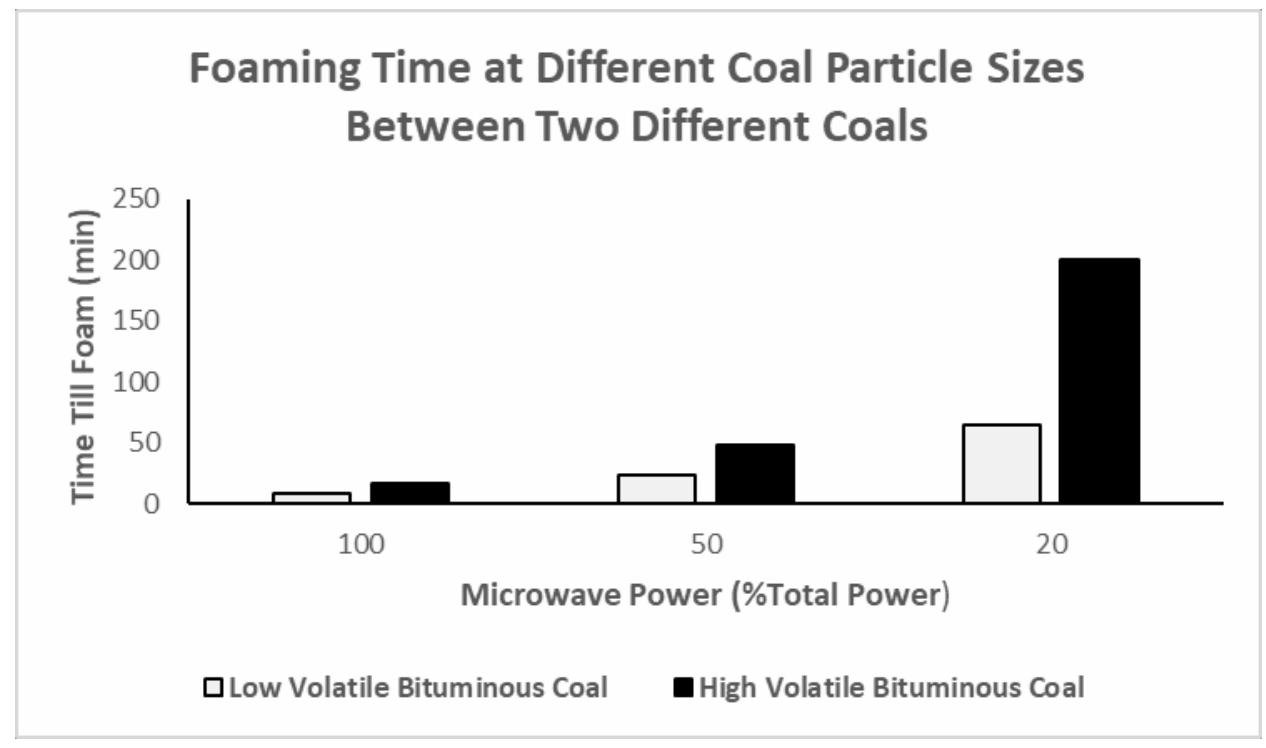

20-35 mesh Particle Size / 5 wt\% Graphite

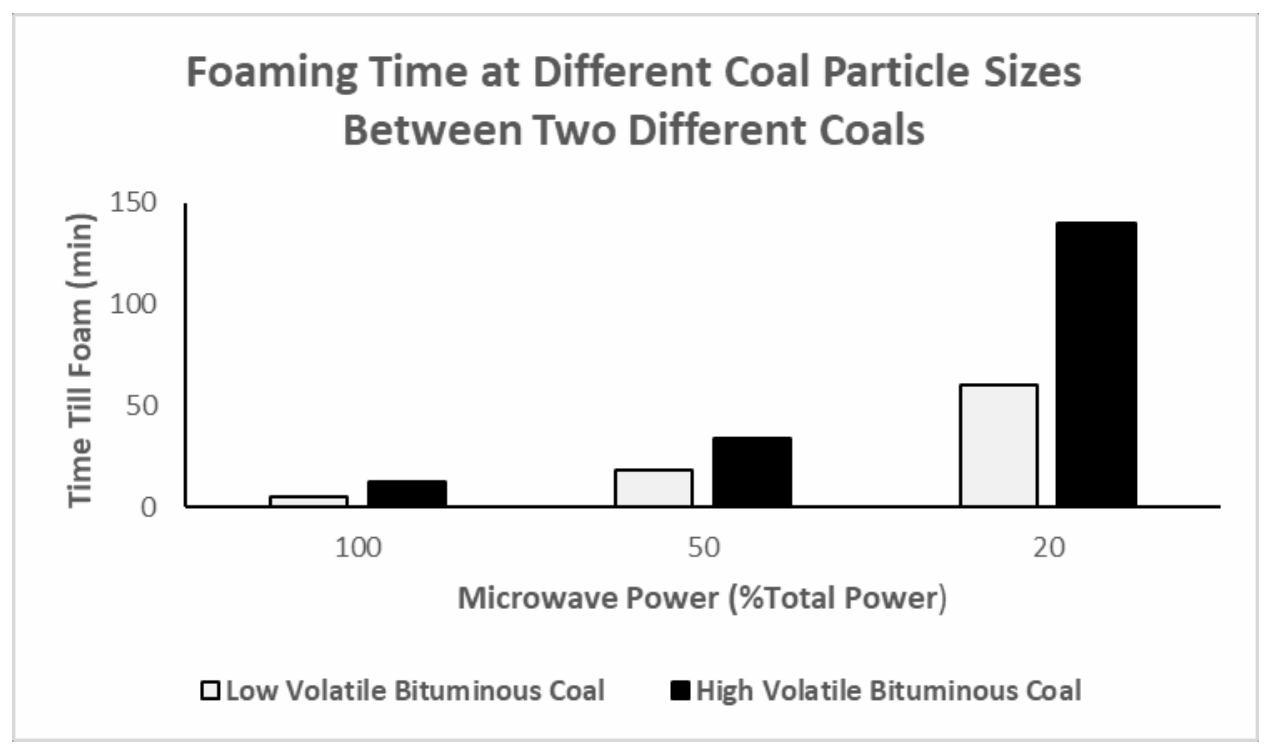


35-60 mesh Particle Size / 0 wt\% Graphite

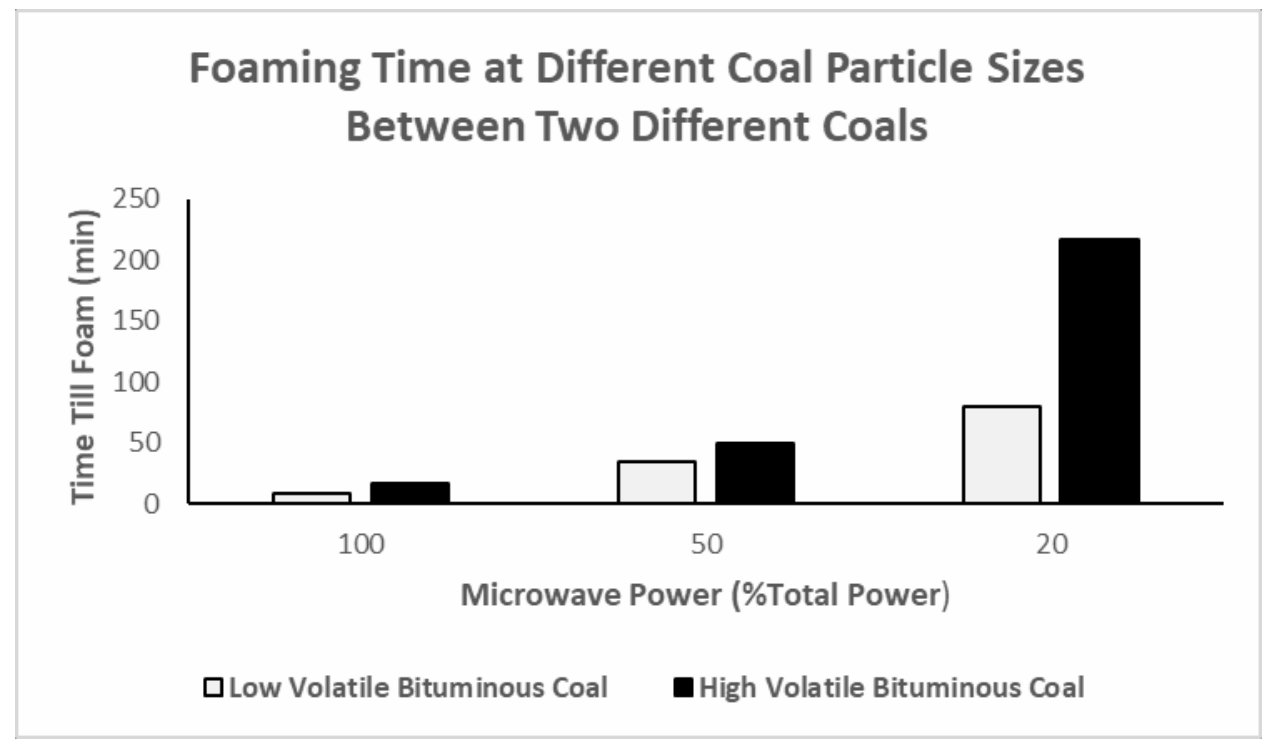

35-60 mesh Particle Size / 1 wt\% Graphite

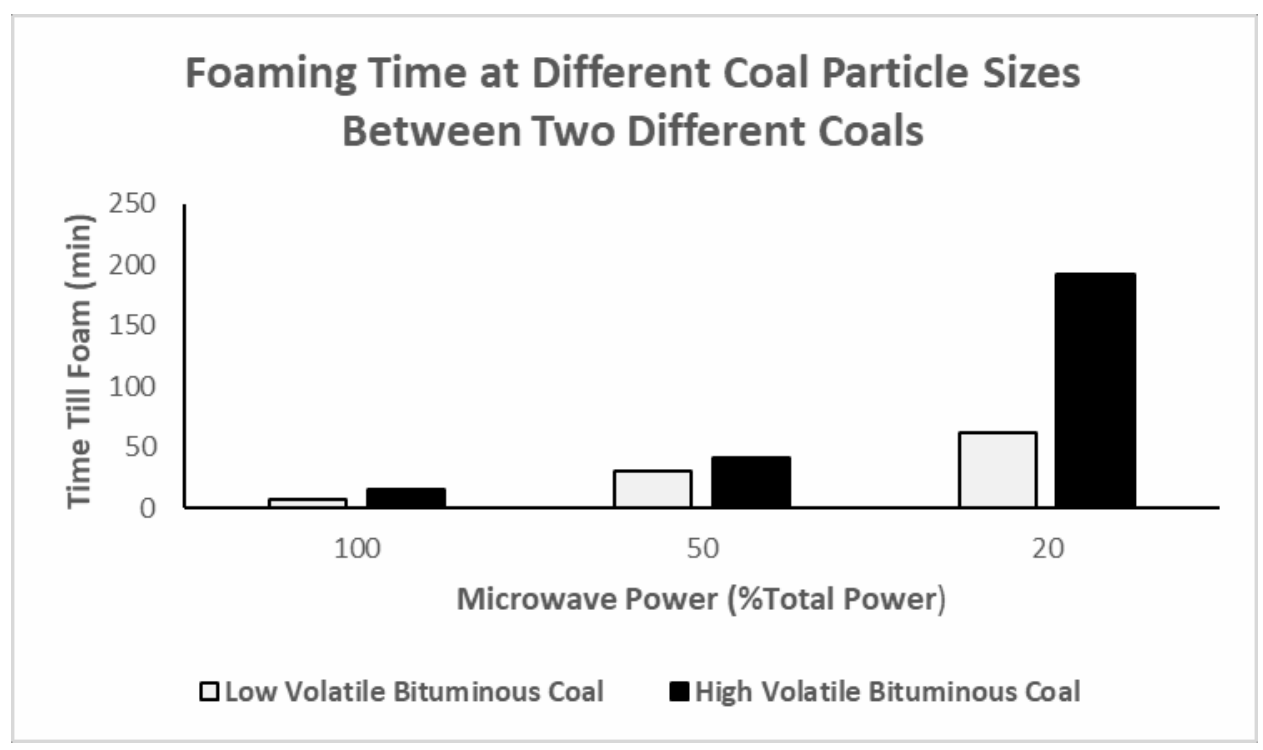


35-60 mesh Particle Size / 5 wt\% Graphite

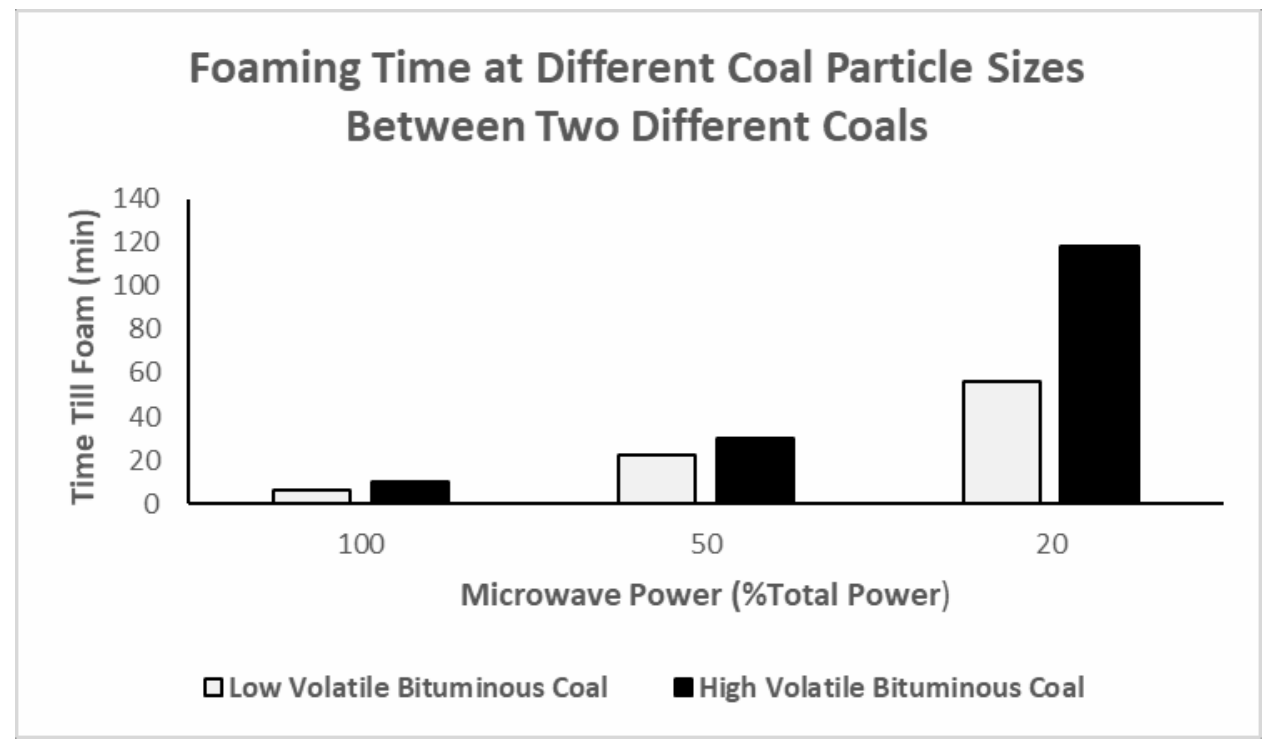

60-100 mesh Particle Size / 0 wt\% Graphite

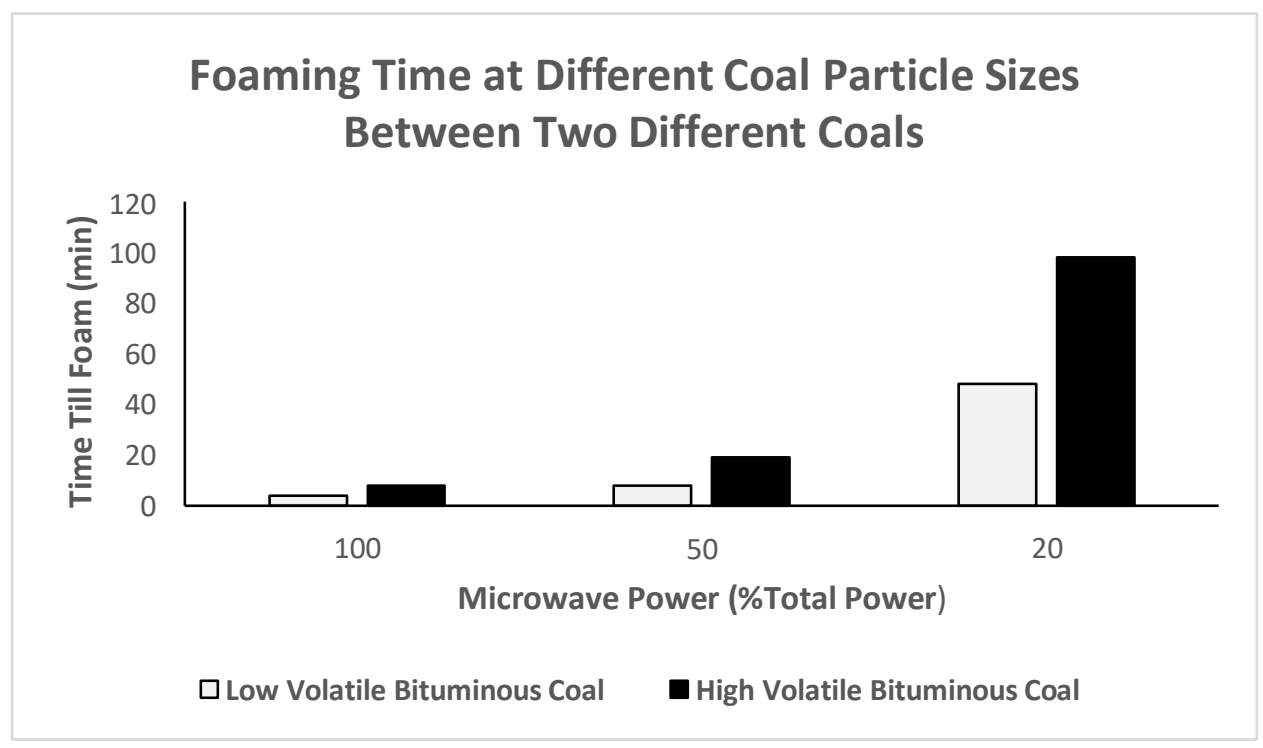


60-100 mesh Particle Size / 1 wt\% Graphite

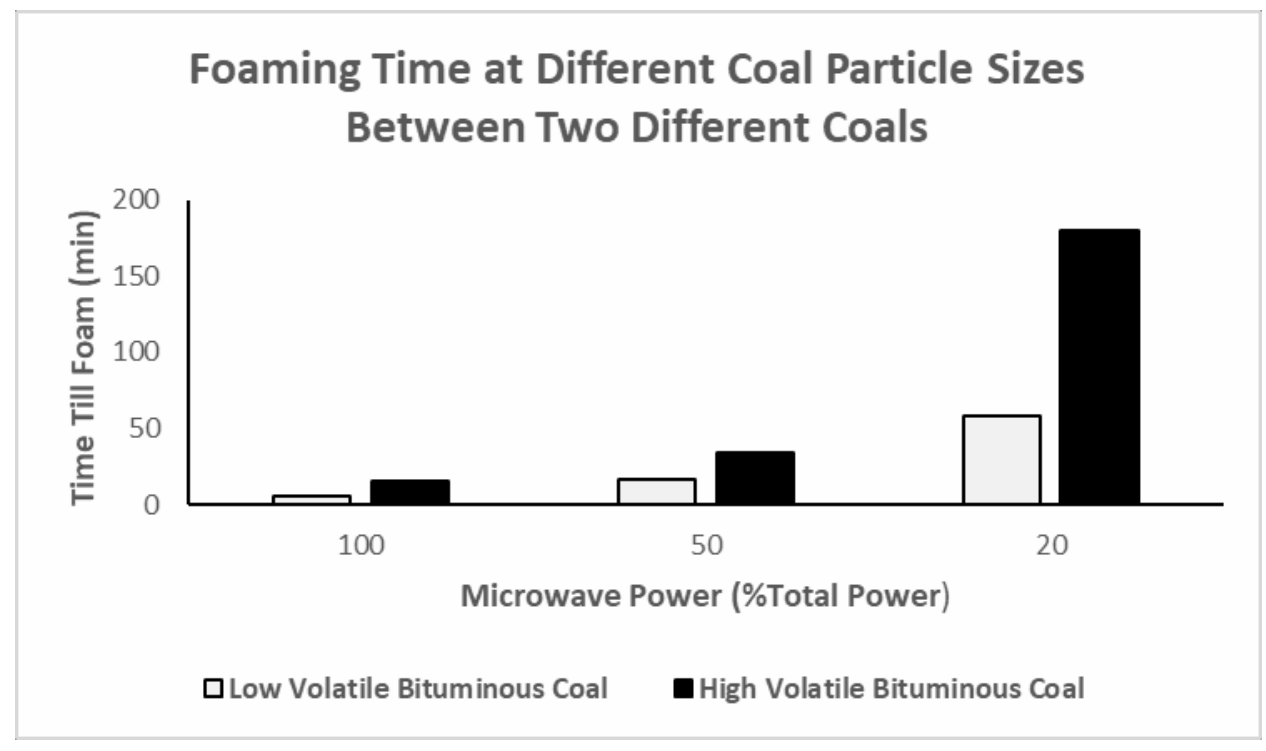

60-100 mesh Particle Size / 5 wt\% Graphite

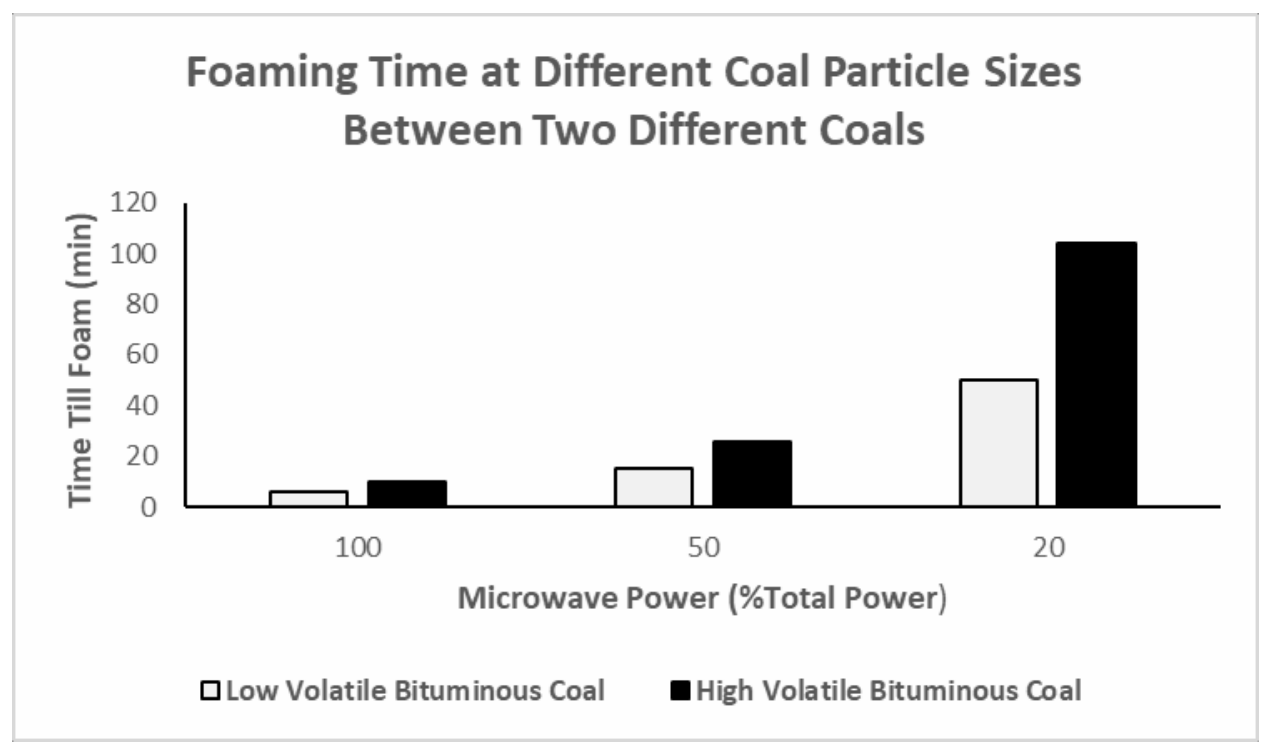


>100 mesh Particle Size / 0 wt\% Graphite

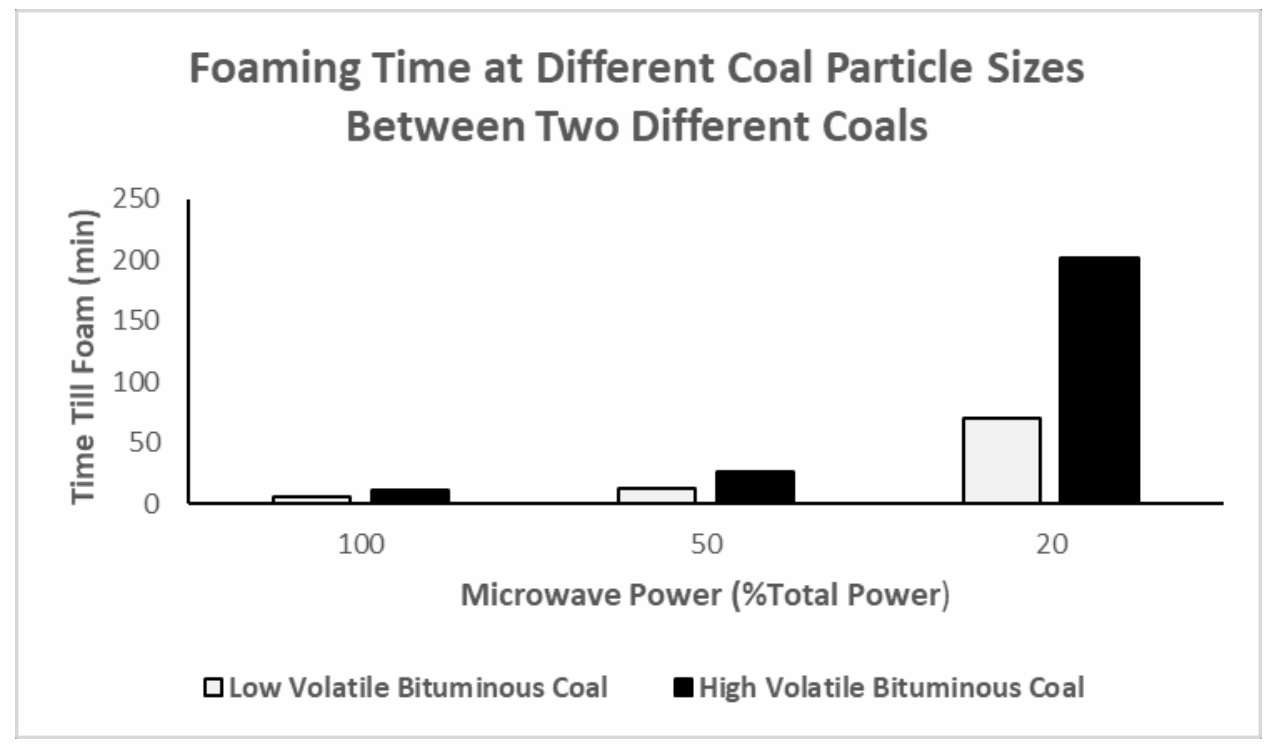

>100 mesh Particle Size / 1 wt\% Graphite

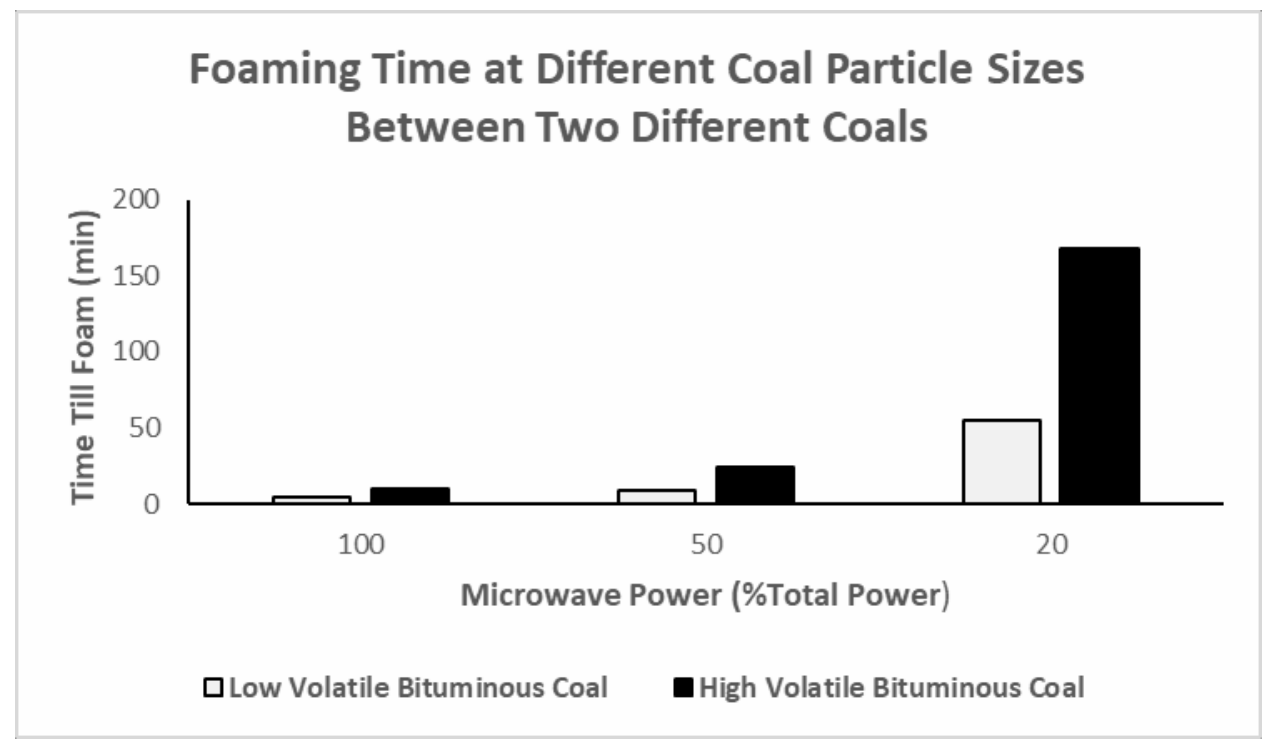


>100 mesh Particle Size / 5 wt\% Graphite

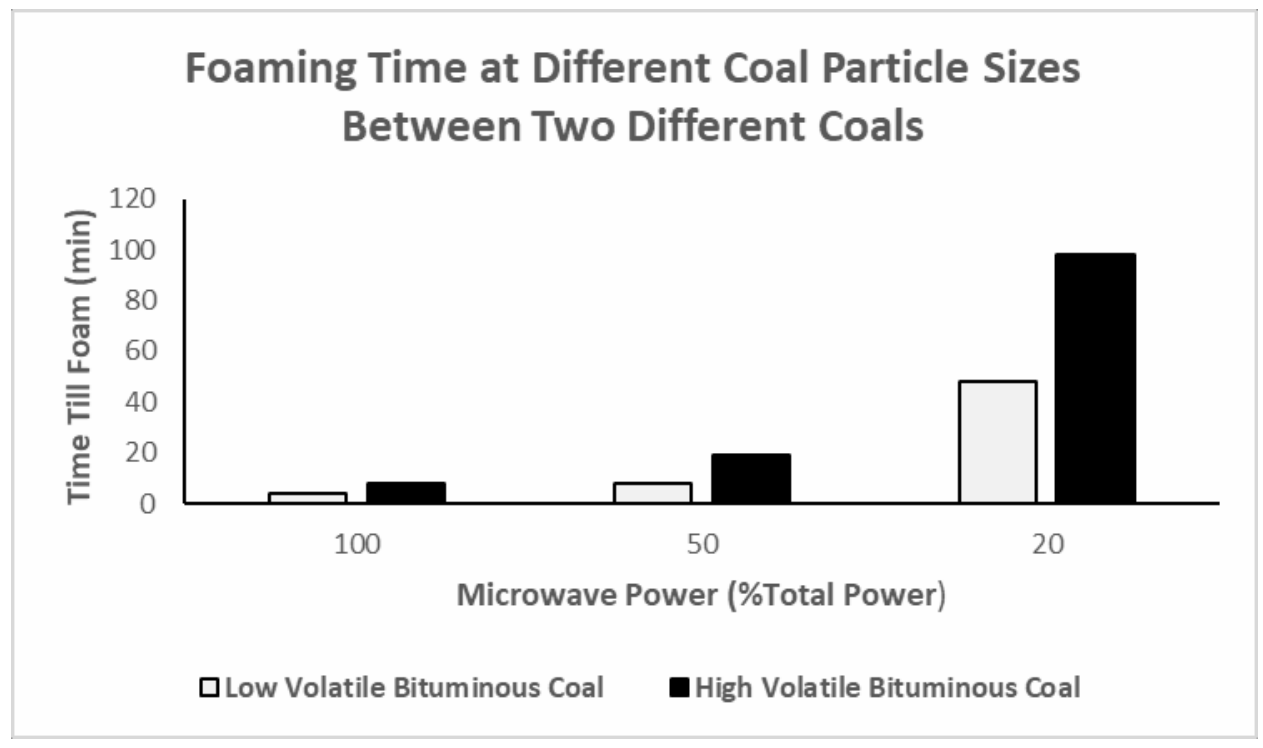




\title{
New Method of Manufacturing Carbon Foam
}

\author{
By

\section{Matthew Artimez} \\ A Thesis \\ Submitted to \\ West Virginia University \\ In partial fulfillment of the requirements \\ For the degree of \\ Master of Science
}

\section{APPROVAL OF EXAMINING COMMITTEE}

Alfred Stiller, Ph.D.

Robin Hissam, Ph.D.

Charter Stinespring, Ph.D.

Date 